\title{
A Review of Information System Integration in Mergers and Acquisitions
}

Henningsson, Stefan; Yetton, Philip; Wynne, Peter J.

\author{
Document Version \\ Accepted author manuscript \\ Published in: \\ Journal of Information Technology \\ DOI: \\ $10.1057 / s 41265-017-0051-9$ \\ Publication date: \\ 2018 \\ License \\ Unspecified
}

Citation for published version (APA):

Henningsson, S., Yetton, P., \& Wynne, P. J. (2018). A Review of Information System Integration in Mergers and Acquisitions. Journal of Information Technology, 33(4), 255-303. https://doi.org/10.1057/s41265-017-0051-9

Link to publication in CBS Research Portal

\section{General rights}

Copyright and moral rights for the publications made accessible in the public portal are retained by the authors and/or other copyright owners and it is a condition of accessing publications that users recognise and abide by the legal requirements associated with these rights.

\section{Take down policy}

If you believe that this document breaches copyright please contact us (research.lib@cbs.dk) providing details, and we will remove access to the work immediately and investigate your claim.

Download date: 26. Apr. 2023

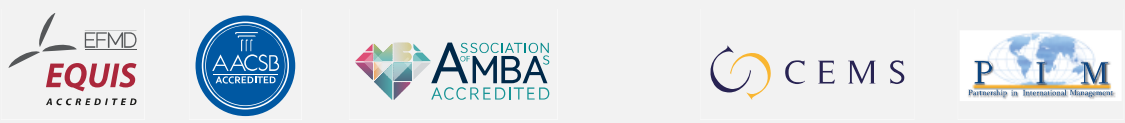




\section{A Review of Information System Integration in Mergers and Acquisitions Stefan Henningsson, Philip Yetton, and Peter J. Wynne}

Journal article (Accepted version)

CITE: A Review of Information System Integration in Mergers and Acquisitions. / Henningsson, Stefan; Yetton, Philip; Wynne, Peter J. In: Journal of Information Technology, Vol. 33, №. 4, २०18, p. 25५-303.

This is a post-peer-review, pre-copyedit version of an article published in Journal of Information Technology. The final authenticated version is available online at: https://doi.org/10.1057/s41265-017-0051-9

Uploaded to CBS Research Portal: January 2019 


\section{A Review of Information System Integration in Mergers \& Acquisitions}

\section{ABSTRACT}

For three decades, research has investigated the role of information systems integration (ISI) in mergers and acquisitions (M\&As). This research has improved our understanding of the $M \& A I S$ challenges and their solutions. However, consolidation and integration across the research is limited. To redress this omission, we review 70 articles published between 1989 and 2016. To do this, we adopt and extend the methodology developed by Lacity and her colleagues to review the empirical evidence in a fragmented IT literature. We code 53 dependent variables and 195 independent variables to identify the robust relationships among them and to model how ISI decisions, including the choice of IS integration methods, partially mediate the effects of the independent variables on ISI outcomes. Examining the relationships in this model, we identify five quasi-independent thematic domains on which we draw to develop an agenda for future research. Our contribution is the aggregation, organization and structuring of the empirical findings in the M\&A ISI literature as a basis on which to develop a cumulative knowledge process.

Keywords: Merger, Acquisition, Information Systems, Integration, Literature Review 


\section{INTRODUCTION}

In 2016, 46,000 mergers and acquisitions (M\&As) were recorded with a total value of more than US\$3.7 trillion (Thomson Reuters, 2017). M\&As are a source of great opportunity for a few companies, including Cisco, Cemex and Santander (Kanter et al., 2007; Busquets, 2015; Toppenberg et al., 2015), but are frequently challenging and problematic for the many. In practice, $60-70 \%$ of M\&As in the private sector destroy rather than create financial value as measured by short-term performance, long-term performance, and market value (See, for example, King et al., 2004).

Stimulated by the growth in activity, M\&As have become a subject of research in several academic fields. Haleblian et al. (2009) reviewed M\&A research in the accounting, economics, finance, management and sociology literatures from 1992 to 2007 . They identified 864 articles that examine the challenges to successful M\&As and recommend how to overcome those challenges. The research shows that M\&As are multifaceted phenomena to which financial, strategic, managerial, sociological, organizational and psychological research contribute insights and normative recommendations.

One critical factor not considered by Haleblian et al. (2009) is that businesses have become pervasively dependent on their information systems (IS). These now play a critical role in the realization of value in M\&As. Sarrazin and West (2011) estimate that $45-60 \%$ of the expected benefits from M\&As directly depend on IS integration (ISI). Similarly, a survey by Accenture reports that ISI is the second most important reason for M\&A failures, causing billions of dollars in losses (Accenture, 2006).

In response to these and other surveys, research on the role of ISI in M\&As has increased, documenting an emerging understanding of ISI as a highly diverse challenge. Three cases 
illustrate this diversity. First, Yetton et al. (2013) explain why the Danish sugar producer, Danisco, had to halt its acquisition program after several years to consolidate its scattered IT infrastructure onto one standardized central IT platform that could support a growth-byacquisition strategy in the area of food ingredients. The accumulated IT infrastructure, consisting of more than 150 different ERP systems that were loosely integrated with peerto-peer interfaces and middleware, made continued growth slow and costly. The critical challenge for Danisco was to develop the capacity of the IT infrastructure to support growth. This took Danisco several years and could not have been financially justified by a single acquisition.

Second, the Teaching Health Centre (THC) case (Vieru and Rivard, 2014) shows how people involved in ISI affect the outcome significantly. They interpret, object, politicize, discover, and, in many other ways, shape the unfolding ISI, creating unintended work processes, structures and power relationships. The initial design for THC, a merger of three Canadian hospitals, was based on best practice, but the final configuration revealed a blend of industry standards and local pre-merger contingencies. Personnel at the different sites actively engaged in interpreting the new systems, shaping them to work within pre-merger working procedures, norms, and cultures.

Third, the Mekong-Indus acquisition (Mehta and Hirschheim, 2007) illustrates how external factors, particularly time pressure, exacerbate the ISI challenges. Because of shareholder pressure to quickly realize the merger synergies, Mekong decided to standardize the post-acquisition combined businesses based on its own IS platform. This was despite the fact that the Indus IS platform was generally considered to be a better fit for the new organization's business aspirations. Mekong management considered the Indus systems to be unproven and that adopting it would be high risk. However, after a few years 
of struggling with operating on Mekong's pre-acquisition IS platform, the combined organization migrated to an updated platform similar to the Indus platform that had been retired during the merger project.

The three cases illustrate how critical factors, including, for example, time pressures and IT platform flexibility, affect ISI outcomes. The cases also illustrate how ISI decisions, including diagnosis, planning and implementation, both affect ISI outcomes and partially mediate the effect on ISI outcomes of other variables, including time pressures and IT platform flexibility. To explain these relationships, the literature on ISI in M\&A has adopted at least 18 different theoretical perspectives and has employed grounded theory approaches to identify new and intriguing aspects of the phenomenon. However, because of this theoretical diversity and the explorative research approaches, the literature is fragmented (Wijnhoven et al., 2006), and has evolved in a non-cumulative way (Mehta and Hirschheim, 2007; Henningsson and Carlsson, 2011) with inconsistent definitions and conceptualizations.

We address the fragmentation by aggregating, organizing and structuring the findings in the M\&A IS literature. To do this, we adopt the methodology outlined by Jeyaraj et al. (2006) and developed by Lacity et al. $(2010 ; 2011 ; 2016)$ that was specifically designed to consolidate the knowledge in another fragmented IT literature, namely, the IT outsourcing literature. Within this approach, the review is guided by a single research question:

- How to aggregate, organize and structure what we know about M\&A ISI decisions and their outcomes?

To answer this question, we examine 70 articles published between 1989 and 2016. We inspect both the quantitative and qualitative research to identify the most frequently studied constructs and the relationships among those constructs. Specifically, we investigate the 
variables that affect ISI decisions and ISI outcomes. Aggregating these findings, we develop a descriptive model of the robust findings that explain how ISI decisions partially mediate the effects on ISI outcomes of the critical M\&A factors (Figure 1), where robust findings are defined as empirical findings that have been replicated a minimum of five times in the ISI literature (see methodology section for explanation).

\section{[FIGURE 1]}

This review is written primarily for an academic readership with an interest in M\&A ISI research. The output of Lacity et al.'s $(2010 ; 2011 ; 2016)$ methodology is not a theory or a theoretical model. Instead, it is a structured documentation of the findings in a research domain. Taken together, the research reviewed here contributes a consolidated base of the existing, robust findings in M\&A ISI research. Inspecting these findings, we identify five research themes. Discussing the themes, we propose new research questions to develop each theme and briefly speculate how research between the themes could develop our overall understanding of M\&A ISI.

The remainder of this review is structured as follows. First, we describe the Lacity et al. $(2010 ; 2011 ; 2016)$ protocol to identify the robust relationships in the M\&A ISI literature and our extension to their protocol to identify five themes to structure the interdependences among the robust relationships. Second, the findings are presented in two sections. One begins by setting the context with a short overview of the M\&A ISI research over three decades, then identifies and presents the robust relationships in the literature. The other section examines the density of relationships among the robust findings to identify five research themes and to develop future research questions within and between the themes. Finally, we discuss the implications of our findings for future research and present a short conclusion. 


\section{METHODOLOGY}

M\&A ISI research is fragmented across many authors and theories, and across the explorative case studies of the challenges to M\&A ISI. For example, only one author, Yetton (Johnston and Yetton, 1996; Böhm et al., 2011; Henningsson and Yetton, 2011; Yetton et al., 2013), from the first decade continued publishing in this domain after 1999, and few theories or concepts have consistently been the subject of research. An exception to the latter observation is the frequent study of the choice of methods to implement M\&A ISI as both a dependent and an independent variable in ISI research. In addition, the research has been practice led rather than theory driven, with many practitioner authors. Indeed, many studies are atheoretical and report only empirical findings.

Inspecting the literature, there are no two or three dominant analytical frameworks on which to base a traditional narrative, theory-based review. Instead, the literature includes research that ranges across many different topics, including studies of politics and power (Kovela and Skok, 2012), the effects of stock market-based time pressures on ISI project performance (Tanriverdi and Uysal, 2011), and rebuilding the acquisition target's supply chain management system on the acquirer's IT platform (Yetton et al., 2013).

Responding to these characteristics, this review adopts an empirical-based (see, for example, Lacity et al., 2016), rather than a theoretical-based approach (Leidner and Kayworth, 2006). The role of data as a basis for theory development is a position shared by many researchers, including those who adopt methodologies as distinct as grounded theory methodology (Strauss and Corbin, 1990) and meta-analysis (See, for example, Hunter and Schmidt, 2004). As Hunter and Schmidt (p xxvii) write: "There are two steps to the accumulation of knowledge: (1) the accumulation of results across studies to establish facts, 
and (2) the formulation of theories to organize the facts into a coherent and useful form." The primary focus of this review is the first step: the established facts (empirical findings) across studies in the M\&A ISI literature.

Here we describe, classify, and present a descriptive model of what is known about M\&A ISI. This is similar to the reviews by Lacity et al. $(2010 ; 2011 ; 2016)$ that Rowe $(2014)$ defines as an example of a descriptive review. Adopting and extending the Lacity et al. protocol, we describe our review protocol under three headings: locate and select, code, and aggregate.

\section{Locate and select}

To identify the relationships to review, we first drew on our knowledge of the domain to select databases that contain journals and conference proceedings on the general topic of M\&A ISI. We also drew on Webster and Watson (2002), Boell and Cecez-Kecmanovic (2015b), and Okoli and Schabram (2010) to design a rigorous literature search. By searching databases, as opposed to specific journals, we included sources other than those with which we were already familiar. As Webster and Watson point out, IS is a multidisciplinary field, and, therefore, it was important to conduct a broad search to identify articles outside a limited sample based, for example, on only the AIS library and the Basket of Eight journals.

We searched for empirical articles on the phenomena of M\&A ISI in ABI Inform, AISeL library, EBSCOHost, JSTOR, Science Direct, and Springer Link using the search terms of 'information systems', 'information technology', 'IS', 'integration', 'acquisition', 'merger', 'M\&A', 'acquire', and 'merge'. As recommended by Boell and Cecez-Kecmanovic (2015b), we widened our search as we became more familiar with other terminologies, 
research, and authors. Finally, we extended the search by performing backward and forward searches (Webster and Watson, 2002).

Collectively, the searches of the six databases identified 563 publications for potential inclusion in the review. Inspecting the titles and abstracts of these publications, articles were judged to be relevant only if they specifically researched the phenomenon of ISI in the M\&A context. Of the initial list of 563 articles, 461 were judged not to be relevant. Most frequently, this was because the articles researched the integration of new IT systems, rather than the integration of IS in M\&As.

We agree with Boell and Cecez-Kecmanovic (2015a) that, even for experienced reviewers, judging whether a paper is relevant to a review only on its title and abstract is difficult and subject to error. Therefore, we took a conservative approach to minimize false negatives by reviewing in full any paper about which there was any doubt as to whether the paper did, or did not, study M\&A ISI. A further 43 publications were rejected after full reviews because they included topics judged to be tangential to our focus on M\&A ISI. Frequently, these included conceptual or methodological papers. In addition, some papers that had been provisionally accepted were rejected. These were conference papers that were later published as journal papers, and which are included in the sample.

This database-driven search was incomplete because several journals and conferences were not indexed throughout the time span for the search. For example, the AISeL library indexes AMCIS only after 1997, and the Information Systems Journal is included in the Business Source Complete database only after 1997. To compensate for these limitations, and to widen the search as recommended by Webster and Watson (2002), we conducted backward and forward searches for additional articles. 
In the backward search, we reviewed the reference lists of the articles included in the preliminary sample to identify relevant articles not captured by our database search. For the forward search, Thomson Reuters' Web of Science and Google Scholar were used to identify articles that reference articles already included in the sample. These searches identified seven additional articles, and three unpublished $\mathrm{PhD}$ theses (Linder, 1989; Tafti, 2009; Glazar-Stavnicky, 2016). Other relevant $\mathrm{PhD}$ theses were identified but were not included in the sample because their relevant findings are included in subsequent journal publications (e.g. Alaranta and Henningsson, 2007; 2008).

The final sample contained 66 articles and three PhD theses. For shorthand, this sample of 70 studies is henceforth referred to as the sample of 70 articles published between 1989 and 2016. The complete list of the studies included in the review sample is reported in Appendix A. This appendix also presents an overview of the unit of analysis, empirical data, industry context and theoretical framing for each study in the sample. Table 1 lists the publication sources of the review sample.

\section{[TABLE 1]}

\section{Code}

To identify the constructs to be investigated in this review, we adopted the coding protocols for open coding, axial coding, and constant comparison, that are specified in grounded theory methodology (Strauss and Corbin, 1990) to develop a list of master codes and their definitions/descriptions. Creating the list was a five-step iterative process that required coding individual papers multiple times. 
First, two of the authors, with experience in qualitative research and grounded theory methodology, independently coded 20 randomly selected articles from the sample of 70 articles. They listed each dependent and independent variable as named and described in each article. These became the list of 'author variables' and 'author variable descriptions.'

The two authors then met to identify the variables that could be combined across studies to begin to build the two lists of 'master variables' and 'master variable descriptions'. For example, Alaranta and Kautz (2012) use the term 'culture conflict', while Weber and Pliskin (1996) and Robertson and Powell (2001) use the term 'culture clash' to refer to a similar phenomenon of friction between the merging units' organizational cultures that spills over on to the ISI project. Some variables required careful consideration. For example, we coded a number of variables that describe the effects on the people involved in the merger, including stress from additional work tasks and the loss of required competences. In those situations, we resolved coding consolidation through discussions among the authors.

Second, during the next iteration, the same authors independently coded another random set of 20 articles. As before, they coded the dependent and independent variables used in each study. They also mapped the variables onto the master list of variables and descriptions. They then met to compare and discuss any differences in the two sets of codes.

Third, the remaining 30 articles were coded by the two authors. As new variables and descriptions were added to the master list, the two authors reviewed previously coded articles to determine if they needed to be recoded based on the extended master list. This process was repeated until all the articles had been coded. 
Fourth, when all articles had been coded, one author did a final review of each article to check that the codes for all variables in the 70 articles were consistent with the final master list. By following this method, we standardized the variables across articles that used different terms to capture essentially the same variable. The final list of master codes and their descriptions is presented in Appendix B.

Fifth, for each paper we then identified independent and dependent variables and documented relationships between the two variables types. Doing so, we documented 619 relationships in the 70 articles. As recommended by Lacity et al. $(2010 ; 2011 ; 2016)$, we coded significant positive relationships as ' +1 ', significant negative relationships as ' -1 ' and non-significant relationships as ' 0 '. In quantitative studies, we relied on the values of test statistics to judge whether the relationships are significant. In qualitative studies, we based our judgments on the strength of the verbal arguments.

Significant relationships that include categorical variables are coded $\mathrm{M}$ because no direction, positive or negative, could be assigned to the relationships. For example, in Toppenberg (2015), Industry is operationalized as a categorical variable referring to the specific industry of the M\&A. While in some studies in the sample that employ categorical variables, it is possible to speculate that there is an underlying dimension on which the categories could be assigned, we did not do this if the authors treated the variables as distinct categories. Critically, coding relationships $\mathrm{M}$ (rather than positive or negative) does not affect the total number of significant relationships among these variables in the analysis below. Instead, this protocol affects only the relative number of significant variables that are coded positive/negative or as generally mattering. Table 2 provides an overview of the guidelines adopted to code relationships in the 70 reviewed articles.

\section{[TABLE 2]}




\section{Aggregate}

The aggregation process involves two steps. In step 1, we follow Lacity et al. (2010) to identify the robust findings reported in the M\&A ISI literature. Robust findings are relationships that are replicated at least five times in the literature: These are the facts in Hunter and Schmidt's (2004) terms. To do this, we aggregate across relationships that include variations on the same underlying constructs.

Then, in step 2, we extend Lacity et al.'s approach to organize and structure the robust relationships into five themes: the ISI context, relational fit, the human side, pre-conditions, and time pressures. Doing this, we create a research database within which researchers can locate their research or on which they can draw to motivate research. Essentially, this step is a precondition to support and focus the theorizing that Hunter and Schmidt (2004) describe as step 2 in their research strategy.

\section{Step 1: Identifying the robust relationships}

Our review identified a large number of dependent and independent variables. To facilitate the identification and presentation of the robust relationships among them, we mapped the variables onto a limited number of categories. To do this, we followed a grounded sorting process based on the principles of the constant comparison method (Strauss and Corbin, 1990). Disagreements on categorization were resolved by the researchers through discussion (Saldaña, 2009).

This process was chosen to capture and document the variety in the research, rather than restricting that variety by selecting those findings could be integrated within a single or limited number of theoretical frameworks. Importantly, this categorization process 
introduces only an organizing layer for improved presentation and does not affect the analysis of the robust findings, or of the five research themes. For researchers who wish to map the variables within various theoretical frameworks, the full set of variables is presented in Appendix C.

We found 619 relationships involving the effects of 195 independent variables on 53 dependent variables. For reference, the full list of relationships between variables is presented in Appendix D. At this fine-grained level of analysis, the frequency with which findings are replicated across studies is minimal. To aggregate the empirical literature to be concise, meaningful, and well-structured, we follow Lacity et al.'s $(2010 ; 2011 ; 2016)$ methodology and move to a higher-level of abstraction.

To do this, we partition the 619 findings into two broad categories for the dependent variable: ISI decisions and ISI outcomes (see Appendix C). We retain the specific independent variables and sort them by frequency within the two broad categories. Although we lose some precision when we aggregate the findings, we gain a better overall understanding of the variables that affect M\&A ISI decisions and outcomes.

To identify the independent variables that consistently have an effect on ISI decisions and ISI outcomes, we follow two decision rules proposed by Lacity et al.'s $(2010 ; 2011 ; 2016)$ methodology. One is to extract the relationships that have been examined by researchers at least five times. Although five may seem an arbitrary number, it has been used elsewhere in this type of review as a means by which to identify 'well-utilized' variables (Jeyaraj et al., 2006; Lacity et al., 2010; 2011; 2016). Restricting our results to only those studied five or more times ensures they can be relied on as solid evidence and not emergent concepts. However, quantity alone is not a suitable measure; therefore, we couple this with a second decision rule: to differentiate between the levels of $60-80 \%$ and above $80 \%$ corroboration 
across findings. Lacity et al. $(2010 ; 2011 ; 2016)$ report that these decision rules were valuable in their research to distil nuances within the IT outsourcing literature.

Consistent with Lacity et al.'s $(2010 ; 2011 ; 2016)$ methodology, we use '(++)' to indicate that more than $80 \%$ of the time, when a relationship has been examined, the authors found a positively significant relationship. For example, in Appendix C, IT flexibility has been examined seven times in relation to ISI outcome and, in all seven cases, it is found to positively and significantly affect ISI outcomes. Therefore, we assign the relationship between IT flexibility and ISI outcome the symbol '(++)'. We use a ' $(+)$ ' when $60-80 \%$ of the evidence is positively significant.

Conversely, we use '(- -)' to indicate when more the $80 \%$, and '(-)' when $60-80 \%$, of the evidence show a negative relationship. Consistent with this notation, we use '(00)' and '(0)' to indicate when $80 \%$ or more, or between 60 and $80 \%$, are found to not have a significant relationship. Finally, we use '(MM)' to indicate when more than $80 \%$ of the evidence shows an independent variable mattered when operationalized as a categorical variable, and '(M)' to indicate when it mattered in $60-80 \%$ of the studies.

\section{Step 2: Integrating relationships within research themes}

To begin to address the challenge of fragmentation represented by the large number of robust relationships identified, we extended the Lacity et al (2010) protocol to investigate whether there is a limited number of research themes that structure and contextualize those relationships. To address this question, two criteria were imposed on the search for the themes. One is that the themes collectively span the research domain, where span is defined as including all, or nearly all, of the robust relationships. The other is that the themes are independent of each other. Specifically, few relationships are included in more than one theme. 
We began the search by identifying the most frequently studied robust relationship. This is the impact of IS-business collaboration in planning on ISI outcomes. This has been studied 14 times (see Table 3). We assigned this relationship to a theme initially labelled as Theme A. Then, analysing the research in which this relationship is investigated, we assigned the relationships among those variables and ISI to Theme A.

\section{[TABLE 3]}

Next, we identified the second most frequently studied robust relationship not included in Theme A. This is between Application and IT compatibility and ISI outcomes. We assigned this relationship to Theme B and investigated its relationships to variables in other robust relationships. Continuing this process identified five themes A-E that satisfy the first criterion of spanning the space defined by the robust relationships.

With respect to the second criterion, there is a low degree of overlap among three of the five themes and between those themes and the other two themes. However, there is a high overlap between the other two themes. We discuss the overlaps below when we present a brief overview of the themes after describing and modelling each theme.

\section{THE RELATIONSHIPS}

To understand what we know, it is frequently helpful to reflect on where we have come from. So, before identifying and describing the robust relationships in the ISI literature, we briefly inspect the time line of the research on ISI. We then present the findings from step one in the aggregation process: the robust relationships in the ISI literature. 


\section{The time line 1989-2016}

Figure 2 presents the temporal distribution of the articles in the review sample. During the two first decades, the pace of publication was slow. Seventy-one percent of all articles are published since 2008, and more than 50\% since 2012. If this trend continues, the literature would more than double in less than five years.

\section{[FIGURE 2]}

The first decade of research (1989-1999) is explorative. Frequently, the research does not distinguish between different types of M\&As and lacks an explicit theoretical framing. An exception is Johnston and Yetton (1996), who adopt an alignment framework. Only two findings are carried forward to research in the next decade. One is the conclusion that the critical role of IS is to realize IT-dependent business benefits. The other is that ISI methods can be partitioned under four headings: absorption, co-existence, best-of-breed, and renewal.

Comparing the second decade (2000-2009) with the first decade of research, the style is more explanatory and relies more on formal theoretical frameworks. For example, Brunetto (2006) draws on a contingency perspective, Wijnhoven et al. (2006) and Mehta and Hirschheim (2007) employ a framing based on alignment theory, and Alaranta and Henningsson (2008) adopt a strategic planning perspective.

As mentioned earlier only one of the authors who published on ISI during the first decade ever published on the topic again. This may have contributed to the fragmentation in the literature. During the second decade, authors generally refer to the first decade of research to motivate the focus on ISI as an enabler of M\&A benefits. However, when doing this, 
they do not draw on the constructs and findings from the previous decade. The exception, as also noted above, is the continued use of the four ISI methods.

In the third decade (2010 and onwards), research increasingly distinguishes between different types of M\&A transactions. For example, Seddon et al. (2010) explicitly focus on the merger of equals. Smaller acquisitions by serial acquirers is the explicit focus in papers by Henningsson and colleagues (Henningsson and Yetton, 2011; Henningsson, 2015; Henningsson and Kettinger, 2016); and Du (2015) analyses horizontal acquisitions.

Other researchers highlight different aspects of the ISI challenge, including, for example, merging IS departments (Alaranta and Martela, 2012), and problems with vendor-acquirer collaboration in acquisitions that are also divestments (Böhm et al., 2011). Generally, research in the third decade, compared with previous years, is empirically and methodologically more sophisticated, reporting a higher frequency of significant robust research findings (e.g. Tanriverdi and Uysal, 2011; 2015).

Over the three decades, research displays pluralism in theoretical framings and methodological approaches (see Appendix B). Eighteen different theoretical perspectives are adopted in the 70 articles. Of these, alignment theory and the resource-based view of the firm are the most frequently adopted theoretical frameworks. They are also the dominant analytical frameworks adopted in two of the five themes discussed below. Critically, many articles do not employ an explicit theoretical framework.

Methodological approaches include single and multiple case studies, expert panels, surveys, database analysis, design research, and focus groups. Fifty-six articles are qualitative, eleven are quantitative, and three combine qualitative and quantitative analysis. The relative use of qualitative and quantitative data has been stable over the three decades. 


\section{$\underline{\text { Relationships }}$}

Figure 3 presents all relationships in the IS M\&A literature that are corroborated at least five times. The data are reported in Appendix D to allow others to conduct analyses using different decision rules.

\section{[FIGURE 3]}

\section{Independent variables affecting ISI decisions}

Four broad categories - the M\&A context, ISI design, ISI capabilities, and External environment - include independent variables that are examined at least five times and report consistent results for their effect on ISI decisions (see Appendix D).

$M \& A$ context: Within this category, the three variables merger motivation, organizational integration objectives, and power and politics, are found to affect the choice of integration method.

There is general consensus about how M\&A motivation influences ISI methods. In all ten studies that this variable has been investigated, M\&A motivation is found to affect the choice of ISI methods. For example, Yetton et al. (2013) report that Danisco used an expansion integration method to realize economies of scale, and an extension method to realize economies of scope. Similarly, after reviewing the answers from an expert panel, Meyers (2008) models "M\&A Objectives and Business Strategy" as a critical factor affecting the ISI decision. In addition, Gregory et al. (2012) argue that, at times, M\&A motivations are paradoxical and that the parties involved develop decision-making strategies that balance the tensions between conflicting objectives. 
The ISI method is also contingent on the organizational structure that the merger companies intend to implement (Wijnhoven et al., 2006). For example, a preservation approach is linked to an IT co-existence integration method (Henningsson and Carlsson, 2011). Similarly, Gorla and Pang (2001) find that an absorption approach to organizational integration is closely linked to an ISI method based on the redeployment of one organization's IS to the other.

The variable power and politics shows how factors other than efficiency and effectiveness influence the ISI method. The decision on how to integrate IS effectively becomes the decision on which business processes to keep, and which IS department post-M\&A keeps its headcount intact. In this way, the decision on the ISI method is heavily influenced by the relative organizational power within the M\&A (Mehta and Hirschheim, 2007; Kovela and Skok, 2012).

ISI design: Within this category, the variable of ISI objectives refers to the strategic objectives that have been assigned to the IS functions in the IT merger project. The effect of these objectives on the ISI decision has been investigated five times. For example, Wijnhoven et al. (2006) compare how the ISI objectives influence decision-making in different hospital mergers. In one case, the ISI objective of enabling a single organization was difficult to achieve in one step. Instead, patient administration, the function with the highest operational priority, was integrated first. This resulted in partial integration in the short term. Subsequently, the financial and managerial systems were integrated. In another case, the ISI objectives of retaining the organization's independence influenced the decision to leave any unique systems intact during the integration process.

Brunetto (2006) distinguishes between the strategic goals of synergy and value and cost rationalization in his analysis of ISI in the construction industry. He finds that these broad 
ISI objectives typically result in the choice of different ISI methods. Similarly, Steininger et al. (2016b) find that Migration objectives were the key criteria when three hospitals decided on the appropriate migration scenario. The importance of ISI objectives is that they shape the compromises and priorities in ISI decisions when optimal solutions are out of reach.

ISI capabilities: The use of external IT resources, commonly sourced as consultants, influences ISI decision-making. Henningsson and Øhrgaard (2016) identify four different roles for consultants in ISI projects: muscle, expertise, craft and brain. In the fourth role, brain, the merging companies rely extensively on external resources to actively design the ISI method. The uses of external resources in this capacity range from complete reliance for all ISI decisions to active avoidance of giving away decision authority.

Wynne (2016) reports an alternative strategy in which the focal organization hired managers with substantial M\&A experience to guide them in ISI decisions. Seddon et al. (2010, p. 1087) explain that, while this strategy might be relevant to retaining knowledge after the ISI project, this use of external resource can still be challenged by the fact that "many key decisions about people, systems, technologies, and their locations, remain both complex and highly situationally dependent."

External environment: Time pressure is an independent variable that influences the ISI decision. Five studies highlight its importance for the ISI decision. Time pressure comes partly from the market, which expects merger synergies to be realized within a short time frame. For example, Mehta and Hirshheim (2007) explain how synergy promises have a time component and that shareholders expect to see rapid value creation. Similarly, Robertson and Powell (2001) explain how the targets set when 'selling' the merger to shareholders and to the market become a constraint on IS decision making. Along similar 
lines, Holm-Larsen (2005) explains how the long-term ideal option of building a new IT platform could not meet the time expectations.

Time pressures also come from legal and regulatory authorities. Johnston and Yetton (1996) report that, within a bank merger, pressure from financial authorities demanding joint reporting and risk governance after the legal merger was in place contributed to the bank abandoning plans for a best-of-breed integration method. Because of time pressures, organizations may choose interim integration methods that meet market and legal demands, keeping long-term roadmaps of more radical redesigns that unlock the full potential of mergers.

\section{Independent variables and the ISI outcome}

Eleven broad categories - ISI implementation, within-firm IS conditions, M\&A context, ISI design, IT infrastructure, organizational characteristics, IS relational, ISI decision, ISI capabilities, ISI planning, and external environment- include independent variables that are examined at least five times to generate consistent significant findings (Appendix D).

ISI implementation: As shown in Appendix D, of the 37 variables in this category that are reported to affect ISI outcomes, only seven are investigated at least five times with consistent results. Four of these, changes in IS workforce size, IS employee morale, changes in IS policies and procedures, and decreases in IS staff compensation, have no significant effect on ISI outcomes. All four variables address issues during IS implementation that affect individual IS employees. These variables have commonly been measured through survey instruments (Stylianou et al., 1996; Robbins and Stylianou, 1999; Morsell et al., 2009). As a result, we lack practical examples of why these measures do not affect ISI outcomes. 
When these variables are found to have an effect, it has been on proxy measures such as IS employees' satisfaction with the integrated system. However, there are no significant effects on the value creation measures or the avoidance of M\&A problems. One possibility is that these findings show that IS staff contribute frequently to the goals of the M\&A despite being demoralized. The extent to which the demoralization of staff affects longterm organisational performance has not been measured in the studies investigating these variables.

In contrast, both the extent and qualities of IT communication, and IT leadership in integration projects are found to positively affect ISI outcomes. For example, Brown et al. (2003, p. 24) advise: "Use rich communications media to read emotions and recognize successes at every opportunity because a merger is an emotional event: you cannot communicate too much." Brown et al. also find that the establishment of clear leadership for the ISI project is critical because it addresses difficult decisions quickly and drives the integration forward. Corroborating the importance of leadership, Alaranta and Martela (2012) and Kim et al. (2005) report that insufficient and inadequate leadership has negative effects on ISI outcomes.

Finally, user training and support have been investigated both quantitatively (Robbins and Stylianou, 1999; Morsell et al., 2009) and qualitatively (Kim et al., 2005; Alaranta and Kautz, 2012). The findings are consistent: Better user training has a positive effect on ISI outcomes. These findings are consistent with the findings on related variables, including the involvement of users in ISI decision (Robbins and Stylianou, 1999), the effect of user resistance (Alaranta and Kautz, 2012), and the existence of strong habits and practices (Vieru et al., 2016). 
In general, we conclude that the factors associated with how ISI is implemented affect ISI outcomes and, specifically, that extensive communication, strong leadership, and adequate resourcing for user training and support, have a positive effect on ISI outcomes. However, the explanation for which factors influence which outcomes is in its formative stage. Within-firm IS conditions: Six variables measuring within-firm conditions have been investigated at least five times. Four have significant positive effects on ISI outcomes: ISbusiness collaboration in planning, top management support, ISI proactivity, and communication of M\&A activities to IS personnel, are positively correlated with ISI outcomes. Although these variables emphasise slightly different aspects of the conditions for successful ISI, they all show that a positive perception of the IS organization, early inclusion in M\&A activities, and support throughout the ISI project, have positive effects on ISI outcomes.

As Brown et al. (2003) conclude: “Don't underestimate the value of prior IT-business relationships for project success.” Similarly, LeFave et al. (2008, p. 175) write: “A lack of IT credibility within former Sprint business functions" affected the plans for the merger. Yetton et al. (2013, p.29) report: "A prerequisite for the CIO and IT management team to act efficiently and effectively in the ISI of Genencor was the confidence built by the IT team during the years preceding the acquisition. IT had shown that, instead of being a problem, it had become a strategic resource to implement the Danisco growth-byacquisition strategy."

So, the perception of IT, the involvement of IT in the early phases of the merger, and support throughout the process, are interlinked. When a constructive IT-business relationship exists, it allows the IS organization to hit the ground running at the time of the M\&A announcement (Yetton et al., 2013), reduce cost (Brown et al., 2003), shape the ISI 
to satisfy the critical business needs (Stylianou et al., 1996), and better position the IS organization to support the post-M\&A combined businesses (Brown et al., 2003). When such a relationship does not exist, it leads to the exclusion of IT executives in M\&A planning (Alaranta and Kautz, 2012; Al Suliman, 2015), a view that IT will just make things happen (Mehta and Hirschheim, 2007), top-management steering of ISI activities, including vendor selection (Alaranta and Kautz, 2012), and negative ISI outcomes (Stylianou et al., 1996; Robbins and Stylianou, 1999; Morsell et al., 2009).

Two variables, IT investment at the target in acquisitions, and level of data-sharing preM\&A, have no significant effect on ISI outcomes. Tafti (2009) finds that, while IT investments in the acquirer has a significant effect on ISI outcome, there is no effect for investments in the target. The author reflects on three possible explanations for this. First, acquiring firms are not leveraging or integrating target firms' IT capabilities to the extent that we might expect. Second, acquiring firms do not adopt the 'best-of-breed' ISI method that preserves unique IS capabilities in the target. Third, the IT infrastructure and capabilities of the target firm are phased out in favour of the acquiring firm's IT infrastructure. All three explanations are examples of trade-offs and sub-optimal decisionmaking during the ISI process.

Finally, the level of data sharing in the organizations pre-M\&A (Robbins and Stylianou, 1999) does not have a significant effect on ISI outcomes. While Stylianou et al. (1996) report that there is a significant effect on the IS department's own assessment of ISI success, data sharing does not have a significant effect on users' perception, the exploitation of M\&A opportunities, or the avoidance of M\&A problems.

$M \& A$ context: The M\&A context, as a category of variables, is the second most researched category that influences ISI decisions and outcomes. However, the research covers a wide 
range of variables, only one of which, organizational M\&A planning, is consistently found to have a positive effect on ISI outcomes. This effect has been validated qualitatively by Kim et al. (2005) and quantitatively by Stylianou et al. (1996), Robbins and Stylianou (1999) and Morsell et al. (2009). High quality planning creates a foundation for the ISI project, while low quality M\&A planning has a negative spill over effect on ISI project performance.

Given the fragmented research, we can say that the M\&A context is critical for ISI project outcomes. However, there is limited knowledge about which specific attributes of the context are most relevant. Interestingly, despite the importance of the overall M\&A context, there is no research on who should, or how to, reframe the M\&A context to improve IT project performance.

ISI design: Four variables in this category have been investigated more than five times with consistent results. Constructive collaborative dynamics and the presence of Risk management are consistently found to positively affect ISI outcomes (Brown et al., 2003; Henningsson and Kettinger, 2016). Constructive ISI collaboration requires that the parties to an M\&A form teams to develop integration plans. Risk management accepts that there are always unpleasant surprises and organizes to act proactively. Consistently, higher values of these two variables have a positive effect on M\&A ISI decision-making. Together with the previously discussed variable capturing emergence in the ISI planning process, the three variables represent complementary strategies to manage the lack of information required to design ISI at the closure of an M\&A deal. Emergent IS planning processes, collaborative dynamics, and a proactive orientation towards risk management, align ISI decision-making to the specific characteristics of an M\&A. 
Political considerations in the ISI design and consideration of system size/complexity have no significant effect on ISI outcomes. Stylianou et al. (1996) find that political considerations have a significant negative effect on the users' assessment of ISI success, but no significant effect on the IS function's own assessment, the exploitation of M\&A opportunities, or M\&A problem avoidance. Similarly, while taking complexity into account has a significant positive effect on the users' assessment of ISI success, complexity has no significant effect on the IS function's own assessment, the exploitation of M\&A opportunities or M\&A problem avoidance.

Where the strategic objectives assigned to the IS function in the M\&A were found to significantly impact the decisions made, a close examination of the effect of ISI design on ISI decisions suggests that the effect of design on outcomes is mediated by how it influences the trade-offs made in the choices of ISI method and degree of ISI.

IT infrastructure: Two attributes of the IT infrastructure, flexibility and standardization, are consistently found to influence ISI outcomes. Higher values of these attributes have a positive effect on M\&A ISI outcomes. These effects can be explained in terms of pathdependency. The historical development of IS constrains how the IS can be developed. Lack of flexibility constrains options, resulting in unrealized M\&A potential or difficulties in the integration project. For example, options are constrained when IT resources do not scale, limiting the realization of the potential M\&A value (Tanriverdi and Uysal, 2015).

Three of the four ISI methods re-use the existing IS of the two parties to the M\&A to develop the shared IS assets. This redeployment of IT resources is supported by IT infrastructure flexibility and modularity, typically delivered through a service-oriented architecture (SOA) (Benitez-Amado and Ray, 2012). Because SOA is designed to provide reusable components, IS departments do not need to reinvent the wheel, decreasing both the 
time to integration and development costs. Additionally, a well-designed SOA lets organizations manage multiple small integration projects with less capital and resource investment compared with the high investment and resource commitments associated with traditional solution development architectures (Henningsson et al., 2007).

Organizational characteristics: A wide range of organizational characteristics has been studied. However, only one characteristic shows consistent results. Pre-M\&A organizational performance, profit, has a positive effect on ISI outcome. Stylianou et al. (1996) find that acquirer revenues have a significant effect on the IS function's own assessment of ISI success, but no significant effect on the users' assessment, the exploitation of M\&A opportunities, or M\&A problem avoidance. Tanriverdi and Uysal (2015) report that high profitability in combination with extensive previous growth and a large IT capability gap between the involved organizations triggers a positive reaction from the stock market on deal announcement, as measured through Cumulative Abnormal Returns (CAR). These positive effects of high profitability on ISI outcomes appear to be contingent on the presence of both extensive previous growth and a large IT capability gap. The study by Tanriverdi and Uysal (2015) shows that the effect of organizational characteristics on ISI outcomes play out through complex systems of interacting variables.

IS relational: IT compatibility between the M\&A organizations is one of the earliest variables investigated in the ISI literature. Buck-Lew et al. (1992, p. 363) argue: "Since company data and information technology (IT) are as much a management resource as the financial and human resources for the combined firm, the proposal is made that IT fit should be explicitly considered in analysis of corporate acquisitions." Motivating this argument are the findings that IT compatibility has a positive effect on ISI outcomes in 
terms of the time and resources needed to complete integration. This finding has been corroborated ten times (Johnston and Yetton, 1996; Stylianou et al., 1996).

However, the data supporting these findings were collected in the 1990s. It may be that technological innovations have made some of the 1990s hardware and IT application compatibility issues irrelevant. Since then, research has shifted to study a broader framing of IS compatibility that includes other attributes of the IS organization. This research suggests that IS configurational fit, both technical (application and IT) and organizational, has a positive effect on ISI outcomes (Brunetto, 2006).

ISI decision: Considering all the variables in the category ISI decision, the only two that are linked consistently to ISI outcomes are the ISI method and the Integration alignment variables. In the relationship between ISI method and ISI outcomes, each of the four integration methods is designed to deliver specific, different outcomes (Holm-Larsen, 2005; Garcia-Canal et al., 2013). Effectively, the choice of the ISI method becomes the choice of which benefits are given priority in practice. For example, a co-existence strategy both enables economies of scope and increases IT infrastructure complexity.

In the relationship between ISI outcomes and integration alignment, which refers to the fit between the strategy for organizational integration and ISI, alignment is typically found to have a positive impact on ISI outcomes (Wijnhoven et al., 2006; Mehta and Hirschheim, 2007). However, recently this conclusion has been challenged by evidence showing that alignment is not a pre-requisite for M\&A success (Baker and Niederman, 2014). ISI capabilities: Enterprise architecture (EA) is the only capability that is consistently linked to ISI outcomes. EA is frequently referred to as "the organizing logic for business process and IT capabilities, reflecting the integration and standardization requirements of the firm's operating model.” (Ross et al., 2006, p. 9) Specifically in M\&As, an enterprise architecture 
capability contributes to ISI processes in pre-M\&A preparation, partner selection, merger integration, and post-integration management (Toppenberg et al., 2015). EA enables M\&A organizations to manage the specific M\&A objectives without losing track of the potential long-term organizational performance effect of induced complexity and accumulated inefficiencies over a series of M\&As. No other ISI capability has been consistently linked to M\&A performance. While many authors agree that ISI capabilities are important, little agreement exists about which other capabilities are required for effective delivery of ISI in M\&As.

ISI planning: Discovery and quality of ISI planning, two variables belonging to the category ISI planning, are found to have a positive effect on ISI outcomes. The discovery variable captures the degree of emergence in the planning process (Busquets, 2015). In an emergent planning process, instead of committing to a fixed strategy, the M\&A partners adapt integration plans as the organizations discover synergistic potential. This is essential in large mergers, where not all the IT synergies can be specified in advance because the relevant information to create a detailed integration scenario is not available. Busquets ( $\mathrm{p}$. 178) argues that "while some steps that lead to synergies can be planned in advance, other essential variations are only learned and discovered during the M\&A process itself, thus leading to emergent synergies."

Morsell et al. (2009) argue that the quality of ISI planning has two effects on ISI outcomes. One is a direct effect on the IS function's ability to complete the project on time and budget. The other is that planning failures spill over onto the overall M\&A project, contributing negatively to the scheduling and resourcing of the M\&A project. These two robust findings present a paradoxical tension and a dilemma for management. Developed 
plans that are followed are important, but so too is the flexibility to respond to emergent opportunities.

External environment: Research on how time pressures affect ISI decisions reports that time pressure forces M\&A organizations both to make decisions without having all the relevant information, and to choose sub-optimal solutions that can be accomplished within the given time frame (Holm-Larsen, 2005; Henningsson and Kettinger, 2016). These suboptimal decisions reduce performance. Specifically, time pressure forces the parties to focus on short-term goals, ignoring the potential negative long-term effects on the integration.

\section{FIVE RESEARCH THEMES}

The consolidated model presented in Figure 3 summarises the robust empirical findings in the ISI literature. However, given the number and complexity of the relationships in Figure 3 , this model does not identify any core set or sets of relationships that explain the effects of ISI on M\&A performance. This is an outcome of adopting the Lacity et al (2010) approach with its focus on identifying the list of robust relationships and its absence of a protocol to investigate the interdependences among the relationships.

Here, to address the challenge of fragmentation, we apply the protocol developed and described in the Methodology section. This process identifies five themes that include the robust findings that define the critical, known challenges of ISI. To ground the discussion, we present a case study to illustrate the relevance of each theme.

As described in the method section, we began the search for research themes by identifying the most frequently studied robust relationship. This is the effect on ISI outcomes of IS- 
business collaboration in planning. This has been studied 14 times (see Table 3). We assigned this relationship to a theme initially called 'Theme A'. Inspecting the research in which this relationship is investigated (e.g. Main and Short, 1989; Al Suliman, 2015), we identified associations with other variables, for example, quality of ISI planning, top management support, organizational integration objectives, organizational M\&A planning, ISI objectives, and ISI method. We also assigned the relationships among these variables and ISI to Theme A.

The most frequently studied robust relationship that is not included in Theme $\mathrm{A}$ is between application and IT compatibility and ISI outcomes. We assigned this relationship to Theme $\mathrm{B}$, and investigated its relationships to variables in other robust relationships. Continuing this process, we identified five models A-E that satisfy the first criterion of spanning the space defined by the robust relationships. Specifically, all but one of the robust relationships are included in at least one theme. The exception is the effect on ISI outcomes of system size/complexity.

In addition, relationships involving ISI method are included in each of the five themes. In each of the models of the five themes, ISI method mediates the influence of ISI decisions on ISI outcomes. For two reasons, we should have expected the overlaps involving ISI methods. One is the structure of the research literature in which ISI methods occupies a unique position as both a dependent and independent variable (see Figure 1). The other reason is that ISI methods is the only construct that has been the subject of research in all three decades.

In the second step of our protocol, we labelled the five themes in terms of their core constructs: M\&A context, relational fit, human behaviour, pre-conditions, and time pressures. Within each of these research sub-domains, we propose a research agenda to 
address research gaps in the theme. This research would begin to develop a set of middlerange, substantive (c.f. Boudon et al., 1991; Lee, 2015) theories that are contextually contingent and managerially actionable.

\section{Theme A: The M\&A context}

Taken together, the variables defining the M\&A context form a thematic domain that is embedded in the M\&A project (see Figure 4). For example, the outcomes of the ISI project are partially defined in terms of the M\&A business objectives (Holm-Larsen, 2005; Steininger et al., 2016a). It is impossible to understand how ISI success is realized without considering the M\&A context. This is so pervasive in its effect on ISI success that future research should investigate how much of ISI success is contingent on the ISI project and how much on the overall M\&A context.

\section{[FIGURE 4]}

The importance of the context is illustrated by the ForestCo case study (Jain and Ramesh, 2015). ForestCo, a Fortune 500 company in the paper and packaging industry, aggressively completed multiple acquisitions. The rapid growth was partially a consequence of industry consolidation. During a period of 15 years, $40 \%$ of the capacity expansions at existing firms in this industry were achieved through horizontal acquisitions.

The timing of acquisitions was not entirely in the hands of ForestCo. It had to act as companies became available in the market. Nor could ForestCo stop its growth program in order to restructure because opportunities would have been foregone. Therefore, ForestCo did not consolidate business at the corporate level as the firm expanded. Instead ISI was resolved by retaining much of the pre-existing IS in the acquired businesses. 
While this supported the rapid growth, the rapid expansion created four business divisions that were vertically structured silos. These were governed within a federated organizational structure with limited interaction among the divisions. Independence was valued over any benefits contingent on corporate control and cross division synergies. Doing this, ForestCo failed to realize the synergies at the corporate level. To unlock the cross-division synergies, the top management team of ForestCo finally decided to develop a shared corporate IT platform.

The M\&A context is a component in several explanations of ISI performance (GarciaCanal et al., 2013; Glazar-Stavnicky, 2016). However, it is rarely treated as central to explaining the dynamics between the overall M\&A business context and the ISI project (Freitag et al., 2010; Jain and Ramesh, 2015). To extend the explanation of ISI performance, future research should examine how M\&A contexts affect the design and implementation of ISI projects.

The theoretical frameworks to do this potentially include general theories of coordination (Malone and Crowston, 1994) and task dependency (Thompson, 1967). These theoretical frameworks could provide the mechanisms for modelling differences among dependencies, the challenges that dependencies create, and how the proposed coordination processes address those challenges (Grant, 1996; Medema, 1996). Recognition of these differences is fundamental to understanding how processes or integration methods are contingent on the context. Other theoretical frameworks addressing, for example, industrial characteristics could provide a starting point for analysing how the contextual influencers emerge in the first place. 


\section{Theme B: Relational fit}

The most frequently studied relationship that is not a member of Theme A is the impact of application and IT compatibility on ISI outcomes (Chang et al., 2014; Hsu and Chen, 2015). These relationships comprise a sub-dimension of the construct IS configuration fit, which affects ISI outcomes (Buck-Lew et al., 1992; Johnston and Yetton, 1996; Brunetto, 2006). The effects of these variables are frequently explained in terms of the limitations that they impose on the options for implementing ISI, restricting the choice of ISI methods (Johnston and Yetton, 1996; Gorla and Pang, 2001; Brunetto, 2006; Myers, 2008).

Incompatibilities and lack of fit lead to misalignment between business and ISI integration processes (Wijnhoven et al., 2006). Cumulatively, this creates an organization in misalignment (Figure 5) (Wijnhoven et al., 2006; Mehta and Hirschheim, 2007; Baker and Niederman, 2014). The basic argument is that the ISI method should be matched to the M\&A strategy to create the expected business benefits (Giacomazzi et al., 1997; Wijnhoven et al., 2006).

\section{[FIGURE 5]}

This argument is illustrated by the discussion of Cisco's acquisition of VS (Toppenberg et al., 2015), a provider of solutions for streaming video. At Cisco, the acquisition protocols include mechanisms to design and implement multiple work streams to integrate its business and technical capabilities with those of an acquisition. Frequently, these are complex acquisitions with multiple business benefits that require multiple work streams to retain business/IT alignment.

The VS acquisition was driven by three distinct business benefits. First, the primary motivation for acquiring VS was to rapidly extend Cisco's product offerings in video 
services. VS's major product was VideoGuard, which was used by 85 pay TV operators around the world. Second, the intent was to extend VS's reach to the service provider market in China and India, where VS had an established customer footprint. Third, Cisco expected that some of VS's technical capabilities could be integrated into Cisco to support its existing business operations.

Instead of applying a single integration method to realize the multiple benefits, Cisco adopted and combined three ISI methods, absorption, co-existence and best-of-breed. Cisco then integrated VS at a capability level, where each capability was matched to an integration method. This meant that in the VS acquisition, various VS business and technical capabilities were retained, running in parallel with Cisco's corresponding capabilities. Others were implemented across the Cisco organization to deliver business improvements, and yet others were replaced by Cisco's pre-existing set of capabilities to implement best practice and to realize economies of scale in the VS business.

Typically, alignment theory is adopted to explain the influence of the four integration methods on ISI. For example, within this framework, research has investigated the effects on IS and business strategic alignment of the choice of ISI method (Mehta and Hirschheim, 2007), alignment as an outcome of M\&As (Wijnhoven et al., 2006), and whether alignment between organizational and ISI methods is necessary to create value (Johnston and Yetton, 1996; Baker and Niederman, 2014).

The findings for the effect on M\&A performance of alignment are inconsistent. Johnston and Yetton (1996), Wijnhoven et al. (2006) and Mehta and Hirschheim (2007) conclude that alignment is critical for ISI success. Baker and Niederman (2014) challenge this assumption. They report eight cases of misalignment out of 22 successful mergers. They conclude that alignment is not a prerequisite for ISI success. Consequently, for alignment 
theory to be a valid theoretical framework for the explanation of ISI outcomes, future research must theoretically integrate these disparate findings. A careful examination of methods and alignment in relation to the different definitions of ISI outcomes is a potential starting point to do this.

One major knowledge gap revealed by this review is that the existing literature does not have a well-defined understanding of the relevant outcomes of M\&A ISI. Above, we identify 53 outcome variables, ranging from the time and resources required to complete the ISI project (Stylianou et al., 1996), to stock-market reactions and post-integration operational performance (Tanriverdi and Uysal, 2011; 2015). Most researchers focus on only one or two of these outcomes.

A few researchers attempt to conceptualize ISI success as a multi-dimensional construct. For example, Stylianou et al. (1996), Robbins and Stylianou (1999), and Morsell et al. (2009), define ISI success as a five-dimensional construct: user satisfaction, ability to exploit merger opportunities, ability to avoid merger problems, IS resource utilization, and improved IS capability.

However, these composite constructs of success are difficult to investigate because a close examination of the outcome variables reveals that several of them would be almost impossible to achieve at the same time, while others appear to be closely related. For example, the two constructs, more time and more resources, that are required to realize ISI benefits are highly interdependent. Similarly, user satisfaction and avoiding ISI problems are difficult to measure independently. To compare and contrast findings to develop theory, we need improved conceptualization of ISI outcomes.

In addition, the literature typically assumes the adoption of a single ISI method. For example, in their analysis of post-integration alignment, Baker and Niederman (2014) map 
a single ISI method to a single organizational integration strategy. In contrast, several of the rich case descriptions in the literature present ISI projects with mixed integration methods. For example, Cisco's acquisition of VS, discussed briefly above, combined three integration methods (Toppenberg et al., 2015). In addition, some ISI methods can be partial, for example a partial IS co-existence method (Wijnhoven et al., 2006; Henningsson and Kettinger, 2016). In practice, this method is effectively a combination of a co-existence and an absorption integration method.

This analysis shows that the current conceptualizations of ISI methods are subject to two limitations. One is that they do not allow for fine-grained definitions of integration methods. The other is that the choice of method is limited to the choice of a single method and not a portfolio of methods to realize multiple ISI benefits. Therefore, the improved precision of explanations based on alignment theory is contingent on conceptual development of the ISI method construct and its relationship to performance. Future research should address this issue.

\section{Theme C: The human side}

Changes in workforce size, IS employee morale, and user training and support, are frequently linked to ISI outcome. Typically, these explanations of ISI outcomes emphasise the importance of communication (Stylianou et al., 1996), politics (Linder, 1989; Kovela and Skok, 2012) and leadership (Kim et al., 2005; Williams et al., 2015). Taken together, these studies represent an explanatory theme that ISI includes an important human dimension: ISI methods affect and are affected by human behaviour (Figure 6) (Linder, 1989; Kovela and Skok, 2012).

\section{[FIGURE 6]}


The THC case (Vieru and Rivard, 2014) illustrates this theme. In the THC case, a merger of three Canadian hospitals, the new organization tried to integrate the different units and introduce best practice through the introduction of a laboratory IS. At the outset of the merger, the three sites that formed THC had distinct lab procedures. Management saw the ISI project as an opportunity to implement standardized processes throughout the merged organization, enabled by a single unified IT system.

The initial implementation design was based on a single IT system. However, it was only partly implemented because the people involved shaped the implementation to fit with their pre-merger working habits. Divergent organizational identities and team members' alternative interpretations of others' practices, norms and organizational symbols, prevailed during the integration phase. In general, the people involved in and subject to an ISI project do not simply enact managerial intentions. Rather, they take an active role in shaping ISI and its outcomes.

The human side of ISI design and implementation includes culture, power, change management, resistance, and knowledge gaps (Linder, 1989; Alaranta and Martela, 2012; Vieru and Rivard, 2014). This human side of ISI comprises three critical dimensions: the human resources involved in realizing ISI, operating the integrated IS solutions, and using the services contingent on ISI (Linder, 1989; Alaranta and Martela, 2012; Vieru and Rivard, 2014). While research has explored the scope of these three constructs, it is comparatively silent on how to resolve the associated ISI challenges (Alaranta and Martela, 2012).

So while there is limited understanding of what causes an ISI project to drift from its initial plans (Alaranta and Henningsson, 2008; Vieru and Rivard, 2014) and the importance of creating a project environment with good leadership, communication, and user support 
(Linder, 1989; Alaranta and Martela, 2012; Vieru and Rivard, 2014), the answers as to how this can be achieved are inadequate. Attending to this issue requires attention to a broader range of questions pertaining to skill sets, team construction, location of decision making on tactics and operations, and the potential to build and source expertise. Critically, future research on the human side of ISI should develop solutions to these challenges by studying these variables individually while also looking for overarching variables that may enable or influence all of them. Another important observation is to recognise that even projects with good leadership, communication, and user support have failed. The presence of these three variables does not guarantee ISI success.

The above analysis implicitly treats the pre-M\&A IS of the acquirer and of the acquisition as independent of each other and self-contained. Instead, human resource-based explanations of ISI must also address the permeability of organizational boundaries. Initially, this was limited to the growth of IT outsourcing and supply chain management (Richmond and Seidmann, 1992). Increasingly, organizations share their IS with other stakeholders, including suppliers, customers and partners that form part of larger information infrastructures that transcend organizational boundaries to form platforms on which other organizations build (Baldwin and Clark, 2000; Tiwana and Konsynski, 2010). Currently, the relevant dimensions of the composition and structure of these links with respect to M\&A ISI are unknown. To understand the human side of ISI, future research should extend the scope of inquiry to include the wider set of stakeholders involved in codesigning, co-developing, and co-implementing ISI.

\section{Theme D: Pre-conditions for ISI}

The fourth theme focuses on the pre-conditions to deliver successful ISI. Typically, these are described in terms of three dimensions: Capabilities (Kim et al., 2005; Henningsson, 
2015), IT infrastructure (Tafti, 2009; Benitez-Amado and Ray, 2012), and the Relationship between IT and business in the combined organization (Stylianou et al., 1996; Brown et al., 2003). These pre-conditions enable (or inhibit) organizations to choose and effectively implement the ISI methods to realize the intended M\&A benefits (Yetton et al., 2013; Toppenberg et al., 2015) (Figure 7).

\section{[FIGURE 7]}

The Danisco case (Yetton et al., 2013) illustrates the importance of the ISI pre-conditions. Danisco was created in 1989 through a series of mergers that created a conglomerate in which more than 100 SBUs were managed as profit centres. In 1997, the new CEO initiated a radical strategy to transform Danisco from a regional conglomerate into a global food ingredients company, with sales to food processing companies instead of to retail consumers.

To implement this strategy, Danisco began an acquisition program targeted at food ingredients companies. The program was funded by divestments in other areas. The absences of a flexible IT infrastructure and of standardized business processes were major barriers to post-acquisition ISI. Integrating the next acquisition became an increasingly costly and slow process. Halting its growth program, Danisco rebuilt its IT platform with standardized business processes to support future acquisition ISI projects. The standardization also simplified the training of the integration team.

As a result, the cost of and time to deliver successful ISI was reduced significantly. The extreme case was Danisco's acquisition of Rhodia. This was completed on Day One of the acquisition. Adopting an absorption ISI method, all Rhodia's IT resources were retired and the data transferred to the Danisco platform. The CIO acknowledged that they could not have done this without both implementing the new platform and business process 
standardization strategy and training the acquisition team, to create the required preconditions to support the serial acquisition strategy.

In this theme, the dominant theoretical framing is the resource-based view of the firm (Tanriverdi and Uysal, 2011; Yetton et al., 2013), and its extensions into the capabilitybased and knowledge-based views (Gregory et al., 2012; Henningsson, 2015). Critically, research recognizes that it takes years, not months, to develop the IT resources to deliver successful ISI projects. However, how these resources are developed is not well understood. For example, Tanriverdi and Uysal (2011) report that cross-business IT integration capability affects ISI performance, but they do not address the question of how that capability is developed.

More research is also needed on the pre-conditions to deliver specific categories of ISI. This review reveals a major inconsistency between the variance in potential ISI benefits and the homogeneity in how the literature defines the relevant ISI capabilities and assets. Specifically, capabilities are not elaborated beyond the general capabilities of designing, planning and implementing, and properties of IT assets are typically restricted to issues of flexibility.

The above discussion identifies three gaps for future research. First, research should identify and link particular capabilities to specific ISI integration challenges and benefits. For example, this would include linking capabilities to specific integration methods, and comparing successful ISI in single acquisitions with ISI in successful growth-byacquisition programs.

Second, research should investigate alternative theoretical frameworks to accommodate the observed heterogeneity in the ISI challenges. For example, the capability literature has converged on theories of organizational routines in its search for the micro-foundations of 
capabilities (Helfat et al., 2009). However, Henningsson (2015) observes that even for frequent acquirers, ISI can rarely be routinized. Instead, the formation of ISI capabilities appears to be subject to ad-hoc problem solving.

Third, research should explore technology trends that transform the organizational use of technology. Many research findings are based on studies done or data collected ten or more years ago. What is missing is an understanding of the ISI challenge within the technological context of today's world, where concepts including "cloud computing", "big data", or “BYOD” are no longer buzzwords, but credible options within an IT organisation's toolkit.

For example, a concept running through many studies in the sample is that systems must be able to scale to support an absorbed company's IT records and to process the new load (Merali and McKiernan, 1993; Eckert et al., 2012). However, there is no discussion of how cloud computing may lessen the problems contingent on scaling. Where previously a lack of capacity to support the combined business was a barrier to successful ISI (Hsu and Chen, 2015), cloud-computing potentially enables additional capacity to be sourced as a component in the integration project. A critical unaddressed question is: How do major changes in the provision of IT services shape the challenges of ISI and their solutions? Of course, new technologies would also introduce new challenges and limitations. For example, while the infrastructure may scale as a feature of a cloud-computing platform, perhaps the contracts do not scale so favourably.

\section{Theme E: Time pressures}

The fifth theme emphasizes the role of time pressure, which is frequently found to affect both ISI decisions and outcomes. The pressure to integrate rapidly takes several forms, including market pressure to realize the expected benefits (Mehta and Hirschheim, 2007) 
and legal pressure to report and govern risk (Johnston and Yetton, 1996; Mehta and Hirschheim, 2007). In Figure 8, time pressure interacts with these variables to affect the choice of ISI methods, and, hence, of ISI outcomes (Mehta and Hirschheim, 2007; Eckert et al., 2012).

\section{[FIGURE 8]}

The Mekong-Indus merger (Mehta and Hirschheim, 2007) illustrates the effect of time pressure on merger ISI decision-making. Because ISI had in the past taken too long compared with stock-market expectations, Mekong decided to standardize the postacquisition combined business based on the existing Mekong IS platform. Considering the external time-pressure, moving to the preferred but unproven Indus platform was judged to be too much of a risk.

However, after a few years of struggling with operating on Mekong's pre-acquisition IS platform, the combined organization migrated to an updated platform similar to the Indus platform that had been retired during the merger project. This suggests that an option could have been to manage the ISI in two phases. In phase one, the Indus platform would have been retained. In phase two, the combined organization would have been transferred to a new Indus type platform. It this way, while time pressures cannot be avoided, the timeframe over which the various components of the ISI are achieved is a strategic IT decision.

Time is rarely included as a construct in theories of organizational behaviour or strategic management. Critically, suboptimal decision-making due to time pressure has a major negative effect on ISI performance (LeFave et al., 2008; Busquets, 2015). In addition, ISI decisions exhibit complexity and uncertainty, which make it difficult to identify and 
evaluate all the options within a tight timeframe (LeFave et al., 2008; Busquets, 2015), resulting in suboptimal decisions (Johnston and Yetton, 1996).

Complexity and uncertainty have an extensive history in organizational decision making research beginning with the behavioural theory of the firm (March and Simon, 1958; Cyert and March, 1963), and its extension into the attention-based view of the firm (Ocasio, 1997) and the organizational response literature (Dutton and Duncan, 1987; Dutton and Jackson, 1987). In the literature on managerial cognition, complexity and uncertainty are linked to theories of mental models, emotions, intuition, ideology and sense making (Kiesler and Sproull, 1982; Walsh, 1995).

Specifically, in the case of M\&As, ISI is challenged to accommodate complex multibusiness decisions that are frequently the subject of competing and inconsistent business objectives within a short and tight time frame. However, these aspects of ISI project are typically noted in passing, while focusing on other parts of the explanation of ISI outcomes (Johnston and Yetton, 1996; Henningsson, 2015). In the M\&A ISI literature, theoretical explanations that focus on the influence of time pressures are lacking.

ISI decisions are also subject to inter-temporal effects. In our consolidated model, many variables occur as both independent and dependent variables, including ISI capabilities, ISbusiness relationships, and IT infrastructure (Figure 3). For example, improvements in ISI capabilities result from learning processes across a series of acquisitions (Henningsson, 2015). So, ISI performance on one M\&A influences the general perception of the IS organization, which in turn affects its ability to deliver the next ISI project (Main and Short, 1989). In addition, contemporary IT infrastructures are highly path-dependent. Decisions made under time pressure on one ISI may be difficult to reverse and, therefore, could have major cumulative effects beyond the individual acquisition (Yetton et al., 2013). 
In this way, the cumulative effects of a growth-by-acquisition program generate very different managerial challenges compared with those of a single merger or acquisition. It follows that serial acquisitions must be understood not as individual events but as components in a growth-by-acquisition program. Beyond the direct acquisition benefits, research must include learning effects that improve ISI capabilities for the next acquisition, the reputation-trajectory of the IS organization, and the technological limitations built into the IT infrastructure that inhibit future acquisition options.

Analysis of how the serial acquisition context affects ISI decisions and ISI outcomes is absent from the literature. While many of the case studies in the review sample analyse acquisitions by serial acquirers, they generally disregard the serial dimension and treat the acquisition as a discrete event (e.g. Seddon et al., 2010; Busquets, 2015; Jain and Ramesh, 2015). This is a critical gap in research because $60 \%$ of all acquisitions are made by serial acquirers (Kengelbach et al., 2011). While it may not be justified for organizations involved in an individual M\&A to focus on the broader strategic context, doing this is critical for any organization implementing a growth-by-acquisition strategy. Future research should investigate the learning within a project, the learning between projects, and how, in combination, this learning makes an acquirer 'ready to acquire', reducing the time pressures experienced, and, hence, the negative effects of time constraints.

\section{IMPLICATIONS FOR RESEARCH}

The five themes frame the implications for research in four ways. First and foremost, the themes identify five major research sub-domains in the literature on IT in M\&As. By partitioning the robust relationships into five research themes or sub-domains, the 
complexity contingent on the large number of relationships in Figure 3 is kept tractable for research within each theme. This focuses and enables the analysis of each theme.

Second, reviewing and comparing the five themes, we examine the overlaps among the themes. The intent to identify a limited number of themes that include all, or nearly all, of the relationships in Figure 3, while limiting the overlaps among the themes, has two implications for research. One is that it helps to keep the analysis within a theme tractable by limiting the requirement to explain and/or control for interdependences with relationships in other themes. The other implication is that the independence between themes enables us to investigate the theoretical status, or lack of status, within each theme.

Third, we hope that identifying the five themes will influence research in two other ways. One is to motivate the analysis of interdependences between themes at a theme, rather than at a relationship level of analysis. The other is to use what is known, the robust relationships that constitute a theme, to identify and focus on what is not known or is emerging as a new research stream and, therefore potentially as a new theme.

Forth, responding to the identified research gaps will require pluralism in methodological approaches. We note that research in the area has been dominated by qualitative case studies. While these studies continue to be relevant, increased methodological pluralism will be needed to address the knowledge gaps identified within, between, and outside the emergent themes.

\section{Formalizing the research contributions}

We partition the robust findings across five themes. Each theme represents a major subdomain defined by a set of related robust findings in the M\&A literature. Implicit but not made explicit, the analysis of each theme identifies the major thematic themes and core 
constructs, the related theoretical frameworks, the research gaps, and some potential research questions. Here, we extract and formalize those contributions to make them more accessible and potentially useful to other researchers (see Table 4).

\section{[TABLE 4]}

In Table 4, we identify a set of theoretical frameworks that are potential points of departure to develop the theoretical coherence of the emergent themes. In addition, there is an opportunity to investigate the unique M\&A ISI context to increase the explanatory power of the frameworks. For example, the resource-based literature is relatively silent about how resources are recognized, developed, transferred, and discarded when not needed. Research in the novel M\&A ISI context could provide empirical observations that would both develop and validate the theory of M\&A ISI, and generate general insights into the theoretical frameworks adopted.

\section{Overlaps among and theoretical status of the themes}

Inspecting the thematic domains and core constructs in Table 4, the overlaps can be partitioned into two sets. One set consists of the overlap common to the models of preconditions, relational fit and the ISI context. The other set of overlaps is between the relational fit and the ISI context themes. The differences between the theoretically based and the empirically based themes in Table 4 motivated the second issue reviewed here: the theoretical status of each theme.

\section{Overlaps among the themes}

The first overlap above involves the models of pre-conditions, relational fit and the ISI context. All three themes include the effects of ISI objectives on the ISI decision. On 
reflection, we would assign ISI objectives to be a component in the ISI decision construct. ISI objectives determine the ISI methods chosen to deliver the ISI outcomes. This change in classification would remove the interdependence between the pre-conditions theme and the other two themes.

The second set of overlaps is between the relational fit and the ISI context themes. The former, excluding ISI objectives, includes the effects of organizational integration objectives, M\&A motivation, application and IT compatibility, and IT configuration, on the ISI decision. The latter, ISI context, includes the effects of quality of ISI plan, top management support, M\&A motivation, organization integration objectives, and organizational M\&A plans, on the ISI decision.

Two responses to the overlaps were considered. One was simply to combine the themes, reducing the number of themes to four independent themes. Empirically, this would have been a simple solution to satisfy the second criterion, minimizing the overlaps among the themes. The other was to retain them as different themes in which the common variables played different roles in M\&A ISI. Inspecting the two models, the former option was rejected and the latter was accepted.

For example, we concluded above that the relationships comprising the relational fit theme constitute a sub-dimension of the construct IS configuration that affects ISI outcomes (Buck-Lew et al., 1992; Johnston and Yetton, 1996; Brunetto, 2006). In which case, drawing on developments in that theoretical domain could help develop the theme in future research. For example, recent developments include a model to explain business and IT strategic alignment in multi-business organizations (MBOs) (Reynolds and Yetton, 2015).

Reynolds and Yetton (2015) explain how incompatibilities between business and IT strategies lead to functional and structural misalignment within and between strategic 
business units (SBUs) in MBOs. Their model could be extended to explain how different integration methods would affect ISI at the SBU level of analysis. In addition, Reynolds and Yetton explain how dynamic misalignment is created over time within the IT investment cycle. So, their model could also be extended to explain how dynamic misalignment is created in a growth-by-acquisition program. In both suggestions, the basic argument is that the ISI method should be matched to the M\&A strategy to create the expected business benefits (Giacomazzi et al., 1997; Wijnhoven et al., 2006).

In contrast, we conclude above that the relationships in the ISI context theme form a thematic domain that is embedded in the M\&A project in which, for example, the outcomes of the ISI project are contingent on the M\&A business objectives (Holm-Larsen, 2005; Steininger et al., 2016a). Compared with the relationships that constitute the relational fit theme, which share a common theoretical analytical framework, the relationships that constitute the ISI context theme are embedded in what is essentially an empirical, practicebased rather than theory driven research domain. Therefore, there is no theoretical or empirical reason for merging the relational fit and the ISI context themes, which critically would have increased the number of relationships and, in turn, the analytical complexity within the merged single theme.

\section{Theoretical status of the themes}

Inspecting the five themes, the ISI context theme is essentially an empirical practice-led theory, even though in Table 4, we suggest that co-ordination theory and task dependency theory are potentially related theories. As discussed above, the relational fit theme is a theory-led theme based on alignment theory. The pre-conditions theme is a theory-led theme based on the resource and related theories. The human side theme draws on a 
multitude of theoretical frameworks and the time pressures theme is an empirical practiceled theme.

For example, the time pressures on integration take various forms, including market pressure (Johnston and Yetton, 1996; Mehta and Hirschheim, 2007). Similar to the ISI context theme, the time pressure theme is an empirically based theme. However, unlike the ISI context theme, the time pressure theme is not embedded in an IT practice-based domain. Instead, it includes all the external pressures on an M\&A. As such, the reference literature is the general M\&A literature.

The resource-based view of the firm (Tanriverdi and Uysal, 2011; Yetton et al., 2013), and its extensions into the capability-based and knowledge-based views (Gregory et al., 2012; Henningsson, 2015) is the dominant theoretical framing for the pre-conditions theme. So, similar to the relational fit theme, future research on this theme should draw on recent theory developments in the resource-based reference literature.

Finally, the human side of ISI design and implementation includes culture, power, change management, resistance, and knowledge gaps (Linder, 1989; Alaranta and Martela, 2012; Vieru and Rivard, 2014). This is a wide range of reference literatures. However, we speculate that these literatures can be partitioned under three headings: the human resources involved in realizing ISI, operating the integrated IS solutions, and using the services contingent on ISI (Linder, 1989; Alaranta and Martela, 2012; Vieru and Rivard, 2014). To make future research on this theme tractable, it should draw on only one of these three large reference literatures to frame the research. 


\section{Gaps within and between themes}

The third issue discussed here concerns gaps within themes and the relationships between themes. An example of the former would be to acknowledge that the unit of analysis in ISI research is typically a single merger or acquisition. However, in practice, many acquisitions are elements in a growth-by-acquisition strategy (Toppenberg et al., 2015) and, therefore, we know little about the dynamics of performance in growth-by-acquisition strategies. An example of the latter would be combining the pre-conditions for ISI theme with the time pressures theme to focus the analysis on how an organization could become 'ready to acquire' or 'ready to be acquired'.

\section{Gaps within themes}

Here, we present two examples of research in the gaps within themes. First, adopting a single M\&A as the unit of analysis excludes the analysis of growth by acquisition strategies, which account for $60 \%$ of M\&As (Kengelbach et al., 2011), and the development of capabilities over multiple acquisitions. For example, Henningsson (2015) concludes that developing the critical ISI capabilities is contingent on the experience of and the learning from a series of heterogeneous acquisition projects. He does acknowledge, however, that the learning trajectory may be influenced by other related experiences, including, for example, implementing a major enterprise system.

While serial acquirers learn from repeat acquisitions, research should document this knowledge to make it available to novice acquirers. This would enable them to avoid the trial and error learning mistakes that their serial acquiring colleagues have made. Research has already begun to investigate this form of learning (Henningsson, 2015) but without examining the implications for novice acquirers. 
The flipside to this would be to understand the challenges novice acquirers face as they embark on their earliest acquisitions, and how to identify and avoid unexpected pitfalls. Wynne (2016) starts to explore the learning processes of a novice acquirer. Given the prevalence of novice acquirers in the M\&A market, it is critical that research enables the transfer of learning from experienced to novice serial acquirers.

Second, the importance of the M\&A context raises the question of whether ISI has been investigated in all of the relevant M\&A contexts. While research has investigated ISI in a number of industries (see Appendix B), there is limited formal analysis of whether ISI is a standard process for all, or is contingent on the industry, company, or product line? For example, Toppenberg (2015) comments that many of the industries studied are traditional 'low-tech' industries. Studies of 'hi-tech' industries are not well represented in the extant literature. The exceptions include studies of manufacturers of hi-tech goods (Chang et al., 2014), telecoms (Alaranta and Henningsson, 2008; LeFave et al., 2008), and IT service providers (Alaranta and Martela, 2012). However, even in these studies, the 'high-tech' nature of the industry is not treated as relevant and, certainly, not as central to the analysis.

The lack of studies of hi-tech companies is relevant for two reasons. One is that hi-tech industries account for about $20 \%$ of all M\&A activity, including many of the largest M\&As (Toppenberg, 2015). The other reason is that hi-tech industry dynamics differ from those in traditional industries in ways that influence ISI performance (Henningsson et al., 2016). For example, in hi-tech M\&As, the acquisitions are frequently start-ups with emergent, potentially disruptive business models. These are frequently difficult to accommodate within the acquirer's existing IS landscape.

M\&As in digital industries are another example of the salience of the context. These M\&As are different from acquisitions in 'non-digital' hi-tech industries, such as pharmaceuticals 
and health science. Many digital firms, including Google, Apple, Microsoft and Facebook, complete multiple acquisitions each year. This digital dimension is absent from the general research on M\&As (c.f. Graebner et al., 2010). Yet, we know that digital industries are characterized by distinct business dynamics, including network effects, platform-based business models, and cooperation within business ecosystems (Henningsson et al., 2016). The mechanisms of value creation and the interplay with the digital technologies enabling them should be the topic of future studies of ISI performance.

\section{Analysis between themes}

The research in the time pressures theme focuses on the dysfunctional responses to time pressures (Mehta and Hirschheim, 2007). Within this theme, the literature is limited to examining the poor options available to manage this threat to ISI performance. Instead, consider how combining the time pressures theme with the pre-conditions theme would motivate research on how improvements in the capabilities within the pre-conditions theme would reduce time pressures, rather than attempting to improve the management of those pressures within the time pressure theme.

In general, developing a high level of pre-conditions would make acquirers increasingly 'ready-to-acquire' and reduce the level of time pressure on acquisition teams. This research could be extended to enable organizations that are divesting a business unit to make that unit 'ready to be acquired'. Similarly, improving our understanding of the relational fit theme could reduce IT implementation project specification errors. This would enhance IT project performance within the ISI context theme.

In addition, consider how combining the time pressures theme with the ISI context theme could reduce the management challenges in the time pressures theme. For example, in a subsequent acquisition, the bank in Johnston and Yetton (1996) integrated the retail bank 
business of its next acquisition target using an absorption method but ring-fenced the wealth business until the acquirer's next platform upgrade because its current platform could not host the acquired wealth business.

This is similar in form to the two-phase solution that we propose above to the challenge faced by Mekong in its acquisition of Indus. This approach to ISI simply requires that the assumption in which ISI occurs at a single point in time is relaxed, at least for the integration of the IT platforms. Future research should explore the interdependencies among the five themes to identify under-researched effects on ISI.

\section{Methodological considerations}

In the general literature on M\&As, studies based on quantitative data (surveys and empirical studies) outnumber the studies based on qualitative data (single and multiple case studies) by a factor of 20 (Bengtsson and Larsson, 2012). In the extant research on ISI issues in M\&A, only 14 of 70 identified publications are based on quantitative data (see Appendix A).

The primarily case-based research approach employed has been instrumental in the exploratory theory development that has taken place. Certainly, further case-based exploration will continue to be important to expand the current knowledge base to additional actors and types of M\&As, yet to be addressed from an IS perspective, for example, in expanding the study of the M\&A context to digital industries (Toppenberg, 2015) or to uncover the impact of the increased adoption of cloud technologies to extend the theme on pre-conditions for ISI.

For the areas that are already relatively well covered, in particular the acquisition of individual business units, and the themes that have reached some degree of theoretical 
maturity, there is now a requirement to empirically investigate and statistically verify the theoretical propositions that have been developed. For example, a survey could provide valuable insights into the relationships between ISI capabilities and integration methods. It could reveal both positive and negative effects of different capabilities within the context of a range of different M\&As.

However, because of the lack of validated constructs, this type of analysis will be expensive in terms of resources needed. We identified 53 different ways of describing the effects of ISI. However, with few exceptions (Stylianou et al., 1996; Tanriverdi and Uysal, 2011; 2015), measurement constructs are not available to model and estimate these effects.

Finally, the status of the themes and their gaps calls for an additional set of qualitative studies. Specifically, these studies would adopt methodologies in which researchers are immersed in the context, and explore from the inside. The methodologies would include action research, design research and participant observation. The general research question would be: How do the people involved in ISI projects manage the tensions, complexities and uncertainties as the project unfolds?

Two examples illustrate this line of research. In one, the researcher would engage with practitioners in design research to develop tools and approaches grounded in the emergent academic understanding of ISI to address the challenges of the ISI process (Wynne, 2016). The other example could be the subject for an action research study: How is successful M\&A ISI contingent on the level of digitalization? 


\section{CONCLUSIONS}

To overcome the fragmentation of the research on ISI challenges and solutions in M\&As, we document, organize, and structure the empirical findings of 70 research articles that collectively cover three decades of research on the topic. The research question guiding the review is: How to aggregate, organize and structure what we know about M\&A ISI decisions and their outcomes?

To answer this question, we examine the independent and dependent variables investigated in the literature, and the relationships among them. We identify 195 independent variables, 53 dependent variables and 619 relationships among them. Distinguishing between categories of ISI decision and ISI outcomes as dependent variables, we identify the robust research findings reported in the literature and consolidate them in a model that presents the critical factors that consistently affect ISI decisions and ISI outcomes.

We then inspect the consolidated model to identify five themes in the explanations of ISI and its effects on performance: M\&A context, relational fit, human behaviour, preconditions, and time pressure. For each theme, we identify the core constructs, discuss the presence, or absence, of theoretical frameworks, and give an illustrative example of practice. Each of the themes highlights complementary aspects of ISI dynamics. We do not claim that these five themes are the only ones relevant for ISI research. Rather, they represent points of convergence that allow us both to structure the relationships among the robust findings and to identify critical gaps in this fragmented research domain.

Advancing the research domain in the directions suggested would develop a set of midrange theories that are contextually contingent and managerially actionable. Given the practical relevance of the topic, this is an appropriate course of action in the short and mid- 
term perspective. In the longer term, the challenge remains to integrate the diverse themes. In our view, more research needs to be done to develop individual explanatory models of the themes before it would be possible to theoretically integrate them.

We recognize that our review is subject to limitations contingent on the choice and execution of our review methodology. Three are reviewed here. First, while we have attempted to identify all relevant research that meets our criteria for inclusion and to code it correctly, we cannot guarantee that we have not made errors of omission in the former and errors of commission in the latter. However, given the large amount of data analysed, we believe that the major findings and conclusions are independent of any such errors. In addition, we have made our review method transparent to enable other researchers to replicate our analysis.

Second, the relationships in our review do not reflect the substance or magnitude of the effects. Nor do they include interactive and dynamic effects, for example, examining how changes in decisions and contextual conditions evolve during the ISI project. However, there are not enough data to conduct a structured review to do such research. In addition, just because a relation between a set of variables has not been documented, it does not mean that the relation does not exists. The lack of evidence supporting the relationship may be a factor of the industries and in which the context of ISI has been investigated, or that research has investigated variables that are easier to measure than others.

Third, Lacity et al.'s $(2010 ; 2011 ; 2016)$ review methodology organizes and structures the empirical findings to report what is known. It does not provide and is not intended to provide a coherent theoretical explanation of the domain reviewed. Our intent, given the current fragmented state of the research domain, is to document what is known and develop 
a research database within which researchers can locate their research or on which they can draw to motivate research.

Our general conclusion from looking both backwards and forwards to examine the ISI research on M\&As is that, despite an extensive body of literature, we have but scratched the surface of this problem domain. With the large number of relationships identified above that influence ISI decisions and outcomes, it is easy to see why ISI is reported as one of the critical problem areas inhibiting successful M\&As. M\&A ISI should be a major IS future research domain.

\section{ACKNOWLEDGEMENTS}

We want to thank the senior editor and the reviewers for their valuable constructive feedback during the review process. We also want to thank Joan Spiller for copyediting the manuscript. 


\section{REFERENCES}

Accenture (2006). Executives Report that Mergers and Acquisitions Fail to Create Adequate Value [WWW document] http://newsroom.accenture.com/article_display.cfm?article_id=4364 (accessed 10th July 2007).

Al Suliman, M.H. (2015). In Mergers and Acquisitions-IT: Results of the Absence of CIO in Exante Planning and the Absence of Key IT Staff in Ex-post Integration. The Claremont Graduate University, Unpublished PhD thesis.

Alaranta, M. and Henningsson, S. (2007). Shaping the Post-Merger Information Systems Integration Strategy, in Proceedings of Hawaii International Conference on System Sciences (Waikoloa, USA, 2007); Chicago: IEEE Computer Society Press.

Alaranta, M. and Henningsson, S. (2008). An Approach to Analyzing and Planning Post-Merger IS Integration: Insights from two Field Studies, Information Systems Frontiers 10(3): 307319.

Alaranta, M. and Kautz, K. (2012). A framework for Understanding Post-Merger Information Systems Integration, Journal of Information Technology Theory and Application 13(1): 529.

Alaranta, M.E. and Martela, E. (2012). Overcoming Knowledge Gaps in Postmerger Integration, in Proceedings of International Conference on Information Systems (Orlando, USA, 2012); Atlanta, USA: Association for Information Systems.

Baker, E.W. and Niederman, F. (2014). Integrating the IS Functions after Mergers and Acquisitions: Analyzing Business-IT Alignment, The Journal of Strategic Information Systems 23(2): 112-127.

Baldwin, C. and Clark, K. (2000). Design Rules, Cambridge, Ma.: MIT Press.

Bengtsson, L. and Larsson, R. (2012). Researching Mergers \& Acquisitions with the Case Study Method: Idiographic Understanding of Longitudinal Integration Processes, Handbook Of Research On Mergers And Acquisitions (Ed, Weber, Y.) Elgar Publishing. 
The is the pre-edited version of Henningsson et al. (2018) "A review of information system integration in mergers and acquisitions", published in Journal of Information Technology. http://link.springer.com/article/10.1057/s41265-017-0051-9

Benitez-Amado, J. and Ray, G. (2012). Introducing IT-enabled Business Flexibility and IT Integration in the Acquirer's M\&A Performance Equation, in Proceedings of International Conference on Information Systems (Orlando, USA, 2012); Atlanta, USA: Association for Information Systems.

Boell, S.K. and Cecez-Kecmanovic, D. (2015a). Debating Systematic Literature Reviews (SLR) and their Ramifications for IS: A Rejoinder to Mike Chiasson, Briony Oates, Ulrike Schultze, and Richard Watson, Journal of Information Technology 30(2): 188-193.

Boell, S.K. and Cecez-Kecmanovic, D. (2015b). On Being 'Systematic' in Literature Reviews in IS, Journal of Information Technology 30(2): 161-173.

Böhm, M., Henningsson, S., Leimeister, J.M., Yetton, P. and Krcmar, H. (2011). A Dual View on IT Challenges in Corporate Ddivestments and Acquisitions, in Proceedings of International Conference on Information Systems (Shanghai, China, 2011); Atlanta, USA: Association for Information Systems.

Boudon, R., Clark, J., Modgil, C., Modgil, S., Cohen, I.B., Duffin, K., Strickland, S., Feldhay, R., Elkana, Y. and Merton, R.K. (1991). What Middle-range Theories Are, Contemporary Sociology 20(4): 519-522.

Brown, C.V., Clancy, G. and Scholer, R. (2003). A Post-Merger IT Integration Success Story: Sallie Mae, MIS Quarterly Executive 2(1): 15-27.

Brunetto, G. (2006). Integrating Information Systems During Mergers: Integration Modes Typology, Prescribed vs Constructed Implementation Process, in Proceedings of European Conference on Information Systems (Gothenburg, Sweden, 2006); Atlanta, USA: Association for Information Systems.

Buck-Lew, M., Wardle, C.E. and Pliskin, N. (1992). Accounting for Information Technology in Corporate Acquisitions, Information \& Management 22(6): 363-370.

Busquets, J. (2015). Discovery Paths: Exploring Emergence and IT Evolutionary DCsign in CrossBorder M\&As. Analysing grupo Santander's Acquisition of Abbey (2004-2009), European Journal of Information Systems 24(2): 178-201. 
The is the pre-edited version of Henningsson et al. (2018) "A review of information system integration in mergers and acquisitions", published in Journal of Information Technology. http://link.springer.com/article/10.1057/s41265-017-0051-9

Chang, S.-I., Chang, I.-C. and Wang, T. (2014). Information Systems Integration After Merger and Acquisition, Industrial Management \& Data Systems 114(1): 37-52.

Cyert, R.M. and March, J.G. (1963). A Behavioral Theory of the Firm, Englewood Cliffs, NJ: Prentice-Hall.

Dhillon, G., Syed, R. and Pedron, C. (2016). Interpreting Information Security Culture: An Organizational Transformation Case Study, Computers \& Security 56(February 2016): 6369.

Du, K. (2015). Research Note—Parenting New Acquisitions: Acquirers' Digital Resource Redeployment and Targets' Performance Improvement in the US Hospital Industry, Information Systems Research 26(4): 829-844.

Duncan, N.B. (1995). Capturing fFexibility of Information Technology Infrastructure: A Study of Resource Characteristics and their Measure, Journal of Management Information Systems 12(2): 37-57.

Dutton, J.E. and Duncan, R.B. (1987). The Creation of Momentum for Change through the Process of Strategic Issue Diagnosis, Strategic Management Journal 8(3): 279-295.

Dutton, J.E. and Jackson, S.E. (1987). Categorizing Strategic Issues: Links to Organizational Action, Academy of Management Review 12(1): 76-90.

Eckert, M.-L., Freitag, A., Matthes, F., Roth, S. and Schulz, C. (2012). Decision Support for Selecting an Application Landscape Integration Strategy in Mergers and Acquisitions, in Proceedings of European Conference on Information Systems (Barcelona, Spain, 2012); Atlanta, USA: Association for Information Systems.

Freitag, A., Matthes, F. and Schulz, C. (2010). A Method for Consolidating Application Landscapes During the Post-Merger-Integration Phase, in Proceedings of International Multiconference on Computer Science and Information Technology (IMCSIT) (Wisla, Poland, 2010), pp: 241-248; Chicago, USA: IEEE Computer Society Press

Garcia-Canal, E., Rialp-Criado, A. and Rialp-Criado, J. (2013). Speed of ICT Integration Strategies in Absorptions: Insights from a Qualitative Study, European Management Journal 31(3): 295-307. 
Giacomazzi, F., Panella, C., Pernici, B. and Sansoni, M. (1997). Information Systems Integration in Mergers and Acquisitions: A Normative Model, Information \& Management 32(6): 289302.

Glazar-Stavnicky, M. (2016). Organizational and Systems Factors Leading to Systems Integration Success after Merger and Acquisition. Cleveland State University, Unpublished PhD thesis.

Gorla, N. and Pang, P. (2001). Fit Between MIS Integration Strategies and Business Acquisition Strategies, ASCI Journal of Management 30(1\&2): 1-8.

Graebner, M.E., Eisenhardt, K.M. and Roundy, P.T. (2010). Success and Failure in Technology Acquisitions: Lessons for Buyers and Sellers, The Academy of Management Perspectives 24(3): 73-92.

Grant, R.M. (1996). Toward a Knowledge-Based Theory of the Firm, Strategic Management Journal 17(52): 109-122.

Gregory, R.W., Keil, M. and Muntermann, J. (2012). Ambidextrous IS Strategy: The Dynamic Balancing Act of Developing a 'Transform \& Merge' Strategy in the Banking Industry, in Proceedings of International Conference of Information Systems (Orlando, USA, 2012); Atlanta, USA: Association for Information Systems.

Haleblian, J., Devers, C.E., McNamara, G., Carpenter, M.A. and Davison, R.B. (2009). Taking Stock of What we know About Mergers and Acquisitions: A Review and Research Agenda, Journal of Management 35(3): 469.

Haspeslagh, C. and Jemison, B. (1991). Managing Acquisitions. Creating Value Through Corporate Renewal, New York: The Free Press.

Helfat, C.E., Finkelstein, S., Mitchell, W., Peteraf, M., Singh, H., Teece, D. and Winter, S.G. (2009). Dynamic Capabilities: Understanding Strategic Change in Organizations, Hobocken, USA: John Wiley \& Sons.

Henningsson, S. (2015). Learning to Acquire: How Serial Acquirers Build Organisational Knowledge for Information Systems Integration, European Journal of Information Systems 24(2): 121-144. 
The is the pre-edited version of Henningsson et al. (2018) "A review of information system integration in mergers and acquisitions", published in Journal of Information Technology. http://link.springer.com/article/10.1057/s41265-017-0051-9

Henningsson, S. and Carlsson, S.A. (2011). The DySIIM Model for Managing IS integration in Mergers and Acquisitions, Information Systems Journal 21(5): 441-476.

Henningsson, S. and Kettinger, W.J. (2016). Managing IT Integration Risk in Acquisitions, MIS Quarterly Executive 15(1): 1-19.

Henningsson, S., Kude, T. and Popp, K.M. (2016). Managing the Technology Acquisition Integration Paradox at SAP, in Proceedings of International Conference of Information Systems (Dublin, Ireland, 2016); Atlanta, USA: Association for Information Systems.

Henningsson, S. and Øhrgaard, C. (2016). IT Consultants in Acquisition IT Integration, Business \& Information Systems Engineering 58(3): 193-212.

Henningsson, S., Svensson, C. and Vallen, L. (2007). Mastering the Integration Chaos Following Frequent M\&As: IS Integration with SOA Technology, in Proceedings of Hawaii International Conference on System Sciences (Waikoloa, USA, 2007); Chicago, USA: IEEE Computer Society Press.

Henningsson, S. and Yetton, P. (2011). Managing the IT integration of Acquisitions by MultiBusiness Organizations, in Proceedings of International Conference of Information Systems (Shanghai, China, 2011); Atlanta, USA: Association for Information Systems.

Holm-Larsen, M. (2005). ICT Integration in an M\&A Process, in Proceedings of Pacific Asia Conference on Information Systems (Bangkok, Thailand, 2005); Atlanta, USA: Association for Information Systems.

Hsu, J. and Chen, E.T. (2015). The Impact of Mergers and Acquisitions on Information Systems: A Case of A Software Industry Acquisition, Communications of the IIMA 6(1): Article 6.

Hunter, J.E. and Schmidt, F.L. (2004). Methods of Meta-Analysis: Correcting Error and Bias in Research Findings, Thousand Oaks, CA: Sage publications.

Jain, R.P. and Ramesh, B. (2015). The Roles of Contextual Elements in Post-Merger Common Platform Development: An Empirical Investigation, European Journal of Information Systems 24(2): 159-177. 
The is the pre-edited version of Henningsson et al. (2018) "A review of information system integration in mergers and acquisitions", published in Journal of Information Technology. http://link.springer.com/article/10.1057/s41265-017-0051-9

Jeyaraj, A., Rottman, J.W. and Lacity, M.C. (2006). A Review of the Predictors, Linkages, and Biases in IT Innovation Adoption Research, Journal of Information Technology 21(1): 123.

Johnston, K.D. and Yetton, P.W. (1996). Integrating Information Technology Divisions in a Bank Merger - Fit, Compatibility and Models of Change, The Journal of Strategic Information Systems 5(3): 189-211.

Kanter, R.M., Yatsko, P. and Raffaelli , R. (2007). CEMEX (A): Building the Global Framework (1985-2004). In: Harvard Business Review Cases. Harvard Business School.

Kengelbach, J., Klemmer, D.C., Schwetzler, B., Sperling, M.O. and Roos, A. (2011). How the Top Serial Acquirers Create Value [WWW document] https://www.bcgperspectives.com/content/articles/mergers_acquisitions_value_creat ion_strategy_does_practice_make_perfect_top_serial_acquirers/(accessed 7th July 2016).

Kiesler, S. and Sproull, L. (1982). Managerial Response to Changing Environments: Perspectives on Problem Sensing from Social Cognition, Administrative Science Quarterly 27(4): 548570.

Kim, H.-G., Iijima, J. and Ho, S. (2005). A Framework for Analysis of Systems Failure in Information Systems Integration, Industrial engineering and management systems 4(2): 207-217.

King, D.R., Dalton, D.R., Daily, C.M. and Covin, J.G. (2004). Meta-Analyses of PostAcquisition Performance: Indications of Unidentified moderators, Strategic Management Journal 25(2): 187-200.

Kovela, S. and Skok, W. (2012). Mergers and Acquisitions in Banking: Understanding the IT Integration Perspective, International Journal of Business and Management 7(18): 69-80.

Labusch, N., Koebele, F., Aier, S. and Winter, R. (2013). The Architects' Perspective on Enterprise Transformation: An Explorative Study, in Proceedings of Practice-Driven Research on Enterprise Transformation (Utrecht, The Netherlands, 2013); Berlin: Springer. 
The is the pre-edited version of Henningsson et al. (2018) "A review of information system integration in mergers and acquisitions", published in Journal of Information Technology. http://link.springer.com/article/10.1057/s41265-017-0051-9

Lacity, M.C., Khan, S. and Yan, A. (2016). Review of the Empirical Business Services Sourcing Literature: An Update and Future Directions, Journal of Information Technology 21(3): 269-328.

Lacity, M.C., Khan, S., Yan, A. and Willcocks, L.P. (2010). A Review of the IT Outsourcing Empirical Literature and Future Research Directions, Journal of Information Technology 25(4): 395-433.

Lacity, M.C., Solomon, S., Yan, A. and Willcocks, L.P. (2011). Business Process Outsourcing Studies: A Critical Review and Research directions, Journal of information Technology 26(4): 221-258.

Lee, A.S. (2015). Retrospect and Prospect: Information Systems Research in the Last and Next 25 Years, Journal of Information technology 25(4): 336-348.

LeFave, R., Branch, B., Brown, C.V. and Wixom, B. (2008). How Sprint Nextel Reconfigured IT Resources for Results, MIS Quarterly Executive 7(4): 171-179.

Leidner, D.E. and Kayworth, T. (2006). A review of Culture in Information Systems Research: Toward a Theory of Information Technology Culture Conflict, MIS quarterly 30(2): 357399.

Lin, F. and Chao, R. (2008). Post-Merger IT integration: An IT Culture Conflict Perspective, in Proceedings of Pacific-Asia Conference on Information Systems (Suzhou, China, 2008); Association for Information Systems.

Linder, J.C. (1989). Integrating Organizations where Information Technology Matters. Harvard University, Graduate School of Business Administration. Unpublished PhD thesis.

Main, T.J. and Short, J.E. (1989). Managing the Merger: Building Partnership through IT Planning at the New Baxter, MIS Quarterly 13(4): 469-484.

Malone, T.W. and Crowston, K. (1994). The Interdisciplinary Study of Coordination, ACM Computing Surveys 26(1): 87-119.

March, J.G. and Simon, H.A. (1958). Organizations, New York: Wiley.

McKiernan, P. and Merali, Y. (1995). Integrating Information Systems after a Merger, Long Range Planning 28(4): 454-562. 
The is the pre-edited version of Henningsson et al. (2018) "A review of information system integration in mergers and acquisitions", published in Journal of Information Technology. http://link.springer.com/article/10.1057/s41265-017-0051-9

Medema, S.G. (1996). Coase, Costs, and Coordination, Journal of Economic Issues 30(2): 571578.

Mehta, M. and Hirschheim, R. (2007). Strategic Alignment in Mergers and Acquisitions: Theorizing IS Integration Decision Making, Journal of the Association for Information Systems 8(3): 143-174.

Merali, Y. and McKiernan, P. (1993). The Strategic Positioning of Information Systems in PostAcquisition Management, The Journal of Strategic Information Systems 2(2): 105-124.

Morsell, G.A., Deek, F. and Chakrabarti, A. (2009). Post-Merger Technology Integration: Influential Organization and Information Systems Factors, in Proceedings of Americas Conference on Information Systems (San Francisco, USA, 2009); Atlanta, USA: Association for Information Systems.

Myers, M.D. (2008). Integration of Different ERP Systems: The Case of Mergers and Acquisitions, in Proceedings of Pacific Asia Conference on Information Systems (Suzhou, China, 2008); Atlanta, USA: Association for Information Systems.

Ocasio, W. (1997). Towards an Attention-Based View of the Firm, Strategic Management Journal 18(Summer special issue): 187-206.

Okoli, C. and Schabram, K. (2010). A Guide to Conducting a Systematic Literature Review of Information Systems Research, Sprouts: Working Papers on Information Systems 10(26).

Reynolds, P. and Yetton, P. (2015). Aligning Business and IT Strategies in Multi-Business Organizations, Journal of Information Technology 30(2): 101-118.

Richmond, W.B. and Seidmann, A.B. (1992). Incomplete Contracting Issues in Information Systems Development Outsourcing, Decision Support Systems 8(5): 459-477.

Robbins, S.S. and Stylianou, A.C. (1999). Post-Merger Systems Integration: The Impact on IS Capabilities, Information and Management 36(4): 205-212.

Robertson, S. and Powell, P. (2001). Managing the IS Function During Mergers, in Proceedings of European Conference on Information Systems (Bled, Slovenia, 2001); Atlanta, USA: Association for Information Systems. 
The is the pre-edited version of Henningsson et al. (2018) "A review of information system integration in mergers and acquisitions", published in Journal of Information Technology. http://link.springer.com/article/10.1057/s41265-017-0051-9

Ross, J.W., Weill, P. and Robertson, D. (2006). Enterprise Architecture as Strategy: Creating a Foundation for Business Execution, Boston, MA, United States: Harvard Business Press.

Rowe, F. (2014). What Literature Review is Not: Diversity, Boundaries and Recommendations, European Journal of Information Systems 23(3): 241-255.

Saldaña, J. (2009). The Coding Manual for Qualitative Researchers, Los Angeles, CA: Sage.

Sarrazin, H. and West, A. (2011). Understanding the strategic value of IT in M\&A, McKinsey Quarterly 12(1): 1-6.

Schonewille, J. and Bouwman, W. (2012). Contextual Aspects in Enterprise Integration, in Proceedings of 45th Hawaii International Conference on System Science (Maui, USA, 2012); Chicago, USA: IEEE Computer Society.

Scott Morton, M.S. (1991). The Corporation of the 1990s: Information Technology and Organizational Transformation, Oxford, United Kingdom: Oxford University Press

Seddon, P.B., Reynolds, P. and Willcocks, L.P. (2010). Post-Merger IT integration: A Comparison of two Case Studies, in Proceedings of Pacific Asia Conference on Information Systems (Taipei, Taiwan, 2010); Atlanta, USA: Association for Information Systems.

Steininger, K., Kempinger, B., Schiffer, S. and Pomberger, G. (2016a). Critical IS Success Factor Analysis in the Context of a Hospital Merger, in Proceedings of Americas Conference on Information Systems (San Diego, 2016); Atlanta, USA: Association for Information Systems.

Steininger, K., Kempinger, B., Schiffer, S. and Pomberger, G. (2016b). A Process Model for IT Migrations in the Context of a Hospital Merger-Results from an Austrian Case Study, Studies in health technology and Informatics 223(1): 182-190.

Strauss, A. and Corbin, J. (1990). Basics of Qualitative Research: Grounded Theory Procedures and Techniques., Thousand Oaks, USA: Sage.

Stylianou, A.C., Jeffries, C.J. and Robbins, S.S. (1996). Corporate Mergers and the Problems of IS Integration, Information \& Management 31(4): 203-213. 
The is the pre-edited version of Henningsson et al. (2018) "A review of information system integration in mergers and acquisitions", published in Journal of Information Technology. http://link.springer.com/article/10.1057/s41265-017-0051-9

Sumi, T. and Tsuruoka, M. (2002). Ramp New Enterprise Information Systems in a Merger \& Acquisition Environment: A Case Study, Journal of Engineering and Technology Management 19(1): 93-104.

Tafti, A.R. (2009). The Role of Information Technology in Alliances and Mergers. University of Michigan. Unpublished PhD Thesis.

Tanriverdi, H. and Uysal, V.B. (2011). Cross-Business Information Technology Integration and Acquirer Value Creation in Corporate Mergers and Acquisitions, Information Systems Research 22(4): 703-720.

Tanriverdi, H. and Uysal, V.B. (2015). When IT Capabilities are not Scale-Free in Merger and Acquisition Integrations: How do Capital Markets React to IT capability Asymmetries Between Acquirer and Target?, European Journal of Information Systems 24(2): 145-158.

Thompson, J.D. (1967). Organizations in Action: Social Science Bases of Administrative Theory. 1st Edn., Edison, NJ: Transaction Publishers.

Thomson Reuters (2017). Mergers \& Acquisitions Review - Full Year 2016 [WWW document] http://share.thomsonreuters.com/general/PR/MA_4Q_2016_E.pdf (accessed 10th February 2017).

Tiwana, A. and Konsynski, B. (2010). Complementarities Between Organizational IT Architecture and Governance structure, Information Systems Research 21(2): 288-304.

Toppenberg, G. (2015). Expanded Understanding of IS/IT Related Challenges in Mergers and Acquisitions: Methods \& Research Context, in Proceedings of European Conference on Information Systems (Münster, Germany, 2015); Atlanta, USA: Association for Information Systems.

Toppenberg, G., Henningsson, S. and Shanks, G. (2015). How Cisco Systems Used Enterprise Architecture Capability to Sustain Acquisition-Based Growth, MIS Quarterly Executive 14(4): 151-168.

Unkan, E. and Thönssen, B. (2015). EPOs, an Early Warning System for Post-merger IS Integration, in Proceedings of International Conference on Business Information Systems (Leipzig, Germany; 2015); Berlin: Springer. 
The is the pre-edited version of Henningsson et al. (2018) "A review of information system integration in mergers and acquisitions", published in Journal of Information Technology. http://link.springer.com/article/10.1057/s41265-017-0051-9

Vaniya, N., Bernus, P. and Noran, O. (2013). Analysing the M\&A Preparedness Building Approach, in Proceedings of International Conference on Enterprise Information Systems (Angers, France, 2013); Berlin: Springer.

Vieru, D. and Rivard, S. (2014). Organizational Identity Challenges in a Post-Merger Context: A Case Study of an Information System Implementation Project, International Journal of Information Management 34(3): 381-386.

Vieru, D. and Rivard, S. (2015). Knowledge Sharing Challenges during Post-Merger Integration: The Role of Boundary Spanners and of Organizational Identity, International Journal of Business and Management 10(11): 1-12.

Vieru, D., Rivard, S. and Bourdeau, S. (2016). From Boundary Shaker to Boundary Consolidator by Ways of Symbolic Discourses in a Post-Merger Integration Context, in Proceedings of nternational Conference on Information Systems (Dublin, Ireland, 2016); Atlanta, USA: Association for Information Systems.

Walsh, J.P. (1995). Managerial and Organizational Cognition: Notes from a Trip Down Memory Lane, Organization Science 6(3): 280-321.

Weber, Y. and Pliskin, N. (1996). The Effects of Information Systems Integration and Organizational Culture on a Firm's Effectiveness, Information \& Management 30(2): 81-90.

Webster, J. and Watson, R.T. (2002). Analyzing the Past to Prepare for the Future: Writing a Literature Review, MIS Quarterly 26(2): xiii-xxiii.

Wijnhoven, F., Spil, T., Stegwee, R. and Fa, R.T.A. (2006). Post-Merger IT Integration Strategies: An IT Alignment Perspective, The Journal of Strategic Information Systems 15(1): 5-28.

Williams, G.S., Mayer, R.W., Chien, W.-W. and Williams, C.R. (2015). Information Technology Integration in a Postmerger Environment, Journal of Leadership, Accountability and Ethics 12(1): 39-51.

Wynne, P.J. (2016). Developing Acquisition IS Integration Capabilities: The Learning Processes of Novice Acquirers, in Proceedings of Australasian Conference on Information Systems (Wollongong, Australia, 2016); Atlanta, USA: Association for Information Systems. 
The is the pre-edited version of Henningsson et al. (2018) "A review of information system integration in mergers and acquisitions", published in Journal of Information Technology. http://link.springer.com/article/10.1057/s41265-017-0051-9

Yetton, P., Henningsson, S. and Bjørn-Andersen, N. (2013). "Ready to Acquire": The IT Resources Required for a Growth-by-Acquisition Business Strategy, MIS Quarterly Executive 12(1): 19-35. 
The is the pre-edited version of Henningsson et al. (2018) "A review of information system integration in mergers and acquisitions", published in Journal of Information Technology. http://link.springer.com/article/10.1057/s41265-017-0051-9

\section{FIGURES AND TABLES}

\section{Figures}

\begin{tabular}{|c|c|c|}
\hline 1 & & $\downarrow$ \\
\hline \multirow{2}{*}{$\begin{array}{l}\text { Critical } \\
\text { Factors }\end{array}$} & \multirow{2}{*}{$\begin{array}{c}\text { ISI } \\
\text { Decisions }\end{array}$} & $|S|$ \\
\hline & & Outcomes \\
\hline
\end{tabular}

FIGURE 1. Review model 
The is the pre-edited version of Henningsson et al. (2018) "A review of information system integration in mergers and acquisitions", published in Journal of Information Technology. http://link.springer.com/article/10.1057/s41265-017-0051-9

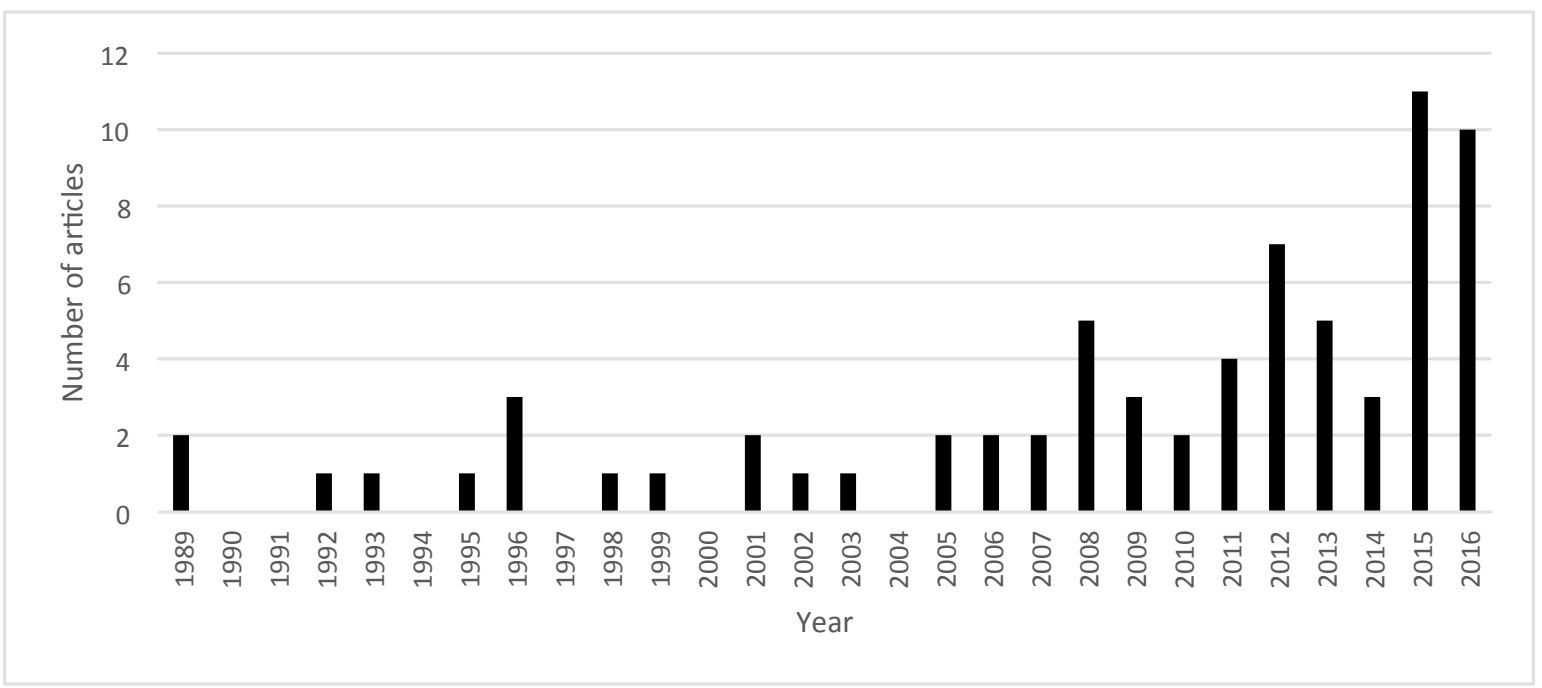

FIGURE 2. Temporal distribution of articles 


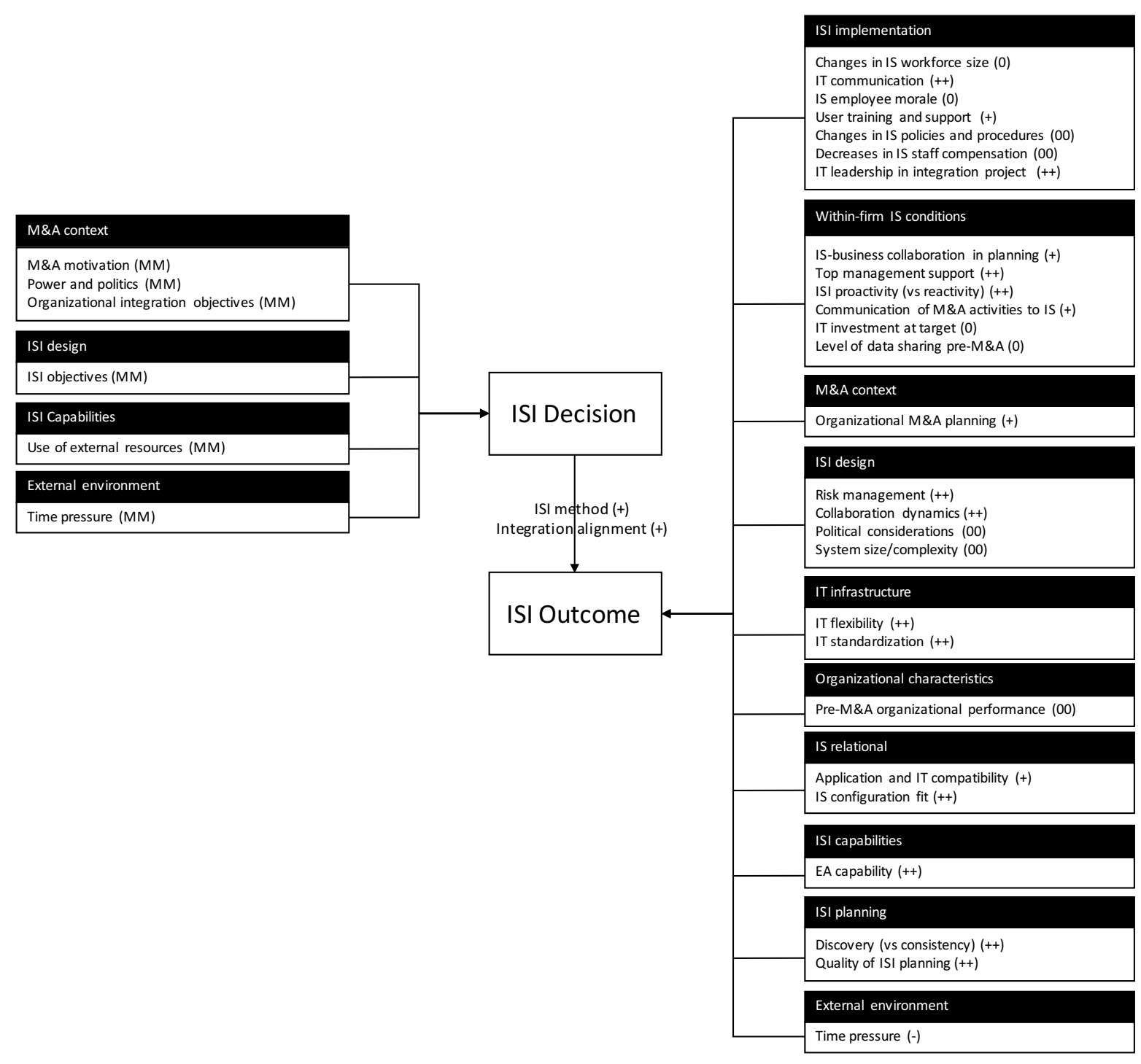

FIGURE 3. Robust research findings 
The is the pre-edited version of Henningsson et al. (2018) "A review of information system integration in mergers and acquisitions", published in Journal of Information Technology. http://link.springer.com/article/10.1057/s41265-017-0051-9

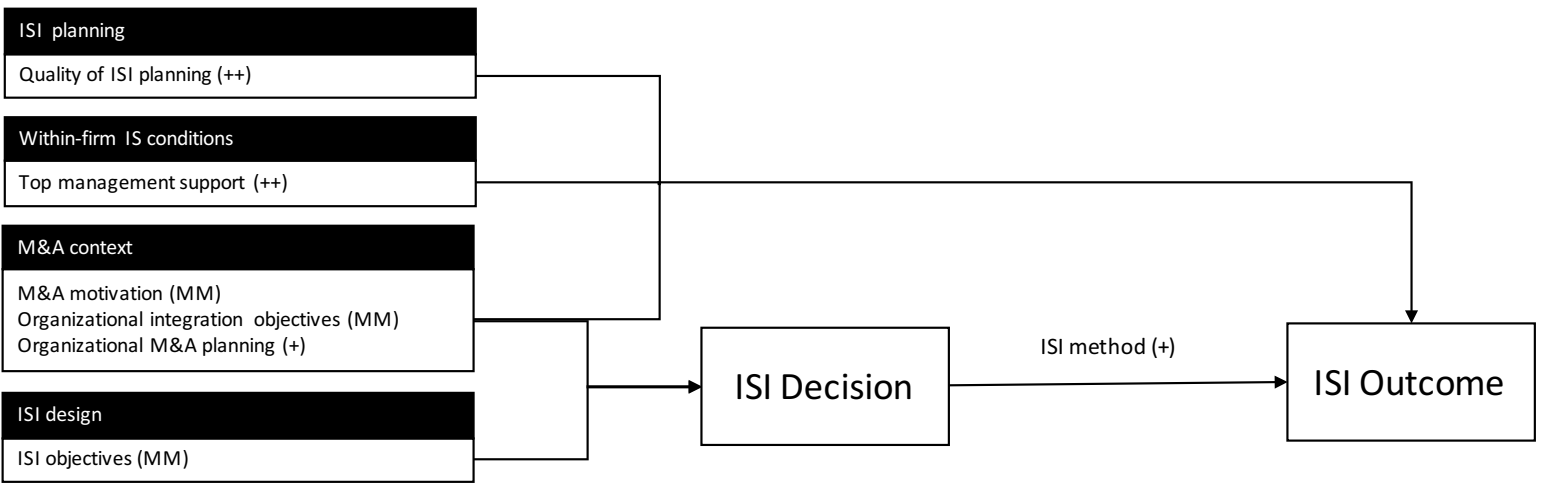

FIGURE 4. M\&A context 
The is the pre-edited version of Henningsson et al. (2018) "A review of information system integration in mergers and acquisitions", published in Journal of Information Technology. http://link.springer.com/article/10.1057/s41265-017-0051-9

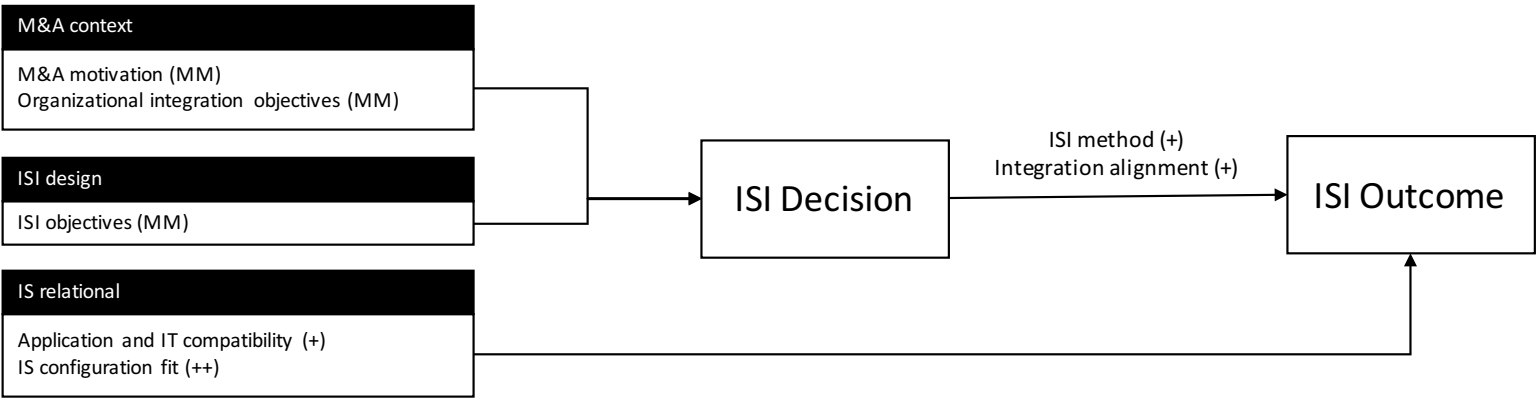

FIGURE 5. Relational fit 
The is the pre-edited version of Henningsson et al. (2018) "A review of information system integration in mergers and acquisitions", published in Journal of Information Technology. http://link.springer.com/article/10.1057/s41265-017-0051-9

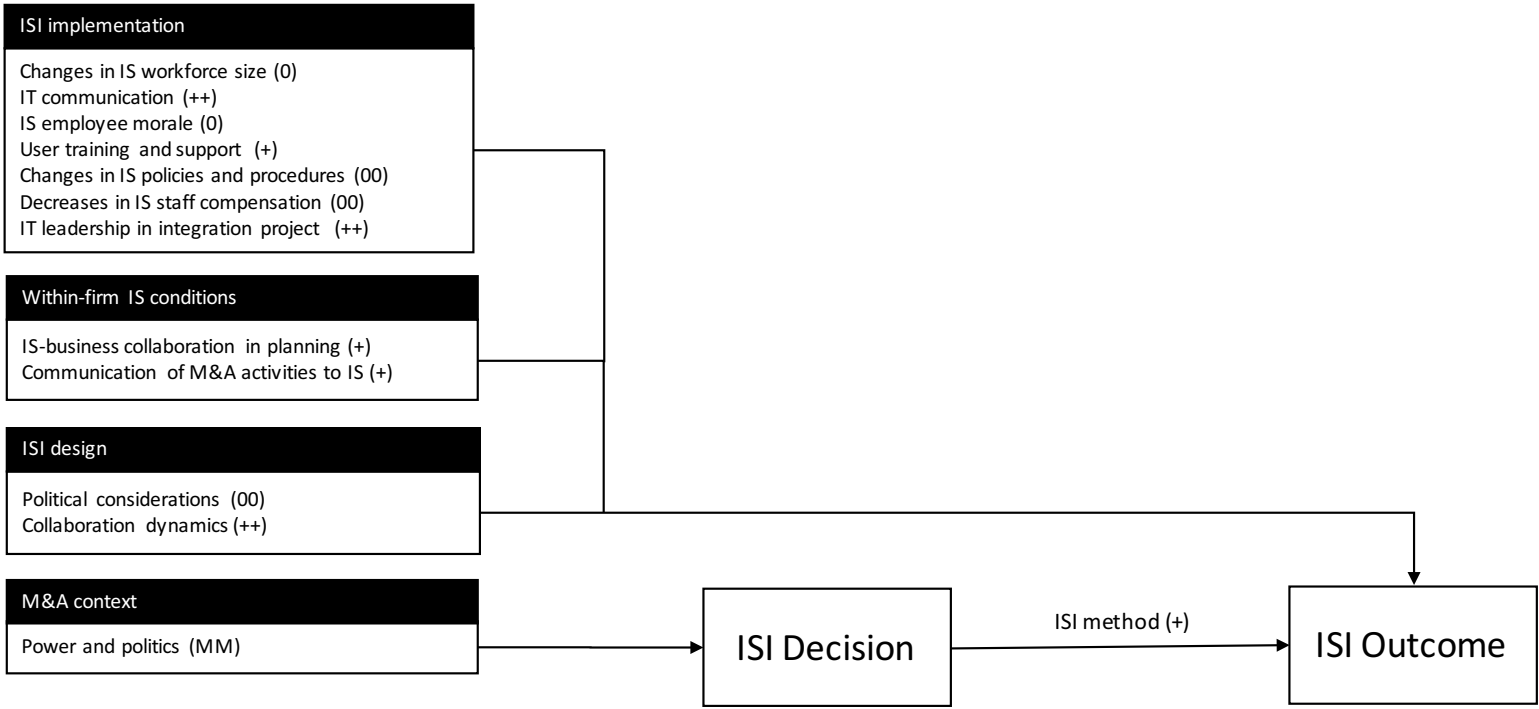

FIGURE 6. The human side of ISI 
The is the pre-edited version of Henningsson et al. (2018) "A review of information system integration in mergers and acquisitions", published in Journal of Information Technology. http://link.springer.com/article/10.1057/s41265-017-0051-9

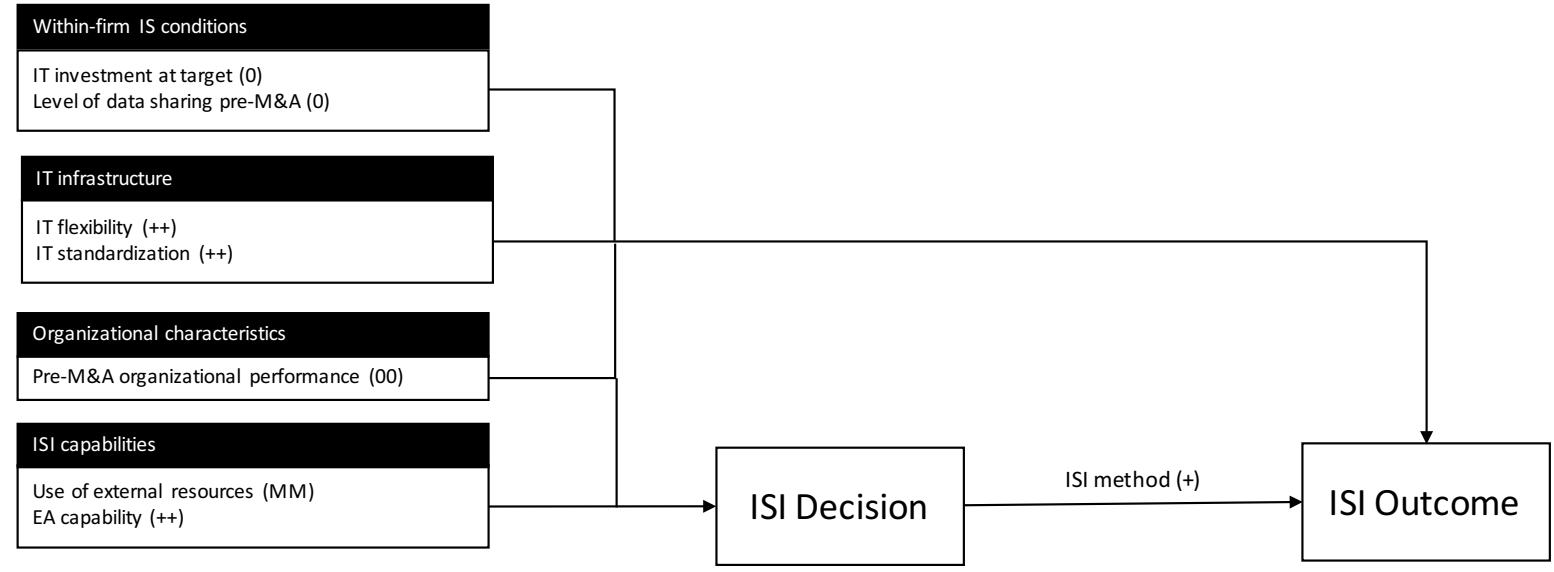

FIGURE 7. Pre-conditions for ISI 
The is the pre-edited version of Henningsson et al. (2018) "A review of information system integration in mergers and acquisitions", published in Journal of Information Technology. http://link.springer.com/article/10.1057/s41265-017-0051-9

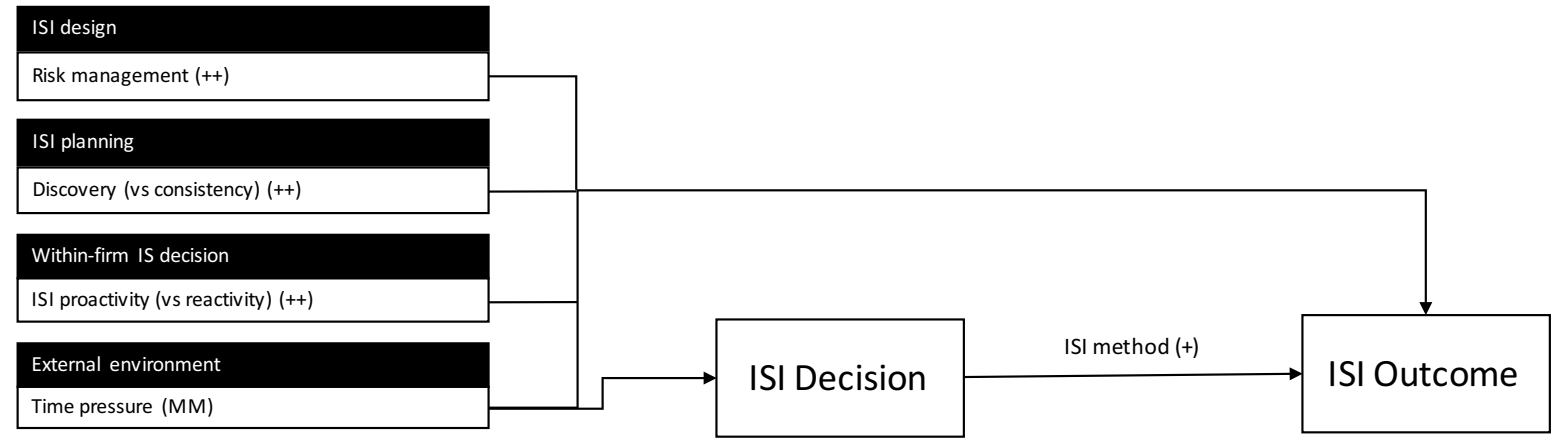

FIGURE 8. Time and sub-optimal decision-making 


\section{Tables}

TABLE 1. Publication frequency by source

\begin{tabular}{|c|c|}
\hline Outlet & Articles \\
\hline International Conference on Information Systems & 7 \\
\hline Information \& Management & 5 \\
\hline European Conference on Information Systems & 4 \\
\hline European Journal of Information Systems & 4 \\
\hline Journal of Strategic Information Systems & 4 \\
\hline Pacific Asia Conference on Information Systems & 4 \\
\hline Management Information Systems Quarterly Executive & 3 \\
\hline PhD thesis & 3 \\
\hline Americas Conference on Information Systems & 2 \\
\hline Hawaii International Conference on System Sciences & 2 \\
\hline Information Systems Research & 2 \\
\hline Long Range Planning & 2 \\
\hline MIS Quarterly Executive & 2 \\
\hline ASCI Journal of Management & 1 \\
\hline Australasian Conference on Information Systems & 1 \\
\hline Business Information Systems & 1 \\
\hline Business \& Information Systems Engineering & 1 \\
\hline Computers \& Security & 1 \\
\hline Communications of the IIMA & 1 \\
\hline Enterprise Information Systems & 1 \\
\hline European Management Journal & 1 \\
\hline Health Informatics Meets eHealth & 1 \\
\hline Industrial Engineering and Management Systems & 1 \\
\hline Industrial Management \& Data Systems & 1 \\
\hline Information Systems Frontier & 1 \\
\hline Information Systems Journal & 1 \\
\hline International Journal of Business and Management & 1 \\
\hline International Journal of Information Management & 1 \\
\hline International Multiconference on Computer Science and Information Technology & 1 \\
\hline Journal of Engineering and Technology Management & 1 \\
\hline Journal of International Technology and Information Management & 1 \\
\hline Journal of Information Technology Theory and Application & 1 \\
\hline Journal of Leadership, Accountability and Ethics & 1 \\
\hline Journal of Management Information Systems \& E-commerce & 1 \\
\hline Journal of Social and Organizational Dynamics & 1 \\
\hline Journal of Systems and Information Technology & 1 \\
\hline Journal of the AIS & 1 \\
\hline Management Information Systems Quarterly & 1 \\
\hline Practice-driven Research on Enterprise Transformation & 1 \\
\hline Grand total & 70 \\
\hline
\end{tabular}


TABLE 2. Coding protocol

\begin{tabular}{|c|c|c|c|c|}
\hline Relationship & Code & Meaning & Quantitative example & Qualitative example \\
\hline $\begin{array}{l}\text { Significant } \\
\text { positive }\end{array}$ & +1 & $\begin{array}{l}\text { Positive Relationship: higher } \\
\text { values of the independent } \\
\text { variable are associated with } \\
\text { higher values of the } \\
\text { dependent variable; } \mathrm{P}<0.05 \\
\text { for quantitative studies or } \\
\text { strong argument by authors } \\
\text { for qualitative studies. }\end{array}$ & $\begin{array}{l}\text { Tanriverdi and Uysal (2011): } \\
\text { 'Cross-business IT integration } \\
\text { capability' has positive } \\
\text { effects on 'stock market } \\
\text { reaction' and 'operating } \\
\text { profit'. }\end{array}$ & $\begin{array}{l}\text { Busquets }(2015) \text { : } \\
\text { 'Discovery' oriented } \\
\text { planning has a } \\
\text { positive effect on 'IS } \\
\text { synergies'. }\end{array}$ \\
\hline $\begin{array}{l}\text { Significant } \\
\text { negative }\end{array}$ & -1 & $\begin{array}{l}\text { Negative Relationship: higher } \\
\text { values of the independent } \\
\text { variable are associated with } \\
\text { lower values of the dependent } \\
\text { variable; } \mathrm{P}<0.05 \text { for } \\
\text { quantitative studies or strong } \\
\text { argument by authors for } \\
\text { qualitative studies. }\end{array}$ & $\begin{array}{l}\text { Robbins and Stylianou } \\
\text { (1999): } \\
\text { 'User involvement in IS } \\
\text { decision' has a negative effect } \\
\text { on 'ISI success' }\end{array}$ & $\begin{array}{l}\text { Holm-Larsen (2005): } \\
\text { 'IT extensiveness' has } \\
\text { negative effects on } \\
\text { 'ISI project time' and } \\
\text { 'ISI project cost'. }\end{array}$ \\
\hline $\begin{array}{l}\text { Significant } \\
\text { matter }\end{array}$ & $\mathrm{M}$ & $\begin{array}{l}\text { A relationship between a } \\
\text { categorical independent } \\
\text { variable and a dependent } \\
\text { variable mattered; } \mathrm{P}<0.05 \text { for } \\
\text { quantitative studies or strong } \\
\text { argument by authors for } \\
\text { qualitative studies. }\end{array}$ & NA & $\begin{array}{l}\text { Henningsson (2015): } \\
\text { 'ISI method' matters } \\
\text { for the dependent } \\
\text { variable 'ISI } \\
\text { capabilities'. }\end{array}$ \\
\hline $\begin{array}{l}\text { Not } \\
\text { significant }\end{array}$ & 0 & $\begin{array}{l}\text { A non-significant relationship } \\
\text { is reported. }\end{array}$ & $\begin{array}{l}\text { Morsell et al. (2009): 'IS } \\
\text { employee morale' has a non- } \\
\text { significant effect on 'ISI } \\
\text { success'. }\end{array}$ & $\begin{array}{l}\text { Baker and Niederman } \\
(2014) \text { : 'Post-merger } \\
\text { alignment' has a non- } \\
\text { significant effect on } \\
\text { 'Merger benefits'. }\end{array}$ \\
\hline
\end{tabular}


TABLE 3. Most studied robust relationships

\begin{tabular}{|c|c|c|c|}
\hline Independent variable & Dependent variable & Count & Thematic association \\
\hline IS-business collaboration in planning & Outcome & 14 & $\mathrm{~A}$ \\
\hline Application and IT compatibility & Outcome & 13 & $\mathrm{~B}$ \\
\hline ISI method & Outcome & 13 & $\mathrm{~A}, \mathrm{~B}, \mathrm{C}, \mathrm{D}, \mathrm{E}$ \\
\hline Changes in workforce size & Outcome & 12 & $\mathrm{C}$ \\
\hline IS employee morale & Outcome & 11 & $\mathrm{C}$ \\
\hline User training and support & Outcome & 10 & $\mathrm{C}$ \\
\hline Organizational M\&A planning & Outcome & 10 & A \\
\hline M\&A motivation & Decision & 10 & A, B \\
\hline IT communication & Outcome & 9 & $\mathrm{C}$ \\
\hline IT investment at target & Outcome & 9 & $\mathrm{D}$ \\
\hline Discovery (Consistency) & Outcome & 8 & $\mathrm{E}$ \\
\hline Risk management & Outcome & 8 & $\mathrm{E}$ \\
\hline IT flexibility & Outcome & 7 & $\mathrm{D}$ \\
\hline Pre-M\&A org. performance & Outcome & 7 & $\mathrm{D}$ \\
\hline Collaboration dynamics & Outcome & 7 & $\mathrm{C}$ \\
\hline Level of data sharing pre-M\&A & Outcome & 7 & $\mathrm{D}$ \\
\hline Use of external resources & Outcome & 6 & $\mathrm{D}$ \\
\hline Top management support & Outcome & 6 & A \\
\hline IT standardization & Outcome & 6 & $\mathrm{D}$ \\
\hline Changes in policies and procedures & Outcome & 6 & $\mathrm{C}$ \\
\hline Decreases in IS staff compensation & Outcome & 6 & $\mathrm{C}$ \\
\hline IT leadership in integration project & Outcome & 6 & $\mathrm{C}$ \\
\hline Political considerations & Outcome & 6 & $\mathrm{C}$ \\
\hline System size/complexity & Outcome & 6 & Not assigned \\
\hline EA capability & Outcome & 6 & $\mathrm{D}$ \\
\hline Time pressure & Outcome & 5 & $\mathrm{E}$ \\
\hline ISI proactivity (vs Reactive) & Outcome & 5 & $\mathrm{E}$ \\
\hline IS configuration fit & Outcome & 5 & $\mathrm{~B}$ \\
\hline Communication of M\&A activities to IS & Outcome & 5 & $\mathrm{C}$ \\
\hline Quality of ISI planning & Outcome & 5 & A \\
\hline Time pressure & Decision & 5 & $E$ \\
\hline Power and politics & Decision & 5 & $\mathrm{C}$ \\
\hline Organizational integration objectives & Decision & 5 & $\mathrm{~A}, \mathrm{~B}$ \\
\hline ISI objectives & Decision & 5 & $\mathrm{~B}$ \\
\hline Integration alignment & Outcome & 5 & $\mathrm{~B}$ \\
\hline
\end{tabular}


TABLE 4. Research agendas within each theme

\begin{tabular}{|c|c|c|c|}
\hline $\begin{array}{l}\text { Thematic domain and } \\
\text { core constructs }\end{array}$ & $\begin{array}{l}\text { Related theoretical } \\
\text { frameworks }\end{array}$ & Research gaps & Potential research questions \\
\hline $\begin{array}{l}\text { The M\&A context } \\
\text { - Quality of ISI } \\
\text { planning } \\
\text { - } \text { Top management } \\
\text { support } \\
\text { - M\&A motivation } \\
\text { - Organizational } \\
\text { integration } \\
\text { objectives } \\
\text { - Organizational M\&A } \\
\text { planning } \\
\text { - ISI objectives } \\
\text { - ISI method }\end{array}$ & $\begin{array}{l}\text { - } \text { Coordination } \\
\text { theory } \\
\text { - } \text { Task- } \\
\text { dependency } \\
\text { theory }\end{array}$ & $\begin{array}{l}\text { - Conceptualizations of } \\
\text { dynamic interactions } \\
\text { between organizational } \\
\text { integration and ISI. } \\
\text { - Unexplored M\&A } \\
\text { contexts, including } \\
\text { innovation-driven } \\
\text { mergers in the hi-tech } \\
\text { industries. } \\
\text { - The value creating } \\
\text { mechanisms of M\&As in } \\
\text { digital industries. } \\
\text { - Challenges in } \\
\text { transitioning from an } \\
\text { established M\&A } \\
\text { practice to an } \\
\text { innovation-oriented } \\
\text { practice. }\end{array}$ & $\begin{array}{l}\text { - What is the interface } \\
\text { between the M\&A project } \\
\text { and the ISI project? } \\
\text { - How can the inter- } \\
\text { dependences between the } \\
\text { M\&A project and ISI project } \\
\text { be managed? } \\
\text { - How can acquirers manage } \\
\text { incremental ISI in highly } \\
\text { uncertain technology } \\
\text { acquisitions? } \\
\text { - What are the appropriate ISI } \\
\text { methods to integrate } \\
\text { disruptive business models? } \\
\text { - What are the implications of } \\
\text { M\&As for digital } \\
\text { ecosystems? }\end{array}$ \\
\hline $\begin{array}{ll}\text { Relational fit } \\
\text { - } & \text { M\&A motivation } \\
\text { - } & \text { Organizational } \\
& \text { integration } \\
& \text { objectives } \\
\text { - } & \text { ISI objectives } \\
\text { - } & \text { Application and IT } \\
& \text { compatibility } \\
\text { - } & \text { IS configuration } \\
\text { - } & \text { Integration } \\
& \text { alignment } \\
\text { - } & \text { ISI method }\end{array}$ & $\begin{array}{l}\text { - } \text { Alignment } \\
\text { theory } \\
\text { - Configuration } \\
\text { theory }\end{array}$ & $\begin{array}{l}\text { - Inconsistencies in the } \\
\text { importance of alignment. } \\
\text { - A coherent framework } \\
\text { for understanding M\&A } \\
\text { ISI outcomes. } \\
\text { - Adopting a portfolio of } \\
\text { ISI methods. }\end{array}$ & 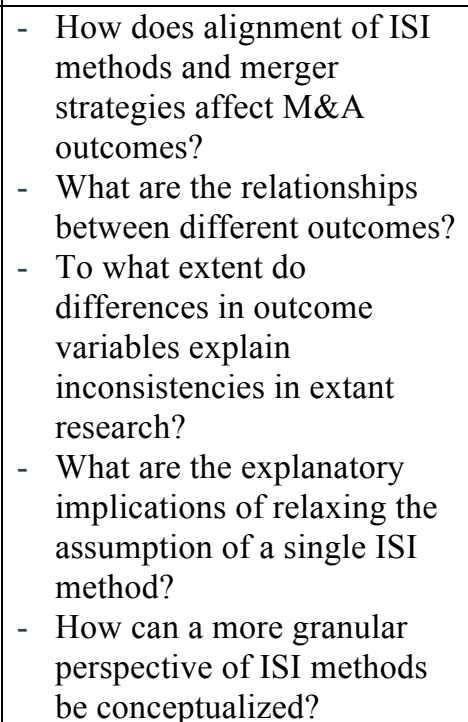 \\
\hline $\begin{array}{l}\text { The human side of ISI } \\
\text { - Changes in IS } \\
\text { workforce size } \\
\text { - } \text { IT communication } \\
\text { - } \text { IS employee morale } \\
\text { - User training and } \\
\text { support } \\
\text { - Changes in IS } \\
\text { policies and } \\
\text { procedures } \\
\text { - Decreases in IS staff } \\
\text { compensation } \\
\text { - IT leadership in } \\
\text { integration project } \\
\text { - IS-business } \\
\text { collaboration in } \\
\text { planning } \\
\text { - Communication of } \\
\text { M\&A activities to IS }\end{array}$ & $\begin{array}{ll}\text { - } & \text { Power and } \\
& \text { politics } \\
\text { - } & \text { Change } \\
& \text { management } \\
\text { - } & \text { Resistance } \\
\text { - } & \text { Human resource } \\
& \text { management }\end{array}$ & $\begin{array}{l}\text { - Resolutions to identified } \\
\text { human challenges. } \\
\text { - The constituents of a } \\
\text { good project } \\
\text { environment. } \\
\text { - The permeability of } \\
\text { organizational } \\
\text { boundaries and the } \\
\text { M\&A ISI project. }\end{array}$ & $\begin{array}{l}\text { - How to manage ISI in } \\
\text { M\&As with valuable IT- } \\
\text { enabled capabilities? } \\
\text { - What are the solutions to } \\
\text { power, politics and } \\
\text { resistance challenges? } \\
\text { - Which actors, excluding the } \\
\text { merging organizations, } \\
\text { affect M\&A ISI and how can } \\
\text { the extended organization be } \\
\text { managed in the merger ISI } \\
\text { context? }\end{array}$ \\
\hline
\end{tabular}




\begin{tabular}{|c|c|c|c|}
\hline \begin{tabular}{|ll} 
- & Political \\
& considerations \\
- & Collaboration \\
& dynamics \\
- & Power and politics \\
- & ISI method
\end{tabular} & & & \\
\hline \begin{tabular}{|l} 
Pre-conditions for \\
delivering ISI \\
- IT investment in the \\
target \\
- Level of data sharing \\
pre-M\&A \\
- IT flexibility \\
- IT standardization \\
- ISI objectives \\
- Use of external \\
resources \\
- EA capability \\
- ISI method
\end{tabular} & $\begin{array}{ll}\text { - } & \text { Resource-based } \\
& \text { view } \\
\text { - } & \text { Capability-based } \\
& \text { view } \\
\text { - } & \text { Knowledge- } \\
& \text { based view }\end{array}$ & $\begin{array}{l}\text { - The building of pre- } \\
\text { conditions for M\&A ISI. } \\
\text { - Interaction between } \\
\text { M\&A ISI learning } \\
\text { processes and other } \\
\text { organizational events. } \\
\text { - Specific ISI capabilities } \\
\text { for specific M\&A } \\
\text { subclasses. } \\
\text { - Conceptualization of ISI } \\
\text { capabilities } \\
\text { accommodating } \\
\text { variation in challenges. } \\
\text { - The impact of emerging } \\
\text { technology management } \\
\text { practices. }\end{array}$ & $\begin{array}{l}\text { - What are the origins of ISI } \\
\text { capabilities and how do } \\
\text { organizations develop them? } \\
\text { - Which ISI capabilities are } \\
\text { required for specific } \\
\text { categories of mergers? } \\
\text { - How can ISI capabilities be } \\
\text { conceptualized to cater for } \\
\text { the heterogeneity of ISI } \\
\text { challenges? } \\
\text { - In which ways do trends } \\
\text { such as cloud computing and } \\
\text { software-as-a-service affect } \\
\text { ISI in M\&As? }\end{array}$ \\
\hline $\begin{array}{l}\text { Time and suboptimal } \\
\text { decision-making } \\
\text { - } \text { Risk management } \\
\text { - Discovery } \\
\text { - ISI proactivity } \\
\text { - } \text { Time pressure } \\
\text { - ISI method }\end{array}$ & $\begin{array}{l}\text { - Organizational } \\
\text { response } \\
\text { - Attention-based } \\
\text { view } \\
\text { - Path- } \\
\text { dependency } \\
\text { theory } \\
\text { - } \text { Temporal scales }\end{array}$ & $\begin{array}{l}\text { - } \text { The impact of time- } \\
\text { pressure on ISI decision- } \\
\text { making in M\&A. } \\
\text { - } \text { Inter-temporal effects in } \\
\text { serial acquirers. } \\
\text { - } \text { The challenges and } \\
\text { management of } \\
\text { acquisition programs and } \\
\text { acquisition-based growth } \\
\text { strategies. } \\
\text { - Antecedents of ISI } \\
\text { capabilities. }\end{array}$ & $\begin{array}{l}\text { - How are ISI decisions } \\
\text { affected by time pressure? } \\
\text { - } \text { To what extent are M\&A } \\
\text { objectives mutually } \\
\text { exclusive or conflicting in } \\
\text { their effects on ISI? } \\
\text { - } \text { How do trade-offs generate } \\
\text { suboptimal outcomes? } \\
\text { - Which are the critical } \\
\text { implications of the inter- } \\
\text { temporal nature of ISI } \\
\text { decisions in M\&As? } \\
\text { - What are the critical } \\
\text { cumulative effects in a series } \\
\text { of M\&As? }\end{array}$ \\
\hline
\end{tabular}




\section{APPENDICES}

\section{Appendix A: Paper overview}

TABLE A1. Papers in the review

\begin{tabular}{|c|c|}
\hline \# & eference \\
\hline 1 & $\begin{array}{l}\text { Al Suliman, M.H. (2015). In Mergers and Acquisitions-IT: Results of the Absence of CIO in Ex-ante Planning } \\
\text { and the Absence of Key IT Staff in Ex-post Integration, Journal of Management Information Systems \& E- } \\
\text { commerce 2(2): 1-110. }\end{array}$ \\
\hline 2 & $\begin{array}{l}\text { Alaranta, M. and Henningsson, S. (2008). An Approach to Analyzing and Planning Post-Merger IS } \\
\text { Integration: Insights from two Field Studies, Information Systems Frontiers 10(3): 307-319. }\end{array}$ \\
\hline 3 & $\begin{array}{l}\text { Alaranta, M. and Kautz, K. (2012). A framework for Understanding Post-Merger Information Systems } \\
\text { Integration, Journal of Information Technology Theory and Application 13(1): 5-29. }\end{array}$ \\
\hline 4 & $\begin{array}{l}\text { Alaranta, M.E. and Martela, E. (2012). Overcoming Knowledge Gaps in Postmerger Integration, in } \\
\text { Proceedings of International Conference on Information Systems (Orlando, USA, 2012); Atlanta, USA: } \\
\text { Association for Information Systems. }\end{array}$ \\
\hline 5 & $\begin{array}{l}\text { Baker, E.W. and Niederman, F. (2014). Integrating the IS Functions after Mergers and Acquisitions: } \\
\text { Analyzing Business-IT Alignment, The Journal of Strategic Information Systems 23(2): 112-127. }\end{array}$ \\
\hline 6 & $\begin{array}{l}\text { Benitez-Amado, J. and Ray, G. (2012). Introducing IT-enabled Business Flexibility and IT Integration in the } \\
\text { Acquirer's M\&A Performance Equation, in Proceedings of International Conference on Information Systems } \\
\text { (Orlando, USA, 2012); Atlanta, USA: Association for Information Systems. }\end{array}$ \\
\hline 7 & $\begin{array}{l}\text { Bhattacharya, P. (2016). Identifying Four Key Means of Business Value Creation using Enterprise Systems: } \\
\text { An Empirical Study, Journal of International Technology and Information Management 25(1): 19-38. }\end{array}$ \\
\hline 8 & $\begin{array}{l}\text { Böhm, M., Henningsson, S., Leimeister, J.M., Yetton, P. and Krcmar, H. (2011). A Dual View on IT } \\
\text { Challenges in Corporate Ddivestments and Acquisitions, in Proceedings of International Conference on } \\
\text { Information Systems (Shanghai, China, 2011); Atlanta, USA: Association for Information Systems. }\end{array}$ \\
\hline 9 & $\begin{array}{l}\text { Brown, C.V., Clancy, G. and Scholer, R. (2003). A Post-Merger IT Integration Success Story: Sallie Mae, } \\
\text { MIS Quarterly Executive 2(1): 15-27. }\end{array}$ \\
\hline 10 & $\begin{array}{l}\text { Brunetto, G. (2006). Integrating Information Systems During Mergers: Integration Modes Typology, } \\
\text { Prescribed vs Constructed Implementation Process, in Proceedings of European Conference on Information } \\
\text { Systems (Gothenburg, Sweden, 2006); Atlanta, USA: Association for Information Systems. }\end{array}$ \\
\hline 11 & $\begin{array}{l}\text { Buck-Lew, M., Wardle, C.E. and Pliskin, N. (1992). Accounting for Information Technology in Corporate } \\
\text { Acquisitions, Information \& Management 22(6): 363-370. }\end{array}$ \\
\hline 12 & $\begin{array}{l}\text { s, J. (2015). Discovery Paths: Exploring Emergence and IT Evolutionary DCsign in Cross-Border } \\
\text { Analysing grupo Santander's Acquisition of Abbey (2004-2009), European Journal of Information } \\
\text { 24(2): 178-201. }\end{array}$ \\
\hline 13 & $\begin{array}{l}\text { Chang, S.-I., Chang, I.-C. and Wang, T. (2014). Information Systems Integration After Merger and } \\
\text { Acquisition, Industrial Management \& Data Systems 114(1): 37-52. }\end{array}$ \\
\hline 14 & $\begin{array}{l}\text { Chun, M. and Whitfield, G. (2008). Social Constraints to Integrating Information Systems, Knowledge, and } \\
\text { Firm Capabilities Following a Corporate Merger, Journal of Systems and Information Technology 10(2): 135- } \\
158 \text {. }\end{array}$ \\
\hline 15 & $\begin{array}{l}\text { Dhillon, G., Syed, R. and Pedron, C. (2016). Interpreting Information Security Culture: An Organizational } \\
\text { Transformation Case Study, Computers \& Security 56(February 2016): 63-69. }\end{array}$ \\
\hline 16 & $\begin{array}{l}\text { Du, K. (2015). Research Note-Parenting New Acquisitions: Acquirers' Digital Resource Redeployment and } \\
\text { Targets' Performance Improvement in the US Hospital Industry, Information Systems Research 26(4): 829-844. }\end{array}$ \\
\hline 17 & $\begin{array}{l}\text { Eckert, M.-L., Freitag, A., Matthes, F., Roth, S. and Schulz, C. (2012). Decision Support for Selecting an } \\
\text { Application Landscape Integration Strategy in Mergers and Acquisitions, in Proceedings of European } \\
\text { Conference on Information Systems (Barcelona, Spain, 2012); Atlanta, USA: Association for Information } \\
\text { Systems. }\end{array}$ \\
\hline 18 & Freitag, A., Matthes, F. and Schulz, C. (2010). A Method for Consolidating A \\
\hline
\end{tabular}


Information Technology (IMCSIT) (Wisla, Poland, 2010), pp: 241-248; Chicago, USA: IEEE Computer Society Press.

19 Garcia-Canal, E., Rialp-Criado, A. and Rialp-Criado, J. (2013). Speed of ICT Integration Strategies in Absorptions: Insights from a Qualitative Study, European Management Journal 31(3): 295-307.

20 Giacomazzi, F., Panella, C., Pernici, B. and Sansoni, M. (1997). Information Systems Integration in Mergers and Acquisitions: A Normative Model, Information \& Management 32(6): 289-302.

21 Glazar-Stavnicky, M. (2016). Organizational and Systems Factors Leading to Systems Integration Success after Merger and Acquisition. Cleveland State University, Unpublished PhD thesis.

22 Gorla, N. and Pang, P. (2001). Fit Between MIS Integration Strategies and Business Acquisition Strategies, ASCI Journal of Management 30(1\&2): 1-8.

23 Gregory, R.W., Keil, M. and Muntermann, J. (2012). Ambidextrous IS Strategy: The Dynamic Balancing Act of Developing a 'Transform \& Merge' Strategy in the Banking Industry, in Proceedings of International Conference of Information Systems (Orlando, USA, 2012); Atlanta, USA: Association for Information Systems.

24 Henningsson, S. (2015). Learning to Acquire: How Serial Acquirers Build Organisational Knowledge for Information Systems Integration, European Journal of Information Systems 24(2): 121-144.

25 Henningsson, S. and Carlsson, S.A. (2011). The DySIIM Model for Managing IS integration in Mergers and Acquisitions, Information Systems Journal 21(5): 441-476.

26 Henningsson, S. and Kettinger, W.J. (2016). Managing IT Integration Risk in Acquisitions, MIS Quarterly Executive 15(1): 1-19.

27 Henningsson, S., Kude, T. and Popp, K.M. (2016). Managing the Technology Acquisition Integration Paradox at SAP, in Proceedings of International Conference of Information Systems (Dublin, Ireland, 2016); Atlanta, USA: Association for Information Systems.

28 Henningsson, S., Svensson, C. and Vallen, L. (2007). Mastering the Integration Chaos Following Frequent M\&As: IS Integration with SOA Technology, in Proceedings of Hawaii International Conference on System Sciences (Waikoloa, USA, 2007); Chicago, USA: IEEE Computer Society Press.

29 Henningsson, S. and Yetton, P. (2011). Managing the IT integration of Acquisitions by Multi-Business Organizations, in Proceedings of International Conference of Information Systems (Shanghai, China, 2011); Atlanta, USA: Association for Information Systems.

30 Henningsson, S. and Øhrgaard, C. (2016). IT Consultants in Acquisition IT Integration, Business \& Information Systems Engineering 58(3): 193-212.

31 Holm-Larsen, M. (2005). ICT Integration in an M\&A Process, in Proceedings of Pacific Asia Conference on Information Systems (Bangkok, Thailand, 2005); Atlanta, USA: Association for Information Systems.

32 Hsu, J. and Chen, E.T. (2015). The Impact of Mergers and Acquisitions on Information Systems: A Case of A Software Industry Acquisition, Communications of the IIMA 6(1): Article 6.

33 Jain, R.P. and Ramesh, B. (2015). The Roles of Contextual Elements in Post-Merger Common Platform Development: An Empirical Investigation, European Journal of Information Systems 24(2): 159-177.

34 Johnston, K.D. and Yetton, P.W. (1996). Integrating Information Technology Divisions in a Bank Merger Fit, Compatibility and Models of Change, The Journal of Strategic Information Systems 5(3): 189-211.

35 Kim, H.-G., Iijima, J. and Ho, S. (2005). A Framework for Analysis of Systems Failure in Information Systems Integration, Industrial engineering and management systems 4(2): 207-217.

36 Kovela, S. and Skok, W. (2012). Mergers and Acquisitions in Banking: Understanding the IT Integration Perspective, International Journal of Business and Management 7(18): 69-80.

37 Labusch, N., Koebele, F., Aier, S. and Winter, R. (2013). The Architects' Perspective on Enterprise Transformation: An Explorative Study, in Proceedings of Practice-Driven Research on Enterprise Transformation (Utrecht, The Netherlands, 2013); Berlin: Springer.

38 LeFave, R., Branch, B., Brown, C.V. and Wixom, B. (2008). How Sprint Nextel Reconfigured IT Resources for Results, MIS Quarterly Executive 7(4): 171-179.

39 Lin, F. and Chao, R. (2008). Post-Merger IT integration: An IT Culture Conflict Perspective, in Proceedings of Pacific-Asia Conference on Information Systems (Suzhou, China, 2008); Association for Information Systems.

40 Linder, J.C. (1989). Integrating Organizations where Information Technology Matters. Harvard University, Graduate School of Business Administration. Unpublished PhD thesis.

41 Main, T.J. and Short, J.E. (1989). Managing the Merger: Building Partnership through IT Planning at the New Baxter, MIS Quarterly 13(4): 469-484.

42 McKiernan, P. and Merali, Y. (1995). Integrating Information Systems after a Merger, Long Range Planning 28(4): 454-562.

43 Mehta, M. and Hirschheim, R. (2007). Strategic Alignment in Mergers and Acquisitions: Theorizing IS Integration Decision Making, Journal of the Association for Information Systems 8(3): 143-174. 


\begin{tabular}{|c|c|}
\hline 44 & $\begin{array}{l}\text { Merali, Y. and McKiernan, P. (1993). The Strategic Positioning of Information Systems in Post-Acquisition } \\
\text { Management, The Journal of Strategic Information Systems 2(2): 105-124. }\end{array}$ \\
\hline 45 & $\begin{array}{l}\text { Morsell, G.A., Deek, F. and Chakrabarti, A. (2009). Post-Merger Technology Integration: Influential } \\
\text { Organization and Information Systems Factors, in Proceedings of Americas Conference on Information } \\
\text { Systems (San Francisco, USA, 2009); Atlanta, USA: Association for Information Systems. }\end{array}$ \\
\hline 46 & $\begin{array}{l}\text { Myers, M.D. (2008). Integration of Different ERP Systems: The Case of Mergers and Acquisitions, in } \\
\text { Proceedings of Pacific Asia Conference on Information Systems (Suzhou, China, 2008); Atlanta, USA: } \\
\text { Association for Information Systems. }\end{array}$ \\
\hline 47 & $\begin{array}{l}\text { Parada, P., Alemany, L. and Planellas, M. (2009). The Internationalisation of Retail Banking: Banco } \\
\text { Santander's Journey Towards Globalisation. Long Range Planning 42(5): 654-677. }\end{array}$ \\
\hline 48 & $\begin{array}{l}\text { Robbins, S.S. and Stylianou, A.C. (1999). Post-Merger Systems Integration: The Impact on IS Capabilities, } \\
\text { Information and Management 36(4): 205-212. }\end{array}$ \\
\hline 49 & $\begin{array}{l}\text { Robertson, S. and Powell, P. (2001). Managing the IS Function During Mergers, in Proceedings of European } \\
\text { Conference on Information Systems (Bled, Slovenia, 2001); Atlanta, USA: Association for Information } \\
\text { Systems. }\end{array}$ \\
\hline 50 & $\begin{array}{l}\text { Schonewille, J. and Bouwman, W. (2012). Contextual Aspects in Enterprise Integration, in Proceedings of } \\
\text { 45th Hawaii International Conference on System Science (Maui, USA, 2012); Chicago, USA: IEEE Computer } \\
\text { Society. }\end{array}$ \\
\hline 51 & $\begin{array}{l}\text { Seddon, P.B., Reynolds, P. and Willcocks, L.P. (2010). Post-Merger IT integration: A Comparison of two } \\
\text { Case Studies, in Proceedings of Pacific Asia Conference on Information Systems (Taipei, Taiwan, 2010); } \\
\text { Atlanta, USA: Association for Information Systems. }\end{array}$ \\
\hline 52 & $\begin{array}{l}\text { Steininger, K., Kempinger, B., Schiffer, S. and Pomberger, G. (2016). Critical IS Success Factor Analysis in } \\
\text { the Context of a Hospital Merger, in Proceedings of Americas Conference on Information Systems (San Diego, } \\
\text { 2016); Atlanta, USA: Association for Information Systems. }\end{array}$ \\
\hline 53 & $\begin{array}{l}\text { Steininger, K., Kempinger, B., Schiffer, S. and Pomberger, G. (2016). A Process Model for IT Migrations in } \\
\text { the Context of a Hospital Merger-Results from an Austrian Case Study, Studies in health technology and } \\
\text { Informatics 223(1): 182-190. }\end{array}$ \\
\hline 54 & $\begin{array}{l}\text { Stylianou, A.C., Jeffries, C.J. and Robbins, S.S. (1996). Corporate Mergers and the Problems of IS } \\
\text { Integration, Information \& Management 31(4): 203-213. }\end{array}$ \\
\hline 55 & $\begin{array}{l}\text { Sumi, T. and Tsuruoka, M. (2002). Ramp New Enterprise Information Systems in a Merger \& Acquisition } \\
\text { Environment: A Case Study, Journal of Engineering and Technology Management 19(1): 93-104. }\end{array}$ \\
\hline 56 & $\begin{array}{l}\text { Tafti, A.R. (2009). The Role of Information Technology in Alliances and Mergers. University of Michigan. } \\
\text { Unpublished PhD Thesis. }\end{array}$ \\
\hline 57 & $\begin{array}{l}\text { Tanriverdi, H. and Uysal, V.B. (2011). Cross-Business Information Technology Integration and Acquirer } \\
\text { Value Creation in Corporate Mergers and Acquisitions, Information Systems Research 22(4): 703-720. }\end{array}$ \\
\hline 58 & $\begin{array}{l}\text { Tanriverdi, H. and Uysal, V.B. (2015). When IT Capabilities are not Scale-Free in Merger and Acquisition } \\
\text { Integrations: How do Capital Markets React to IT capability Asymmetries Between Acquirer and Target?, } \\
\text { European Journal of Information Systems } \mathbf{2 4}(2): 145-158 \text {. }\end{array}$ \\
\hline 59 & $\begin{array}{l}\text { Toppenberg, G. (2015). Expanded Understanding of IS/IT Related Challenges in Mergers and Acquisitions: } \\
\text { Methods \& Research Context, in Proceedings of European Conference on Information Systems (Münster, } \\
\text { Germany, 2015); Atlanta, USA: Association for Information Systems. }\end{array}$ \\
\hline 60 & $\begin{array}{l}\text { Toppenberg, G., Henningsson, S. and Shanks, G. (2015). How Cisco Systems Used Enterprise Architecture } \\
\text { Capability to Sustain Acquisition-Based Growth, MIS Quarterly Executive 14(4): 151-168. }\end{array}$ \\
\hline 61 & $\begin{array}{l}\text { Unkan, E. and Thönssen, B. (2015). EPOs, an Early Warning System for Post-merger IS Integration, in } \\
\text { Proceedings of International Conference on Business Information Systems (Leipzig, Germany, 2015); Berlin: } \\
\text { Springer. }\end{array}$ \\
\hline 62 & $\begin{array}{l}\text { Vaniya, N., Bernus, P. and Noran, O. (2013). Analysing the M\&A Preparedness Building Approach, in } \\
\text { Proceedings of International Conference on Enterprise Information Systems (Angers, France, 2013); Berlin: } \\
\text { Springer. }\end{array}$ \\
\hline 63 & $\begin{array}{l}\text { Weber, Y. and Pliskin, N. (1996). The Effects of Information Systems Integration and Organizational Culture } \\
\text { on a Firm's Effectiveness, Information \& Management } \mathbf{3 0}(2): 81-90 .\end{array}$ \\
\hline 64 & $\begin{array}{l}\text { Vieru, D. and Rivard, S. (2014). Organizational Identity Challenges in a Post-Merger Context: A Case Study } \\
\text { of an Information System Implementation Project, International Journal of Information Management 34(3): } \\
\text { 381-386. }\end{array}$ \\
\hline 65 & $\begin{array}{l}\text { Vieru, D. and Trudel, M.C. (2013). Unpredictable Reconfigurations: The Dilemma of the Post-Merger } \\
\text { Information Systems Integration. International Journal of Social and Organizational Dynamics in IT, 3(1): 47- } \\
60 .\end{array}$ \\
\hline 66 & $\begin{array}{l}\text { Vieru, D., Rivard, S. and Bourdeau, } \mathbf{S} \\
\text { Symbolic Discourses in a Post-Merger I }\end{array}$ \\
\hline
\end{tabular}


Information Systems (Dublin, Ireland, 2016); Atlanta, USA: Association for Information Systems.

67 Wijnhoven, F., Spil, T., Stegwee, R. and Fa, R.T.A. (2006). Post-Merger IT Integration Strategies: An IT Alignment Perspective, The Journal of Strategic Information Systems 15(1): 5-28.

68 Williams, G.S., Mayer, R.W., Chien, W.-W. and Williams, C.R. (2015). Information Technology Integration in a Postmerger Environment, Journal of Leadership, Accountability and Ethics 12(1): 39-51.

69 Wynne, P.J. (2016). Developing Acquisition IS Integration Capabilities: The Learning Processes of Novice Acquirers, in Proceedings of Australasian Conference on Information Systems (Wollongong, Australia, 2016); Atlanta, USA: Association for Information Systems.

70 Yetton, P., Henningsson, S. and Bjørn-Andersen, N. (2013). "Ready to Acquire": The IT Resources Required for a Growth-by-Acquisition Business Strategy, MIS Quarterly Executive 12(1): 19-35. 
The is the pre-edited version of Henningsson et al. (2018) "A review of information system integration in mergers and acquisitions", published in Journal of Information Technology. http://link.springer.com/article/10.1057/s41265-017-0051-9

TABLE A2. Research methods

\begin{tabular}{|l|r|}
\hline Research methods & Frequency \\
\hline Single case & 29 \\
\hline Multi-case & 21 \\
\hline Survey & 5 \\
\hline Database & 4 \\
\hline Expert panel & 4 \\
\hline Multi-case and Survey & 2 \\
\hline Survey and Database & 2 \\
\hline Design science & 1 \\
\hline Expert panel and Survey & 1 \\
\hline Focus group & 1 \\
\hline
\end{tabular}


The is the pre-edited version of Henningsson et al. (2018) "A review of information system integration in mergers and acquisitions", published in Journal of Information Technology. http://link.springer.com/article/10.1057/s41265-017-0051-9

TABLE A3. Object of study

\begin{tabular}{|l|r|}
\hline Object of study & Frequency $^{1}$ \\
\hline M\&A generic & 37 \\
\hline Acquisition & 17 \\
\hline Merger & 16 \\
\hline Divestment & 1 \\
\hline
\end{tabular}

${ }^{1}$ One article has both the acquisition and divestment as its object of study. 
TABLE A4. Theoretical framework

\begin{tabular}{|l|r|}
\hline Theoretical framework & Frequency $^{2}$ \\
\hline No explicit theory & 37 \\
\hline Alignment theory & 8 \\
\hline Resource-based view & 7 \\
\hline Process perspective & 4 \\
\hline Strategic planning & 2 \\
\hline Structuralist & 1 \\
\hline Individualist & 1 \\
\hline Knowledge transfer & 1 \\
\hline Evolutionary organisation theory & 1 \\
\hline Knowledge-based view & 1 \\
\hline Culture conflict & 1 \\
\hline Organizational identity & 1 \\
\hline Sociomaterial practice & 1 \\
\hline Ambidextrous IS Strategy & 1 \\
\hline Governance theory & 1 \\
\hline Practice perspective & 1 \\
\hline Learning theory & 1 \\
\hline Boundary spanning & 1 \\
\hline Cultural messages & 1 \\
\hline
\end{tabular}

${ }^{2}$ One article explicitly combines structuralist, individualist and process perspectives. 


\section{Appendix B: Master variables}

TABLE B1. Independent master variables

\begin{tabular}{|c|c|}
\hline$\#$ & Independent master variable \\
\hline 1 & $\begin{array}{l}\text { Acquirer's IT capability. The general IT capability of the acquiring firm (e.g. Tanriverdi and } \\
\text { Uysal, 2011). }\end{array}$ \\
\hline 2 & $\begin{array}{l}\text { Acquiring another MBO. If the target acquired is another multi-business organization (e.g. Du, } \\
\text { 2015). }\end{array}$ \\
\hline 3 & $\begin{array}{l}\text { Acquiring from another MBO. If the target is acquired from another multi-business organization } \\
\text { (e.g. Du, 2015). }\end{array}$ \\
\hline 4 & $\begin{array}{l}\text { Aligned post-M\&A state. Business and IT alignment as a post-M\&A state (e.g. Mehta and } \\
\text { Hirschheim, 2007). }\end{array}$ \\
\hline 5 & $\begin{array}{l}\text { Alignment of integration objectives. The fit between the organizational integration objectives and } \\
\text { the ISI objectives (e.g. Wijnhoven et al., 2006). }\end{array}$ \\
\hline 6 & $\begin{array}{l}\text { Alignment of integration processes. Fit between the choice of organizational integration process } \\
\text { and ISI process (e.g. Baker and Niederman, 2014). }\end{array}$ \\
\hline 7 & $\begin{array}{l}\text { Alignment of vendor and acquirer IT transaction strategies. The fit between the way a unit is } \\
\text { carved-out and integrated (e.g. Böhm et al., 2011). }\end{array}$ \\
\hline 8 & $\begin{array}{l}\text { Application and IT compatibility. The compatibility of technical platforms, programming } \\
\text { languages and software (e.g. Chang et al., 2014). }\end{array}$ \\
\hline 9 & $\begin{array}{l}\text { Attention to IT. The level of attention given to ISI issues in the overall organizational integration } \\
\text { project (e.g. Merali and McKiernan, 1993). }\end{array}$ \\
\hline 10 & $\begin{array}{l}\text { Basic conditions. Technological constraints with importance for the ISI (e.g. Steininger et al., } \\
2016 \text { b). }\end{array}$ \\
\hline 11 & $\begin{array}{l}\text { Boundary consolidation. Presence and effectiveness of strategies to collaborate and alter the pre- } \\
\text { M\&A boundaries (e.g. Vieru et al., 2016). }\end{array}$ \\
\hline 12 & $\begin{array}{l}\text { Boundary spanning versatility. ISI team's ability to assume different roles in the consolidation of } \\
\text { stakeholders (Jain and Ramesh, 2015). }\end{array}$ \\
\hline 13 & $\begin{array}{l}\text { Burning desire. The eagerness of the team to succeed in a once-in-a-lifetime experience (e.g. } \\
\text { Brown et al., 2003). }\end{array}$ \\
\hline 14 & $\begin{array}{l}\text { Business analysis. Quality of the activities to assess the business rationale of integration (e.g. Kim } \\
\text { et al., 2005). }\end{array}$ \\
\hline 15 & $\begin{array}{l}\text { Business and IT alignment preconditions. The pre-M\&A business and IT alignment in the } \\
\text { respective merging organizations (e.g. Henningsson and Yetton, 2011). }\end{array}$ \\
\hline 16 & $\begin{array}{l}\text { Business understanding of IS development. The business manager's knowledge about IS } \\
\text { development challenges (e.g. Kim et al., 2005). }\end{array}$ \\
\hline 17 & $\begin{array}{l}\text { Business-based priorities. The extent to which business needs drives ISI decision-making (e.g. } \\
\text { Kovela and Skok, 2012). }\end{array}$ \\
\hline 18 & $\begin{array}{l}\text { Changes in policies and procedures. The extent of M\&A-related change in IS policies (e.g. } \\
\text { Stylianou et al., 1996). }\end{array}$ \\
\hline 19 & $\begin{array}{l}\text { Changes in workforce size. Increases and decreases in the number of IS staff (e.g. Stylianou et al., } \\
\text { 1996). }\end{array}$ \\
\hline 20 & $\begin{array}{l}\text { Cognitive sunk costs. The social and psychological costs associated with altering firm habits and } \\
\text { routines that prevent firms from seeing economically feasible alternative (e.g. Chun and Whitfield, } \\
2008 \text { ). }\end{array}$ \\
\hline 21 & Collaboration dynamics. The spirit of collaboration in the project team (e.g. LeFave et al., 2008). \\
\hline 22 & $\begin{array}{l}\text { Common ISI goals. The degree to which commonly accepted and realistic goals are established for } \\
\text { the ISI (e.g. Linder, 1989). }\end{array}$ \\
\hline 23 & $\begin{array}{l}\text { Communication of M\&A activities to IS. The effectiveness by which progress and plans of the } \\
\text { M\&A are shared with the IS function (e.g. Morsell et al., 2009). }\end{array}$ \\
\hline 24 & Company language. The language that is commonly used in the company (international vs local) \\
\hline
\end{tabular}




\begin{tabular}{|c|c|}
\hline & (e.g. Schoneville and Bouwman, 2012). \\
\hline 25 & $\begin{array}{l}\text { Company scale. The size of a company, as well as its market and operation (e.g. Schoneville and } \\
\text { Bouwman, 2012). }\end{array}$ \\
\hline 26 & Comparative analysis. Presence of comparative systems analysis (e.g. Seddon et al., 2010). \\
\hline 27 & $\begin{array}{l}\text { Competing business models. The extent of competition between the business models of the } \\
\text { merging organizations (e.g. Toppenberg, 2015). }\end{array}$ \\
\hline 28 & $\begin{array}{l}\text { Complexity being a criterion for ISI decision. The recognition of ISI method complexity } \\
\text { influencing ISI decision (e.g. Robbins and Stylianou, 1999). }\end{array}$ \\
\hline 29 & $\begin{array}{l}\text { Complexity. The overall complexity and therefore risk of an ISI method (e.g. Alaranta and Kautz, } \\
\text { 2012). }\end{array}$ \\
\hline 30 & $\begin{array}{l}\text { Comprehensiveness. Being exhaustive or inclusive in gathering information relevant to ISI } \\
\text { planning (e.g. Alaranta and Henningsson, 2008). }\end{array}$ \\
\hline 31 & $\begin{array}{l}\text { Corporate culture. The way a company and its employees conduct business, work together and } \\
\text { view their business operation and industry network (e.g. Schonewille and Bouwman, 2012). }\end{array}$ \\
\hline 32 & Cost focus. The cost for ISI as a decision-criteria (e.g. Mehta and Hirschheim, 2007). \\
\hline 33 & $\begin{array}{l}\text { Cost-efficient ICT. The existence of a pre-M\&A cost-efficient IT infrastructure (e.g. Parada et al., } \\
\text { 2009). }\end{array}$ \\
\hline 34 & Cost. The cost characteristics of an ISI method (e.g. Holm-Larsen, 2005). \\
\hline 35 & Credible deadlines. The establishment of credible and accepted deadlines (e.g. Linder, 1989). \\
\hline 36 & $\begin{array}{l}\text { Cross-business IT integration capability. The extent to which the acquirer combines the target's } \\
\text { system of complementary IT resources with its own and unifies them into a whole (e.g. Tanriverdi } \\
\text { and Uysal, 2011). }\end{array}$ \\
\hline 37 & $\begin{array}{l}\text { Culture clashes. The extent of cultural inconsistencies between the merging firms (e.g. Weber and } \\
\text { Pliskin, 1996). }\end{array}$ \\
\hline 38 & $\begin{array}{l}\text { Data integration. Level of data sharing across applications in combined organization (e.g. } \\
\text { Stylianou et al., 1996). }\end{array}$ \\
\hline 39 & $\begin{array}{l}\text { Decision process. The structure of the ISI decision process: Market, Negotiate, Cooperate (e.g. } \\
\text { Linder, 1989). }\end{array}$ \\
\hline 40 & $\begin{array}{l}\text { Decreases in IS staff compensation. M\&A-related limitation in the compensation to IS staff (e.g. } \\
\text { Stylianou et al., 1996). }\end{array}$ \\
\hline 41 & $\begin{array}{l}\text { Defined business strategy. Existence of a clearly specified business strategy for the M\&A (e.g. } \\
\text { Williams et al., 2015). }\end{array}$ \\
\hline 42 & Degree of ISI. The level to which IS are integrated in the M\&A (e.g. Weber and Pliskin, 1996). \\
\hline 43 & $\begin{array}{l}\text { Development and testing. Presence and quality of adequate IS development and testing (Kim et } \\
\text { al., 2005). }\end{array}$ \\
\hline 44 & $\begin{array}{l}\text { Diagnostic capability. The ability to design the mix of ISI methods that fits the M\&A (e.g. Yetton } \\
\text { et al., 2013). }\end{array}$ \\
\hline 45 & $\begin{array}{l}\text { Differences in management needs. The extent to which management in the merging organization } \\
\text { needs different input from IS (e.g. Giacomazzi et al., 1996). }\end{array}$ \\
\hline 46 & $\begin{array}{l}\text { Digital resource redeployment. The extent to which the acquirer's software is implemented in the } \\
\text { target after the acquisition (e.g. } \mathrm{Du}, 2015) \text {. }\end{array}$ \\
\hline 47 & $\begin{array}{l}\text { Discovery (Consistency). As opposed to planning consistency, the inclusion of emergent } \\
\text { variations in ISI plans throughout the ISI (e.g. Busquets, 2015). }\end{array}$ \\
\hline 48 & $\begin{array}{l}\text { Distributed decision-authority. The distribution of decision-making authority to the seasoned } \\
\text { people close to the ISI (e.g. Brown et al., 2003). }\end{array}$ \\
\hline 49 & $\begin{array}{l}\text { Division of integration task. The decomposition of the ISI project into a set of minor tasks (e.g. } \\
\text { Sumi and Tsuruoka, 2002). }\end{array}$ \\
\hline 50 & $\begin{array}{l}\text { EA capability. The extent to which the EA capability contributes to the ISI (e.g. Toppenberg et al., } \\
\text { 2015). }\end{array}$ \\
\hline 51 & $\begin{array}{l}\text { Economic climate. The state of the economy when a M\&A takes place (Schonewille and } \\
\text { Bouwman, 2012). }\end{array}$ \\
\hline 52 & Effort. The overall resources needed to complete an ISI method (e.g. Eckert et al., 2012). \\
\hline 53 & $\begin{array}{l}\text { End user involvement in ISI. Degree to which end-users are included in integration activities (e.g. } \\
\text { Morsell et al., 2009). }\end{array}$ \\
\hline 54 & $\begin{array}{l}\text { Enterprise systems (presence of). The presence of an integrated enterprise-wide IS (e.g. } \\
\text { Bhattacharya, 2016). }\end{array}$ \\
\hline 55 & Ex-post evaluation. Presence of activities to assess ISI after completion (e.g. Merali and \\
\hline
\end{tabular}




\begin{tabular}{|c|c|}
\hline & McKiernan, \\
\hline 56 & Existing IS-IT qualities. The qualities of pre-M\&A IS (e.g. Eckert et al., 2012). \\
\hline 57 & Expansion (shrinkage) of target. The changes in size of the target's business (e.g. Du, 2015). \\
\hline 58 & $\begin{array}{l}\text { Experience variation. The degree of disparity between a set of ISI experiences (e.g. Henningsson, } \\
\text { 2015). }\end{array}$ \\
\hline 59 & $\begin{array}{l}\text { Financial slack - Target. If the target produced a positive financial result pre-M\&A (e.g. Du, } \\
\text { 2015). }\end{array}$ \\
\hline 60 & $\begin{array}{l}\text { Flow. Top-down or bottom-up flow of decisions in ISI planning (e.g. Alaranta and Henningsson, } \\
\text { 2008). }\end{array}$ \\
\hline 61 & $\begin{array}{l}\text { Focus. Focus on creativity (opportunities) or control (risk) focus in ISI planning (e.g. Alaranta and } \\
\text { Henningsson, 2008). }\end{array}$ \\
\hline 62 & $\begin{array}{l}\text { For-profit status difference. Whether the transaction is between a for-profit organization and a } \\
\text { non-for-profit organization (e.g. } \mathrm{Du}, 2015) \text {. }\end{array}$ \\
\hline 63 & $\begin{array}{l}\text { Formalization. The presence of structures, techniques, written procedures, and policies to guide } \\
\text { the ISI planning (e.g. Alaranta and Henningsson, 2008). }\end{array}$ \\
\hline 64 & $\begin{array}{l}\text { Geographical distribution. The extent to which the merging organizations are distributed across } \\
\text { different geographical locations (e.g. Mehta and Hirschheim, 2007). }\end{array}$ \\
\hline 65 & $\begin{array}{l}\text { Geographical distribution of IS. The placement of IS activities in different locations (e.g. Hsu and } \\
\text { Chen, 2015). }\end{array}$ \\
\hline 66 & $\begin{array}{l}\text { Geographical distribution of IT. The extent to which IT hardware is located in different locations } \\
\text { (e.g. Robbins and Stylianou, 1999). }\end{array}$ \\
\hline 67 & $\begin{array}{l}\text { Geographical relatedness. Extent to the merging organizations are present in the same physical } \\
\text { locations (e.g. Du, 2015). }\end{array}$ \\
\hline 68 & Habits and practice. The presence of socially resilient pre-M\&A practices (e.g. Vieru et al., 2016). \\
\hline 69 & $\begin{array}{l}\text { High profitability and high-growth firm. The combination of high profitability and growth pre- } \\
\text { M\&A (e.g. Tanriverdi and Uysal, 2015). }\end{array}$ \\
\hline 70 & $\begin{array}{l}\text { High profitability and low-growth firm. The combination of high profitability and low growth pre- } \\
\text { M\&A (e.g. Tanriverdi and Uysal, 2015). }\end{array}$ \\
\hline 71 & $\begin{array}{l}\text { HR management. The requirements and aspects of human relations management during and after } \\
\text { the migration in terms of effective IS usage (e.g. Steininger et al., 2016a). }\end{array}$ \\
\hline 72 & $\begin{array}{l}\text { Implementation capability. The ability to deploy IT resources to realize ISI (e.g. Yetton et al., } \\
\text { 2013). }\end{array}$ \\
\hline 73 & $\begin{array}{l}\text { Inclusion of IT staff. The extent of participation of IS staff in the ISI planning (e.g. Alaranta and } \\
\text { Henningsson, 2008). }\end{array}$ \\
\hline 74 & $\begin{array}{l}\text { Inclusion of key IT staff in ex-post integration. The assignment of ISI tasks to the most skilled IS } \\
\text { employees (e.g. Al Suliman, 2015). }\end{array}$ \\
\hline 75 & $\begin{array}{l}\text { Industry characteristics. Features of the industry in which the M\&A takes place (e.g. Toppenberg, } \\
\text { 2015). }\end{array}$ \\
\hline 76 & $\begin{array}{l}\text { Industry relatedness. If the organizations operate in the same industry (e.g. Tanriverdi and Uysal, } \\
\text { 2015). }\end{array}$ \\
\hline 77 & $\begin{array}{l}\text { Information security management. The degree to which security culture is managed throughout the } \\
\text { ISI (e.g. Dhillon et al., 2016). }\end{array}$ \\
\hline 78 & Integration cost. M\&A-related restructuring and integration costs (e.g. Tafti, 2009). \\
\hline 79 & $\begin{array}{l}\text { IS configuration fit. The degree of compatibility between IS configurations, drawing on the } \\
\text { MIT'90s schema (Scott Morton, 1991) (e.g. Johnson and Yetton, 1996). }\end{array}$ \\
\hline 80 & $\begin{array}{l}\text { IS culture integration. The extent to which IS cultures of the combined organizations are } \\
\text { integrated (e.g. Baker and Niederman, 2014). }\end{array}$ \\
\hline 81 & IS employee morale. IS employees' spirit and belief in ISI (e.g. Stylianou et al., 1996). \\
\hline 82 & $\begin{array}{l}\text { ISI area of application. The extent to which applications of the combined organizations are } \\
\text { integrated (e.g. Alaranta and Martela, 2012). }\end{array}$ \\
\hline 83 & $\begin{array}{l}\text { ISI area of personnel. The extent to which IS personnel of the combined organizations are } \\
\text { integrated (e.g. Alaranta and Martela, 2012). }\end{array}$ \\
\hline 84 & $\begin{array}{l}\text { ISI process. The quality of the administrative IS supported processes in general and specifically } \\
\text { for the M\&A project (e.g. Steininger et al., 2016a). }\end{array}$ \\
\hline 85 & IS morale. The extent to which IS staff morale is critical to the project (e.g. Seddon et al., 2010). \\
\hline 86 & $\begin{array}{l}\text { IS organizational compatibility. The compatibility of organizational structures and cultures within } \\
\text { the merging IS functions (e.g. Lin and Chao, 2008). }\end{array}$ \\
\hline
\end{tabular}




\begin{tabular}{|c|c|}
\hline 87 & $\begin{array}{l}\text { IS perception. The credibility of the IS function among business functions (e.g. Yetton et al., } \\
\text { 2013). }\end{array}$ \\
\hline 88 & IS performance. The quality and performance of the pre-M\&A IS (e.g. Steininger, 2016a). \\
\hline 89 & IS planning. The general approach taken to IS planning (e.g. Robbins and Stylianou, 1999). \\
\hline 90 & IS staff motivation. Availability of motivated IS staff (e.g. Kovela and Skok, 2012). \\
\hline 91 & IS strategy. General pre-M\&A IS strategy (e.g. Gregory et al., 2012). \\
\hline 92 & $\begin{array}{l}\text { IS strategy compatibility. The compatibility between the merging organizations IS strategies (e.g. } \\
\text { Johnston and Yetton, 1996). }\end{array}$ \\
\hline 93 & $\begin{array}{l}\text { IS-business collaboration in planning. Degree of IS participation in M\&A planning (e.g. Morsell } \\
\text { et al., 2009). }\end{array}$ \\
\hline 94 & $\begin{array}{l}\text { ISI capability. A higher-order construct determined by IT technical infrastructure integration, IT } \\
\text { personnel integration, and IT and business processes integration capabilities (e.g. Benitez-Amado } \\
\text { and Ray, 2012). }\end{array}$ \\
\hline 95 & $\begin{array}{l}\text { ISI expertise. A conceptual framework for interpreting acquisition ISI experiences (e.g. } \\
\text { Henningsson, 2015). }\end{array}$ \\
\hline 96 & $\begin{array}{l}\text { ISI implementation speed. The time needed to complete integration with the right functionality } \\
\text { (e.g. Kovela and Skok, 2012). }\end{array}$ \\
\hline 97 & $\begin{array}{l}\text { ISI method. The fundamental approach used to combine the IS of the merging organization (e.g. } \\
\text { Henningsson and Kettinger, 2016). }\end{array}$ \\
\hline 98 & $\begin{array}{l}\text { ISI objectives. The strategic objectives assigned to the IS function in the M\&A (e.g. Wijnhoven et } \\
\text { al., 2006). }\end{array}$ \\
\hline 99 & $\begin{array}{l}\text { ISI proactivity (vs reactivity). The degree to which IS facilitate organizational change or } \\
\text { contribute to deal motivation (e.g. McKiernan and Merali, 1995). }\end{array}$ \\
\hline 100 & $\begin{array}{l}\text { ISI routines. A coordinated, repetitive set of organizational activities for implementing ISI } \\
\text { (Henningsson, 2015). }\end{array}$ \\
\hline 101 & ISI skill. The involved organizations' available skills for addressing ISI (e.g. Kim et al., 2005). \\
\hline 102 & ISI speed. The time need for ISI as a decision-criterion (e.g. Garcia-Canal et al., 2013). \\
\hline 103 & $\begin{array}{l}\text { IT communication. Communication between IS function and other organizational units during the } \\
\text { ISI (e.g. Morsell et al., 2009). }\end{array}$ \\
\hline 104 & $\begin{array}{l}\text { IT culture conflict management. The extent to which the merging organizations effectively } \\
\text { manage cultural conflicts between the merging IS functions (e.g. Lin and Chao, 2008). }\end{array}$ \\
\hline 105 & IT extensiveness. The relative scale of IT assets compared to organizational size (e.g. Du, 2015). \\
\hline 106 & $\begin{array}{l}\text { IT flexibility. The IT assets' ability to support change in use, commonly compatibility, } \\
\text { connectivity, modularity (e.g. Benitez-Amado and Ray, 2012). }\end{array}$ \\
\hline 107 & $\begin{array}{l}\text { IT governance mode. Whether an acquired unit is allowed to make independent IT investment } \\
\text { decisions (e.g. Du, 2015). }\end{array}$ \\
\hline 108 & IT in charge. IT (vs business) in charge of ISI decision (e.g. Kim et al., 2005). \\
\hline 109 & $\begin{array}{l}\text { IT infrastructure. A general construct for the characteristics of the existing IT infrastructure (e.g. } \\
\text { Wijnhoven et al., 2006). }\end{array}$ \\
\hline 110 & ISI team. The qualities of the ISI team (e.g. Alaranta and Kautz, 2012). \\
\hline 111 & IT investment at target. The amount invested annually in the target (e.g. Tafti, 2009). \\
\hline 112 & $\begin{array}{l}\text { IT investment in acquirer. The amount invested annually pre-M\&A in the acquirer (e.g. Tafti, } \\
\text { 2009). }\end{array}$ \\
\hline 113 & $\begin{array}{l}\text { IT leadership in integration project. Quality of the managerial direction during the ISI (e.g. } \\
\text { Alaranta and Martela, 2012). }\end{array}$ \\
\hline 114 & IT standardization. The entropy of IT assets (e.g. Du, 2015). \\
\hline 115 & $\begin{array}{l}\text { Joint sourcing. The decision to source IS through the combined organization (e.g. Seddon et al., } \\
2010) \text {. }\end{array}$ \\
\hline 116 & $\begin{array}{l}\text { Language support. The pre-M\&A IS' ability for multi-language support (e.g. Mehta and } \\
\text { Hirschheim, 2007). }\end{array}$ \\
\hline 117 & Leadership. Quality of managerial leadership in the M\&A (e.g. Williams et al., 2015). \\
\hline 118 & Legislation. The legal framework impacting the ISI (Schonewille and Bouwman, 2012). \\
\hline 119 & $\begin{array}{l}\text { Level of data sharing pre-M\&A. The level of data sharing in the organizations pre-M\&A (e.g. } \\
\text { Robbins and Stylianou, 1999). }\end{array}$ \\
\hline 120 & $\begin{array}{l}\text { Level of location integration. The extent to which the merging organization is established in } \\
\text { shared physical locations (e.g. Wijnhoven et al., 2006). }\end{array}$ \\
\hline
\end{tabular}




\begin{tabular}{|c|c|}
\hline 121 & Leverage of existing teams. The use of pre-existing project teams (e.g. Brown et al., 2003). \\
\hline 122 & $\begin{array}{l}\text { Leverage of increased purchasing power. Use of ability of the combined organization to improve } \\
\text { purchasing conditions (e.g. Brown et al., 2003). }\end{array}$ \\
\hline 123 & $\begin{array}{l}\text { Long-term integration vision. The extent of long-term considerations influencing ISI decision (e.g. } \\
\text { Merali and McKiernan, 1993). }\end{array}$ \\
\hline 124 & $\begin{array}{l}\text { Low profitability and high-growth firm. The combination of low profitability and high growth pre- } \\
\text { M\&A (e.g. Tanriverdi and Uysal, 2015). }\end{array}$ \\
\hline 125 & $\begin{array}{l}\text { M\&A context (general). A structural element including ISI method, distribution of decision } \\
\text { making, IS/business alignment and the role of the IS in the M\&A (e.g. Alaranta and Kautz, 2012). }\end{array}$ \\
\hline 126 & M\&A experience. The organization's previous M\&A experiences (e.g. Du, 2015). \\
\hline 127 & M\&A motivation. The business reasons why the M\&A was decided on (e.g. Myers, 2008). \\
\hline 128 & $\begin{array}{l}\text { M\&A type. The nature of the M\&A, hostile vs friendly combination (e.g. Schonewille and } \\
\text { Bouwman, 2012). }\end{array}$ \\
\hline 129 & MA frequency. How often the merging parties are involved in M\&As (e.g. Henningsson, 2015). \\
\hline 130 & $\begin{array}{l}\text { Management style. The most dominant and accepted way managers act and behave, including how } \\
\text { they plan, communicate, prioritize and make their decisions (e.g. Schonewille and Bouwman, } \\
\text { 2012). }\end{array}$ \\
\hline 131 & Modularity. The level of modularization of an IT infrastructure (e.g. Henningsson et al., 2006). \\
\hline 132 & $\begin{array}{l}\text { Need for organizational transformation. Pre-M\&A accumulated need to restructure and reengineer } \\
\text { the company (e.g. Gregory et al., 2012). }\end{array}$ \\
\hline 133 & $\begin{array}{l}\text { Novelty. As opposed to familiarity, the merging organizations' experience and/or access to } \\
\text { knowledge of an ISI method (e.g. Henningsson and Kettinger, 2016). }\end{array}$ \\
\hline 134 & $\begin{array}{l}\text { Operational uniformity. The way the business operations executed across different units and } \\
\text { divisions (e.g. Schonewille and Bouwman, 2012). }\end{array}$ \\
\hline 135 & $\begin{array}{l}\text { Organizational integration objectives. The ambition to structurally combine elements from the } \\
\text { merging parties (e.g. Henningsson and Carlsson, 2011). }\end{array}$ \\
\hline 136 & $\begin{array}{l}\text { Organizational change management. The extent to which the merging organizations effectively } \\
\text { manage change (e.g. Baker and Niederman, 2014). }\end{array}$ \\
\hline 137 & $\begin{array}{l}\text { Organizational competency fit. The match of performance levels of the organizations (e.g. Glazar- } \\
\text { Stavnicky, 2016). }\end{array}$ \\
\hline 138 & Organizational infrastructure. Organizational conditions and priorities (Wijnhoven et al., 2007). \\
\hline 139 & $\begin{array}{l}\text { Organizational M\&A planning. Quality of the planning for the organizational integration (e.g. } \\
\text { Robbins and Stylianou, 1999). }\end{array}$ \\
\hline 140 & $\begin{array}{l}\text { Organizational process fit. The match between organizational process efficiency (e.g. Glazar- } \\
\text { Stavnicky, 2016). }\end{array}$ \\
\hline 141 & $\begin{array}{l}\text { Organizational structure. The division of the organization into units or functions (e.g. Seddon et } \\
\text { al., 2010). }\end{array}$ \\
\hline 142 & Organizational uniformity. The match of organizational characteristics (e.g. Linder, 1989). \\
\hline 143 & $\begin{array}{l}\text { Outsourcing. Degree of outsourcing in place at the time of the M\&A (e.g. Robbins and Stylianou, } \\
\text { 1999). }\end{array}$ \\
\hline 144 & $\begin{array}{l}\text { Planning style. The way a company and its employees execute plans and undertake scheduling } \\
\text { (e.g. Schonewille and Bouwman, 2012). }\end{array}$ \\
\hline 145 & $\begin{array}{l}\text { Political considerations. The extent to which political considerations drive ISI decision-making } \\
\text { (e.g. Stylianou et al., 1996). }\end{array}$ \\
\hline 146 & Power and politics. Strategizing for control of the M\&A process (e.g. Kovela and Skok, 2012). \\
\hline 147 & $\begin{array}{l}\text { Pre-existing business-IT relations. Established working relationships between IS and business } \\
\text { functions (e.g. Seddon et al., 2010). }\end{array}$ \\
\hline 148 & $\begin{array}{l}\text { Pre-M\&A alignment. The way a company positions IT within its organization (e.g. Schonewille } \\
\text { and Bouwman, 2012). }\end{array}$ \\
\hline 149 & $\begin{array}{l}\text { Pre-M\&A organizational performance. The pre-M\&A financial performance of the organization } \\
\text { (e.g. Schonewille and Bouwman, 2012). }\end{array}$ \\
\hline 150 & $\begin{array}{l}\text { Prior ISI experience. The IS-related experiences made from the partners' previous M\&As (e.g. } \\
\text { Benitez-Amado and Ray, 2012). }\end{array}$ \\
\hline 151 & $\begin{array}{l}\text { Prioritization of customer-facing applications. If the prioritization of customer-facing applications } \\
\text { is a decision criteria (e.g. Brown et al., 2003). }\end{array}$ \\
\hline 152 & $\begin{array}{l}\text { Professional approach. The way a company and its employees approach their jobs and the } \\
\text { expertise that is required, the way issues are addressed and what is considered important (e.g. }\end{array}$ \\
\hline
\end{tabular}


Schonewille and Bouwman, 2012).

153 Project governance approach. The approach used to govern the ISI project (e.g. Henningsson et al., 2016).

154 Project management (of ISI) skills. The ability to manage an ISI project (e.g. Wynne, 2016).

155 Quality of ISI planning. The contribution of IS activities to the overall M\&A schedule (e.g. Morsell et al., 2009).

156 Realistic budget and targets. Avoidance of overly aggressive targets (e.g. Kovela and Skok, 2012).

157 Related experiences. Activities that have shared sub-activities or cognitive proximity with ISI (e.g. Henningsson, 2015).

158 Relative IT capability. The gap between the IT capabilities of the M\&A organizations (e.g. Tanriverdi and Uysal 2015).

159 Relative size. Relative organizational size (e.g. Du, 2015).

160 Relocation cost minimization. Efficiency of measures to avoid costs relating to the move of physical technology assets (e.g. Brown et al., 2003).

161 Reporting and documentation. Documentation of the IS changes (e.g. Kim et al., 2005).

162 Retention packages. The provision of compensation to top talent (e.g. Brown et al., 2003).

163 Risk management. The level of dedicated effort to manage risk (e.g. Henningsson and Kettinger, 2016).

164 Same IT-user organization. M\&A partners' participation in the same IT-user organization (e.g. Wijnhoven et al., 2006).

165 Search for similar operational logic. Ambitions to realize standardized operational practices (e.g. Giacomazzi et al., 1997).

166 Shareholder return. Whether or not shareholders benefit from the M\&A (e.g. Schonewille and Bouwman, 2012).

167 Short-term considerations. The degree to which short-term considerations override initial management actions (e.g. Robertson and Powell, 2001).

168 Simplicity of integration. The ease through which the ISI between the merging organizations can be accomplished (e.g. Giacomazzi et al., 1996).

169 Slow response to requirements changes. Failure to adapt to changes in demands (e.g. Kim et al., 2015).

170 Social context. The social relations among the project participants; their social infrastructure; history of the ISI, as well as previous procedures, structures, and commitments (e.g. Alaranta and Kautz, 2012).

171 Speed. The time characteristics of an ISI method (e.g. Robertson and Powell, 2001).

172 Stakeholder collaboration. Willingness of stakeholders in the M\&A to collaborate (e.g. Williams et al., 2015).

173 State of mind. The way a company and its employees feel about their position and value in the market (e.g. Schonewille and Bouwman, 2012).

174 System size/complexity. System size and complexity being drivers for ISI decision-making (e.g. Stylianou et al., 1996).

175 Systems capability fit. The similarity between revenue per IT investment and IT employee (e.g. Glazar-Stavnicky, 2016).

176 Systems importance for business. The importance of the system being integrated to business (e.g. Wijnhoven et al., 2006).

177 Systems novelty for users. Unfamiliarity with the post-M\&A IS (e.g. Kim et al., 2005).

178 Systems technology fit. The similarity between investment levels in PC, Server, Printer, Storage, and Network lines (e.g. Glazar-Stavnicky, 2016).

179 Target age. The number of years since the target was formed (e.g. Du, 2015).

180 Target size. In the hospital context, number of beds covered (e.g. Du, 2015).

181 Target's IT capability. The general IT capability of the acquired firm (e.g. Tanriverdi and Uysal, 2011).

182 Teaching status. If the hospital is a teaching hospital or not (e.g. Du, 2015).

183 Time pressure. Time pressure caused by internal or external sources to complete ISI (e.g. Mehta and Hirschheim, 2007).

184 Top management steering. Top-management exertion of power in specific ISI decisions (e.g. Alaranta and Kautz, 2012). 


\begin{tabular}{|c|l|}
\hline 185 & $\begin{array}{l}\text { Top management support. The extent of top management's commitment to the ISI (e.g. Kim et al., } \\
\text { 2005). }\end{array}$ \\
\hline 186 & $\begin{array}{l}\text { Use of decision criteria. The application of clear criteria and quantitative evaluations to make } \\
\text { decisions (e.g. LeFave } \text { et al., 2008). }\end{array}$ \\
\hline 187 & $\begin{array}{l}\text { Use of external resources. The extent to which external resources, typically sourced as consultants, } \\
\text { contribute to the ISI (e.g. Henningsson and Øhrgaard, 2016). }\end{array}$ \\
\hline 188 & Use of pre-packaged solutions. The use of off-the-shelf solutions (e.g. Sumi and Tsuruoka, 2002). \\
\hline 189 & $\begin{array}{l}\text { User involvement in ISI decisions. The degree to which users are incorporated in ISI decision- } \\
\text { making (e.g. Wijnhoven et al., 2006). }\end{array}$ \\
\hline 190 & $\begin{array}{l}\text { User resistance. The users' attitude and possible resistance to change (e.g. Alaranta and Kautz, } \\
\text { 2012). }\end{array}$ \\
\hline 191 & User skills. The users' abilities to use the post-M\&A IS (e.g. Alaranta and Kautz, 2012). \\
\hline 192 & $\begin{array}{l}\text { User training and support. Means for enabling users to transition to the combined IS (e.g. Alaranta } \\
\text { and Kautz, 2012). }\end{array}$ \\
\hline 193 & $\begin{array}{l}\text { Vague or changing requirements. Ambiguous or recurrently re-specified demands on ISI (e.g. } \\
\text { Alaranta and Kautz, 2012). }\end{array}$ \\
\hline 194 & $\begin{array}{l}\text { Vendor carve-out strategy. The approach by the vendor to carve out the unit being transacted (e.g. } \\
\text { Böhm et al., 2011). }\end{array}$ \\
\hline 195 & $\begin{array}{l}\text { Vendor's knowledge. The competence of the suppliers of the merged organization in the selected } \\
\text { technologies (e.g. Alaranta and Kautz, 2012). }\end{array}$ \\
\hline
\end{tabular}


TABLE B2. Dependent master variables

\begin{tabular}{|c|c|}
\hline \# & Dependent master variable \\
\hline 1 & $\begin{array}{l}\text { Alignment between processes. Fit between the choice of organizational integration process and ISI } \\
\text { process (e.g. Baker and Niederman, 2014). }\end{array}$ \\
\hline 2 & $\begin{array}{l}\text { Avoidance of M\&A problems. The degree to which the IS function manages to avert obstacles in } \\
\text { the integration process (e.g. Stylianou et al., 1996). }\end{array}$ \\
\hline 3 & $\begin{array}{l}\text { Capability preservation. The extent to which unique and valuable capabilities in the target are } \\
\text { preserved post-M\&A (e.g. Henningsson and Kettinger, 2016). }\end{array}$ \\
\hline 4 & Cost reduction. Post-M\&A cost efficiency (e.g. Holm-Larsen, 2005). \\
\hline 5 & $\begin{array}{l}\text { Digital resource redeployment. The extent to which the acquirer's software is implemented in the } \\
\text { target after the acquisition (e.g. } \mathrm{Du}, 2015) \text {. }\end{array}$ \\
\hline 6 & $\begin{array}{l}\text { Enterprise integration. The integration of disparate information systems operated by the companies } \\
\text { involved (e.g. Schonewille and Bouwman, 2012). }\end{array}$ \\
\hline 7 & $\begin{array}{l}\text { Exploitation of M\&A opportunities. The extent to which ISI enables realization of M\&A } \\
\text { objectives (e.g. Stylianou et al., 1996). }\end{array}$ \\
\hline 8 & $\begin{array}{l}\text { Growth opportunities. New possibilities to extend business enabled by the M\&A (e.g. Holm- } \\
\text { Larsen, 2005). }\end{array}$ \\
\hline 9 & $\begin{array}{l}\text { Integrated systems quality. IS and end-user assessment of the quality of the post-M\&A IS in the } \\
\text { combined organization (e.g. Stylianou et al., 1996). }\end{array}$ \\
\hline 10 & $\begin{array}{l}\text { Integration approach. A composite construct including include absorption versus best-of-breed, } \\
\text { phasing versus quick wins, investment versus expedience, and the degree of integration required } \\
\text { (e.g. Robertson and Powell, 2001). }\end{array}$ \\
\hline 11 & $\begin{array}{l}\text { Integration architecture. The decision on architecture to implement ISI (e.g. Henningsson and } \\
\text { Carlsson, 2011). }\end{array}$ \\
\hline 12 & IS credibility. The organizational perception of the IS function's abilities (e.g. Al Suliman, 2015). \\
\hline 13 & $\begin{array}{l}\text { IS performance. How well the post-M\&A IS function supports the combined organization (e.g. } \\
\text { Robbins and Stylianou, 1999). }\end{array}$ \\
\hline 14 & $\begin{array}{l}\text { IS quality. The malfunction of computer systems that occurs as a result of a disagreement between } \\
\text { the components involved in the ISI (e.g. Kim et al., 2005). }\end{array}$ \\
\hline 15 & $\begin{array}{l}\text { IS security culture. The behaviour, values, and assumptions, which ensure information security } \\
\text { (e.g. Dhillon et al., 2016). }\end{array}$ \\
\hline 16 & $\begin{array}{l}\text { IS staff. Demoralization and loss of able employees in the IS function (e.g. McKiernan and Merali, } \\
\text { 1995). }\end{array}$ \\
\hline 17 & $\begin{array}{l}\text { IS structure. The configuration of the IS function and the locus of responsibility for IS } \\
\text { management decision (e.g. Mehta and Hirschheim, 2007). }\end{array}$ \\
\hline 18 & $\begin{array}{l}\text { IS synergies. Synergies, including reduced cost, realized by consolidating the IS of the merging } \\
\text { companies (e.g. Johnson and Yetton, 1996). }\end{array}$ \\
\hline 19 & $\begin{array}{l}\text { IS transaction success. The resources needed to carve out and integrate IS in an organizational } \\
\text { transaction (e.g. Böhm et al., 2011). }\end{array}$ \\
\hline 20 & $\begin{array}{l}\text { IS-business relation. The partnership between business and IS managers in the combined } \\
\text { organization (e.g. Main and Short, 1989). }\end{array}$ \\
\hline 21 & $\begin{array}{l}\text { ISI area - Offering. The extent to which the particular business area of offering (product) is subject } \\
\text { to technological integration (e.g. Toppenberg, 2015). }\end{array}$ \\
\hline 22 & $\begin{array}{l}\text { ISI area - R\&D. The extent to which the particular business area of R\&D is integrated through IS } \\
\text { (e.g. Toppenberg, 2015). }\end{array}$ \\
\hline 23 & $\begin{array}{l}\text { ISI capabilities. The post-M\&A ability for ISI in subsequent M\&As (e.g. Henningsson and } \\
\text { Øhrgaard, 2016). }\end{array}$ \\
\hline 24 & ISI cost. The resource required to complete ISI (e.g. Holm-Larsen, 2005). \\
\hline 25 & $\begin{array}{l}\text { ISI degree. The decision on level to which IS are integrated in the M\&A (e.g. Weber and Pliskin, } \\
\text { 1996). }\end{array}$ \\
\hline 26 & ISI effectiveness. How well the ISI supports the M\&A project (e.g. Linder, 1989). \\
\hline 27 & $\begin{array}{l}\text { ISI efficiency. How well time, personnel and financial resources were used in the ISI (e.g. Morsell } \\
\text { et al., 2009). }\end{array}$ \\
\hline
\end{tabular}


28 ISI levels. Denotes the levels of systems to be integrated, distinguishing between infrastructural, transactional, informational and strategic IS (e.g. Henningsson and Carlsson, 2011).

29 ISI method. The decision on approach used to combine the IS of the merging organization (e.g Wijnhoven et al., 2006).

30 ISI process quality. IS and end-user assessment of the process by which IS were integrated (e.g. Stylianou et al., 1996).

31 ISI strategy. A combination of the standardization and centralization in IS aimed at during the M\&A (e.g. Giacomazzi et al., 1997).

32 ISI success. A general construct representing the extent to which ISI met objectives and requirements (e.g. Al Suliman, 2015).

33 ISI time. Time used to complete the combination of IS (e.g. Garcia-Canal et al., 2013)..

34 IT infrastructure. Characteristics of the post-M\&A IT assets that enable or hinder organizational performance (e.g. McKiernan and Merali, 1995).

35 IT spending. The combined firm's IT intensity ratio after the M\&A (e.g. Glazar-Stavnicky, 2016).

36 Knowledge coverage. As opposed to knowledge gaps, the consistency of knowledge creation, knowledge storage/retrieval, knowledge transfer and knowledge application (e.g. Alaranta and Martela, 2012).

37 M\&A success. A general construct indicating the extent to which ISI supports the M\&A ambitions (e.g. Williams et al., 2015).

38 M\&A synergies. The post-M\&A combination effects including economies of scale and scope, process improvement, growth and renewal (e.g. Busquets, 2015).

39 Migration scenario. Detailed plans for how to combine IS that includes systems selection and vendor offerings to realize them (e.g. Steininger et al., 2016b).

40 Operating performance. Cost-efficiency and profitability of the merged organization (e.g. Parada et al., 2009).

41 Organizational integration. The extent to which the combined organization functions as a whole (e.g. Mehta and Hirschheim, 2007).

42 Organizational performance. The long-term performance of the merged organization, including the sustained return on assets (ROA) (e.g. Tafti, 2009).

43 Post-M\&A alignment. The level of business-IT alignment after the ISI (e.g. McKiernan and Merali, 1995).

44 Post-M\&A IS strategy. The IS strategy employed after the M\&A by the combined organization (e.g. Gregory et al., 2012).

45 Post-M\&A IS success. Drawing on IS success, the success of IS in the post-M\&A organization (e.g. Steininger, 2016a).

46 Sales increase. Revenue enhancements post-M\&A (e.g. Holm-Larsen, 2005).

47 Spirit (non IS). The morale of general employees (not IS) (e.g. Henningsson et al., 2006).

48 Stock market reaction. The effect on the share price, commonly measured as cumulative abnormal returns (CAR) at the time of M\&A announcement (e.g. Tanriverdi and Uysal, 2011).

49 Sustainable growth. The ability for continued organic and acquisition-based growth (e.g. Toppenberg et al., 2015).

50 Systems functionality. The final functionality of the integrated IS (e.g. Vieru and Rivard, 2014).

51 Target's efficiency improvement. The average cost per case-mix-adjusted discharges in a hospital, before and after an acquisition (e.g. Du, 2015). .

52 Target's quality improvements. The quality of care delivery process based on 20 process-of-care quality indicators, before and after an acquisition (e.g. Du, 2015).

53 User acceptance and satisfaction. As opposed to user resistance, the extent to which users welcome and support the ISI scenario (e.g. Vieru and Trudel, 2013). 


\section{Appendix C. Dependent and independent variables in the review}

\section{Dependent Variables}

We identify 53 different dependent variables (Table C.1). Following Lacity et al. (2010;

2011; 2016), we distinguish between decision and outcome variables. Decision variables

refer to the options to implement ISI. Outcome variables capture the various costs and

benefits contingent on the ISI project. Twenty-seven percent of the findings refer to

relationships that predict the choice of ISI decisions. Seventy-three percent of relationships

concern the outcomes of ISI decisions.

TABLE C.1. Dependent variables used in research on ISI in mergers

\begin{tabular}{|c|c|c|}
\hline ISI DECISION VARIABLES & FREQ. & COMMENT \\
\hline ISI method & 79 & \multirow{15}{*}{$\begin{array}{l}\text { ISI research investigates: what to integrate, and how to integrate } \\
\text { (Henningsson and Kettinger, 2016) } \\
\text { primarily investigated with variables relating to the degree of } \\
\text { integration (Giacomazzi } \text { et al., 1997; Wijnhoven } \text { et al., 2006), the } \\
\text { digital resource redeployment (Du, 2015) and the integration area } \\
\text { (Brown et al., 2003; Eckert et al., 2012). The degree of } \\
\text { integration refers to the continuum between separated } \\
\text { independent IS and fully integrated IS. The digital resource } \\
\text { redeployment captures the extent to which software from one } \\
\text { organization is implemented in the other organization (Du, 2015). } \\
\text { The integration area includes variables referring to specific IS } \\
\text { areas that are subject to integration efforts, including applications, } \\
\text { infrastructural technology, strategies, personnel, and practices. }\end{array}$} \\
\hline Degree of ISI & 30 & \\
\hline Digital resource redeployment & 17 & \\
\hline Enterprise integration & 15 & \\
\hline ISI strategy & 10 & \\
\hline ISI levels & 5 & \\
\hline Integration approach & 3 & \\
\hline Post-M\&A IS strategy & 3 & \\
\hline Migration scenario & 3 & \\
\hline Integration architecture & 2 & \\
\hline Systems functionality & 1 & \\
\hline ISI area $-\mathrm{R} \& \mathrm{D}$ & 1 & \\
\hline ISI area - Offering & 1 & \\
\hline Alignment between processes & 1 & \\
\hline IS structure & 1 & \\
\hline Total ISI decision variables & 172 & \\
\hline
\end{tabular}

\begin{tabular}{|l|l|l|}
\hline ISI OUTCOME VARIABLES & FREQ. & \\
\hline ISI project & & \\
\hline
\end{tabular}

\footnotetext{
${ }^{3}$ The 'what', 'how' and 'when' of ISI in M\&A was the subject of a presentation by Carol Brown given in conjunction with ECIS 2011 in Helsinki.
} 


\begin{tabular}{|c|c|c|}
\hline ISI success & 49 & \multirow{11}{*}{$\begin{array}{l}\text { In this category, variables is directly associated with the ISI project. } \\
\text { Some articles use a broadly defined ISI success variable (Stylianou } \\
\text { et al., 1996), some focus on specific aspects of the project, } \\
\text { including time, cost and user satisfaction (Unkan and Thönssen, } \\
\text { 2015), and others investigate the IS synergies created by the } \\
\text { integration project (Johnston and Yetton, 1996). }\end{array}$} \\
\hline ISI process quality & 32 & \\
\hline Integrated systems quality & 32 & \\
\hline ISI effectiveness & 20 & \\
\hline ISI time & 18 & \\
\hline IS synergies & 11 & \\
\hline ISI efficiency & 10 & \\
\hline ISI cost & 9 & \\
\hline User acceptance and satisfaction & 5 & \\
\hline IS transaction success & 1 & \\
\hline \multicolumn{2}{|l|}{ M\&A project } & \\
\hline M\&A synergies & 50 & \multirow{8}{*}{$\begin{array}{l}\text { A broader perspective on outcome investigates the outcome of ISI } \\
\text { in terms of the impact on the integration project as a whole. Here, } \\
\text { beyond the frequently employed conceptualization of ISI success, } \\
\text { both the impact on general M\&A synergies (for example, } \\
\text { economies of scale or scope) enabled by ISI, and capability } \\
\text { destruction contingent on IS re-deployment are studied (Myers, } \\
\text { 2008; Henningsson et al., 2016). }\end{array}$} \\
\hline M\&A success & 25 & \\
\hline Exploit M\&A opportunities & 16 & \\
\hline Avoid M\&A problems & 16 & \\
\hline Sales increase & 1 & \\
\hline Cost reduction & 1 & \\
\hline Capability preservation & 1 & \\
\hline Growth opportunities & 1 & \\
\hline \multicolumn{3}{|l|}{ IS organization } \\
\hline IS quality & 18 & \multirow{12}{*}{$\begin{array}{l}\text { Research on the effects on the long-term impact on the IS } \\
\text { organization beyond the specific M\&A project focus on either the } \\
\text { long-term impact on the IS organization or on the organization as a } \\
\text { whole. Variables used to investigate the performance of the IS } \\
\text { organization include general IS capabilities (Robbins and Stylianou, } \\
\text { 1999), IT infrastructure (McKiernan and Merali, 1995), IS } \\
\text { employee morale (LeFave et al., 2008), and the development of } \\
\text { capabilities to conduct subsequent ISI projects (Henningsson and } \\
\text { Øhrgaard, 2016). }\end{array}$} \\
\hline IS staff & 10 & \\
\hline IT infrastructure & 9 & \\
\hline Knowledge coverage & 7 & \\
\hline IT spending & 7 & \\
\hline ISI capabilities & 6 & \\
\hline IS credibility & 4 & \\
\hline Post-M\&A IS success & 4 & \\
\hline IS-business relation & 3 & \\
\hline IS performance & 2 & \\
\hline IS security culture & 2 & \\
\hline Post-M\&A alignment & 1 & \\
\hline \multicolumn{3}{|l|}{ Org. performance } \\
\hline Organizational performance & 20 & \multirow{8}{*}{$\begin{array}{l}\text { Dependent variables to capture the long-term effects on the } \\
\text { organization include operating performance (Tafti, 2009) and the } \\
\text { potential to sustain a growth strategy (Toppenberg et al., 2015). }\end{array}$} \\
\hline Stock market reaction & 15 & \\
\hline Sustainable growth & 14 & \\
\hline Operating performance & 13 & \\
\hline Target's efficiency improvement & 6 & \\
\hline Target's quality improvements & 6 & \\
\hline Spirit (non IS) & 1 & \\
\hline Organizational integration & 1 & \\
\hline Total ISI outcome variables & 447 & \\
\hline
\end{tabular}




\section{Independent Variables}

Our investigation identified 195 independent variables in the extant literature on ISI. To

facilitate the analysis and discussion of this number of variables, we group them into 12

clusters and sort them by frequency of use (Table C.2).

TABLE C.2. Independent variables

\begin{tabular}{|c|c|c|}
\hline VARIABLE & FREQ. & COMMENT \\
\hline \multicolumn{3}{|l|}{ ISI implementation } \\
\hline Changes in workforce size & 12 & \multirow{32}{*}{$\begin{array}{l}\text { The most frequently studied category of variables includes } \\
\text { those relating to how ISI methods are implemented. These } \\
\text { variables measure how organizations manage ISI. Within } \\
\text { this category, } 37 \text { independent variables have been studied } \\
\text { a total of } 117 \text { times. The most frequently studied aspects } \\
\text { are changes in workforce size (examined } 12 \text { times), IT } \\
\text { communication and IS employee morale during the } \\
\text { implementation (examined } 11 \text { times). Changes in } \\
\text { workforce size include both increases and decreases in } \\
\text { staffing to implement ISI (Stylianou et al., 1996). IT } \\
\text { communication refers to the communication activities } \\
\text { between the IT function and other organizational functions } \\
\text { (Morsell et al., 2009). IS employee morale includes the } \\
\text { spirit and beliefs in the merger among IS employees } \\
\text { (Stylianou et al., 1996). }\end{array}$} \\
\hline IT communication & 11 & \\
\hline IS employee morale & 11 & \\
\hline User training and support & 10 & \\
\hline Changes in policies and procedures & 6 & \\
\hline Decreases in IS staff compensation & 6 & \\
\hline IT leadership in integration project & 6 & \\
\hline ISI method complexity & 4 & \\
\hline ISI method cost & 4 & \\
\hline End user involvement in ISI & 4 & \\
\hline $\begin{array}{l}\text { Inclusion of key IT staff in ex-post } \\
\text { integration }\end{array}$ & 3 & \\
\hline ISI method speed & 3 & \\
\hline ISI method novelty & 3 & \\
\hline ISI method effort & 1 & \\
\hline ISI implementation speed & 2 & \\
\hline Development and testing & 2 & \\
\hline Leverage of existing teams & 2 & \\
\hline Relocation cost minimization & 2 & \\
\hline $\begin{array}{l}\text { Leverage of increased purchasing } \\
\text { power }\end{array}$ & 2 & \\
\hline User resistance & 2 & \\
\hline Burning desire & 2 & \\
\hline Retention packages & 2 & \\
\hline Vague or changing requirements & 2 & \\
\hline Joint sourcing & 2 & \\
\hline Realistic budget and targets & 1 & \\
\hline Division of integration task & 1 & \\
\hline Use of pre-packaged solutions & 1 & \\
\hline Ex-post evaluation & 1 & \\
\hline IT culture conflict management & 1 & \\
\hline Organizational change management & 1 & \\
\hline Reporting and documentation & 1 & \\
\hline Slow response to requirements & 1 & \\
\hline
\end{tabular}




\begin{tabular}{|c|c|c|}
\hline \multicolumn{2}{|l|}{ changes } & \\
\hline Systems novelty for users & 1 & \\
\hline Boundary consolidation & 1 & \\
\hline Information security management & 1 & \\
\hline ISI process & 1 & \\
\hline Vendor's knowledge & 1 & \\
\hline Category total & 117 & \\
\hline \multicolumn{3}{|l|}{ Within-firm IS conditions } \\
\hline IS-business collaboration in planning & 14 & \multirow{13}{*}{$\begin{array}{l}\text { The } 30 \text { variables within the category of within-firm IS } \\
\text { conditions capture variables pertaining to IS pre- } \\
\text { conditions beyond ISI capabilities and IT infrastructure. } \\
\text { These have been examined } 102 \text { times. This category shows } \\
\text { that there are many characteristics of the M\&A parties' IS } \\
\text { that influence the ISI project (Alaranta and Kautz, 2012). } \\
\text { The most frequently studied IS condition is the level of } \\
\text { annual IT investment (Tafti, 2009), which has been } \\
\text { investigated ten times. } \\
\text { Research has also examined prior ISI experience (Mehta } \\
\text { and Hirschheim, 2007; Kovela and Skok, 2012) eight } \\
\text { times, and the level of pre-merger data sharing (Robbins } \\
\text { and Stylianou, 1999) seven times. In addition, research has } \\
\text { investigated the impact of pre-merger habits and practices } \\
\text { (Vieru et al., 2016), governance mode, and user skills (Du, } \\
\text { 2015). }\end{array}$} \\
\hline IT investment at target & 10 & \\
\hline Prior ISI experience & 8 & \\
\hline Top management support & 8 & \\
\hline Level of data sharing pre-M\&A & 7 & \\
\hline ISI proactivity (vs reactivity) & 7 & \\
\hline $\begin{array}{l}\text { Communication of M\&A activities to } \\
\text { IS }\end{array}$ & 5 & \\
\hline IS perception & 5 & \\
\hline Attention to IT & 3 & \\
\hline IT investment in acquirer & 3 & \\
\hline Habits and practice & 3 & \\
\hline IT governance mode & 3 & \\
\hline User skills & 3 & \\
\hline Outsourcing & 2 & \multirow{18}{*}{$\begin{array}{l}\text { Also included in this category are a set of variables that } \\
\text { describe how the relationships between business and IT in } \\
\text { the two parties to the M\&A affect ISI. IS-business } \\
\text { collaboration in planning (Morsell et al., 2009) has been } \\
\text { studied } 14 \text { times. The effect of top management support } \\
\text { (Kim et al., 2005) has been studied eight times and ISI } \\
\text { proactivity in the merger project seven times. The } \\
\text { communication of M\&A activities to ISI (Morsell et al., } \\
\text { 2009) has been studied five times. The large number of } \\
\text { studies that focus on the interaction between business and } \\
\text { IT signals the importance of nurturing a collaborative } \\
\text { approach to ISI. }\end{array}$} \\
\hline IS planning & 2 & \\
\hline Geographical distribution of IS/IT & 2 & \\
\hline Acquirer's IT capability & 2 & \\
\hline Related experiences & 2 & \\
\hline Pre-existing business-IT relations & 2 & \\
\hline Top management steering & 1 & \\
\hline Systems importance for business & 1 & \\
\hline $\begin{array}{l}\text { Business understanding of IS } \\
\text { development }\end{array}$ & 1 & \\
\hline Pre-M\&A alignment & 1 & \\
\hline $\begin{array}{l}\text { Business and IT alignment } \\
\text { preconditions }\end{array}$ & 1 & \\
\hline IS staff motivation & 1 & \\
\hline Cognitive sunk costs & 1 & \\
\hline IS strategy & 1 & \\
\hline Basic conditions & 1 & \\
\hline IS performance & 1 & \\
\hline Target's IT capability & 1 & \\
\hline Category total & 102 & \\
\hline \multicolumn{3}{|l|}{ M\&A context } \\
\hline M\&A motivation & 10 & \multirow{3}{*}{$\begin{array}{l}\text { The ISI project is a component within the overall M\&A } \\
\text { project. How the general M\&A project influences ISI has } \\
\text { been studied } 68 \text { times through } 21 \text { variables. Within this }\end{array}$} \\
\hline Organizational M\&A planning & 10 & \\
\hline Power and politics & 7 & \\
\hline
\end{tabular}




\begin{tabular}{|c|c|c|}
\hline Culture clashes & 7 & \multirow{7}{*}{$\begin{array}{l}\text { category of variables, the most frequently studied variables } \\
\text { are merger motivation and organizational merger planning, } \\
\text { which have each been studied ten times. Merger } \\
\text { motivation refers to the fundamental business reasons } \\
\text { driving the transaction (Myers, 2008). Organizational } \\
\text { merger planning refers to the quality of planning, where } \\
\text { insufficient planning is assumed to spill over onto the ISI } \\
\text { project (Robbins and Stylianou, 1999). }\end{array}$} \\
\hline Org integration objectives & 6 & \\
\hline M\&A type (hostile etc) & 4 & \\
\hline Stakeholder collaboration & 4 & \\
\hline Integration cost & 3 & \\
\hline M\&A context (general) & 2 & \\
\hline Leadership & 2 & \\
\hline Defined business strategy & 2 & \multirow{12}{*}{$\begin{array}{l}\text { Other variables that are frequently studied in this category } \\
\text { include power and politics (the extent of strategizing for } \\
\text { control of the merger process) and culture clashes (the } \\
\text { extent of cultural inconsistencies) (Weber and Pliskin, } \\
\text { 1996). Both have been studied seven times. The } \\
\text { organizational integration objectives variable is examined } \\
\text { six times. This variable is typically conceptualized } \\
\text { employing the Haspeslagh and Jemison (1991) typology of } \\
\text { M\&A integration approaches, distinguishing between } \\
\text { absorption, symbiosis, preservation and holding } \\
\text { approaches (Henningsson and Carlsson, 2011). }\end{array}$} \\
\hline Social context & 2 & \\
\hline M\&A frequency & 1 & \\
\hline Same IT-user organization & 1 & \\
\hline Experience variation & 1 & \\
\hline Business analysis & 1 & \\
\hline Search for similar operational logic & 1 & \\
\hline Expansion (shrinkage) of target & 1 & \\
\hline HR management & 1 & \\
\hline Acquiring from another $\mathrm{MBO}$ & 1 & \\
\hline Acquiring another $\mathrm{MBO}$ & 1 & \\
\hline Category total & 68 & \\
\hline \multicolumn{3}{|l|}{ ISI design } \\
\hline Risk management & 9 & \multirow{22}{*}{$\begin{array}{l}\text { The variable category of ISI diagnosing captures various } \\
\text { aspects of how the M\&A organization designs its approach } \\
\text { to ISI. This has been studied } 64 \text { times through } 20 \\
\text { variables. The most frequently studied variables in this } \\
\text { category are risk management (Unkan and Thönssen, } \\
\text { 2015; Henningsson and Kettinger, 2016) and collaboration } \\
\text { dynamics (LeFave et al., 2008; Alaranta and Martela, } \\
\text { 2012) that are studied nine and eight times, respectively. }\end{array}$} \\
\hline Collaboration dynamics & 8 & \\
\hline Business-based priorities & 7 & \\
\hline Political considerations & 6 & \\
\hline System size/complexity & 6 & \\
\hline ISI objectives & 5 & \\
\hline IS morale & 3 & \\
\hline ISI speed & 2 & \\
\hline $\begin{array}{l}\text { Prioritization of customer-facing } \\
\text { applications }\end{array}$ & 2 & \\
\hline Cost focus & 2 & \\
\hline User involvement in ISI decisions & 2 & \\
\hline Decision process & 2 & \\
\hline Comparative analysis & 2 & \\
\hline Long-term integration vision & 2 & \\
\hline Aligned post-M\&A state & 1 & \\
\hline Alignment of integration objectives & 1 & \\
\hline Short-term considerations & 1 & \\
\hline Common ISI goals & 1 & \\
\hline $\begin{array}{l}\text { Complexity a criterion for ISI } \\
\text { decision }\end{array}$ & 1 & \\
\hline IT in charge & 1 & \\
\hline Category total & 64 & \\
\hline & & \\
\hline IT infrastructure & & \\
\hline
\end{tabular}




\begin{tabular}{|c|c|c|}
\hline Geographical distribution of IT & 11 & \multirow{12}{*}{$\begin{array}{l}\text { The ten variables comprising the IT infrastructure } \\
\text { category, which refer to the properties of the pre-merger IT } \\
\text { infrastructure that affect integration decisions or their } \\
\text { outcomes, have been studied } 45 \text { times in relation to ISI in } \\
\text { M\&As. Geographical distribution of IT (Stylianou et al., } \\
\text { 1996; Robbins and Stylianou, 1999), which has been } \\
\text { studied } 11 \text { times, is the most frequently studied variable in } \\
\text { this category. It refers to whether IT hardware is } \\
\text { distributed across multiple locations. This variable was } \\
\text { first studied in the 1990's. We speculate that it has } \\
\text { gradually decreased in importance as network technologies } \\
\text { have matured. } \\
\text { Also in the IT infrastructure category, the master variable } \\
\text { of IT flexibility draws on Duncan's (1995) definition of IT } \\
\text { infrastructure flexibility. IT flexibility and related } \\
\text { concepts, including scalability and other loosely defined } \\
\text { references to infrastructures that do not permit certain } \\
\text { actions (Wijnhoven et al., 2006; Vaniya et al., 2013), have } \\
\text { been studied eight times. Other frequently studied aspects } \\
\text { of the pre-merger IT infrastructure include IT } \\
\text { standardization and IT extensiveness (Du, 2015) that have } \\
\text { been studied seven and five times, respectively. The many } \\
\text { variables investigated within the IT infrastructure category } \\
\text { signals the importance of considering the capacities of the } \\
\text { IT assets that can take several years to develop. }\end{array}$} \\
\hline IT flexibility & 8 & \\
\hline IT standardization & 7 & \\
\hline IT extensiveness & 5 & \\
\hline Existing IS-IT qualities & 5 & \\
\hline IT infrastructure & 3 & \\
\hline Modularity & 2 & \\
\hline Cost-efficient ICT & 2 & \\
\hline Enterprise systems (presence of) & 1 & \\
\hline Language support & 1 & \\
\hline Category total & 45 & \\
\hline & & \\
\hline \multicolumn{3}{|l|}{ Organizational characteristics } \\
\hline M\&A experience & 9 & \multirow{23}{*}{$\begin{array}{l}\text { The organizational context, specifically, different within- } \\
\text { organizational characteristics of the two M\&A } \\
\text { organizations, has been studied } 43 \text { times through } 22 \\
\text { different variables. Most frequently, research has studied } \\
\text { how previous merger experiences (Stylianou et al., 1996) } \\
\text { and pre-merger organizational performance (Du, 2015), } \\
\text { which have been examined nine and eight times, } \\
\text { respectively, affect ISI. Other related variables include } \\
\text { organizational structure (examined four times) and } \\
\text { geographical distribution (examined three times). Taken } \\
\text { together, the variables in this category contribute to } \\
\text { understanding how the wider organizational context } \\
\text { influences ISI. }\end{array}$} \\
\hline $\begin{array}{l}\text { Pre-M\&A organizational } \\
\text { performance }\end{array}$ & 8 & \\
\hline Organizational structure & 4 & \\
\hline Geographical distribution & 3 & \\
\hline Organizational infrastructure & 2 & \\
\hline $\begin{array}{l}\text { Need for organizational } \\
\text { transformation }\end{array}$ & 1 & \\
\hline Professional approach & 1 & \\
\hline Operational uniformity & 1 & \\
\hline State of mind & 1 & \\
\hline Company scale & 1 & \\
\hline Planning style & 1 & \\
\hline Company language & 1 & \\
\hline Corporate culture & 1 & \\
\hline Teaching status & 1 & \\
\hline Target size & 1 & \\
\hline Target age & 1 & \\
\hline Financial slack - Target & 1 & \\
\hline $\begin{array}{l}\text { High profitability and high-growth } \\
\text { firm }\end{array}$ & 1 & \\
\hline $\begin{array}{l}\text { High profitability and low-growth } \\
\text { firm }\end{array}$ & 1 & \\
\hline $\begin{array}{l}\text { Low profitability and high-growth } \\
\text { firm }\end{array}$ & 1 & \\
\hline Management style & 1 & \\
\hline Level of location integration & 1 & \\
\hline Total & 43 & \\
\hline
\end{tabular}




\begin{tabular}{|c|c|c|}
\hline \multicolumn{3}{|l|}{ IS relational } \\
\hline Application and IT compatibility & 14 & \multirow{11}{*}{$\begin{array}{l}\text { The category labelled IS relational refers to variables } \\
\text { covering the relationship between the pre-M\&A IS assets } \\
\text { and practices of the two parties. The importance of this } \\
\text { relationship is highlighted by the pioneering research in } \\
\text { the 1990's (Buck-Lew et al., 1992; Merali and McKiernan, } \\
\text { 1993). In this category, nine variables frame different } \\
\text { aspects of the relationships. } \\
\text { The most frequently studied construct is application and IT } \\
\text { compatibility, referring to the compatibility of technical } \\
\text { platforms, programming languages, and software (Chang } \\
\text { et al., 2014), which is examined 14 times. IS configuration } \\
\text { fit, which is based on the MIT'90s organizational } \\
\text { configuration schema (Scott Morton, 1991) has been } \\
\text { investigated seven times (Johnson and Yetton, 1996). IS } \\
\text { organizational compatibility, and the organizational } \\
\text { structures and cultures within the parties' IS functions (Lin } \\
\text { and Chao, 2008) have been examined six and five times, } \\
\text { respectively. This category also includes relative IT } \\
\text { capability (Du, 2015; Tanriverdi and Uysal, 2015), which } \\
\text { treats the difference between IT capabilities as a capability } \\
\text { gap. This has been examined five times. }\end{array}$} \\
\hline IS configuration fit & 7 & \\
\hline IS organizational compatibility & 5 & \\
\hline Relative IT capability & 5 & \\
\hline IS strategy compatibility & 3 & \\
\hline Systems capability fit & 2 & \\
\hline Systems technology fit & 2 & \\
\hline Simplicity of integration & 1 & \\
\hline Vendor carve-out strategy & 1 & \\
\hline Category total & 40 & \\
\hline & & \\
\hline \multicolumn{3}{|l|}{ ISI decision } \\
\hline ISI method & 13 & \multirow{10}{*}{$\begin{array}{l}\text { Variables within the category of ISI decision are treated as } \\
\text { both independent and dependent variables in different } \\
\text { studies. As an independent variable, it has been studied } 35 \\
\text { times. When used as an independent variable, researchers } \\
\text { investigate how ISI decisions affect ISI outcomes } \\
\text { (Giacomazzi et al., 1997; Robertson and Powell, 2001). } \\
\text { Specifically, this research focuses on how the choice of } \\
\text { integration method or methods affects ISI outcomes. This } \\
\text { has been studied } 13 \text { times. } \\
\text { Also in the ISI category, alignment between organizational } \\
\text { integration and ISI (Johnston and Yetton, 1996; Baker and } \\
\text { Niederman, 2014) have each been studied five times. The } \\
\text { basic argument is that post-M\&A business and IT strategic } \\
\text { alignment is a prerequisite for realizing the business value } \\
\text { of IT, and, by extension, alignment would also be an } \\
\text { important contributor to IT-based value creation in M\&As. } \\
\text { The effects of other ISI decision variables on ISI outcomes } \\
\text { have rarely been studied. }\end{array}$} \\
\hline Data integration & 8 & \\
\hline Alignment of integration processes & 5 & \\
\hline Degree of ISI & 4 & \\
\hline Digital resource redeployment & 2 & \\
\hline ISI area - Personnel & 2 & \\
\hline ISI area - Application & 1 & \\
\hline IS culture integration & 1 & \\
\hline Category total & 36 & \\
\hline & & \\
\hline \multicolumn{3}{|l|}{ ISI capabilities } \\
\hline Use of external resources & 11 & \multirow{10}{*}{$\begin{array}{l}\text { The capabilities required to manage ISI have been studied } \\
33 \text { times. This research takes four forms. The first defines } \\
\text { ISI capabilities as unique to the M\&A context (Kim et al., } \\
\text { 2005; Yetton et al., 2013). The second treats ISI } \\
\text { capabilities generally and investigates their applicability in } \\
\text { a M\&A context (Tanriverdi and Uysal, 2011; 2015). The } \\
\text { third examines supportive general capabilities, including } \\
\text { EA capabilities and project management capabilities } \\
\text { (Labusch et al., 2013; Toppenberg et al., 2015). } \\
\text { Finally, the fourth form investigates external capabilities, } \\
\text { typically sourced through consultants (Sumi and Tsuruoka, } \\
\text { 2002; Henningsson and Øhrgaard, 2016). The use of }\end{array}$} \\
\hline EA capability & 6 & \\
\hline ISI skill & 3 & \\
\hline Implementation capability & 2 & \\
\hline $\begin{array}{l}\text { Cross-business IT integration } \\
\text { capability }\end{array}$ & 2 & \\
\hline Project management (of ISI) skills & 2 & \\
\hline ISI team & 2 & \\
\hline Boundary spanning versatility & 1 & \\
\hline Diagnostic capability & 1 & \\
\hline ISI expertise & 1 & \\
\hline
\end{tabular}




\begin{tabular}{|c|c|c|}
\hline ISI routines & 1 & \multirow{4}{*}{$\begin{array}{l}\text { external capabilities and the effects of EA capabilities have } \\
\text { been studied eleven and six times, respectively. All four } \\
\text { forms of research into the effects of ISI capabilities } \\
\text { investigate high-level capabilities that generally say more } \\
\text { about the different sub-tasks of M\&A ISI challenges than } \\
\text { they explain what makes some organizations better than } \\
\text { others at resolving M\&A ISI challenges. }\end{array}$} \\
\hline ISI capability & 1 & \\
\hline Category total & 33 & \\
\hline & & \\
\hline \multicolumn{3}{|r|}{ 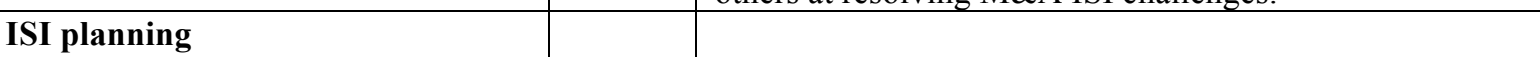 } \\
\hline Discovery (vs consistency) & 10 & \multirow{7}{*}{$\begin{array}{l}\text { The variable category of ISI planning captures various } \\
\text { aspects of how the M\&A organization develops the plan } \\
\text { for ISI. This has been studied } 32 \text { times through } 12 \\
\text { variables. Two of these variables have received substantial } \\
\text { attention. The element of discovery in the planning } \\
\text { process, defined as the inclusion of emergent variations in } \\
\text { ISI plans during the ISI project (Busquets, 2015), has been } \\
\text { studied ten times. The overall quality of ISI planning } \\
\text { (Morsell et al., 2009) has been studied five times. }\end{array}$} \\
\hline Quality of ISI planning & 5 & \\
\hline Inclusion of IT staff & 4 & \\
\hline Use of decision criteria & 3 & \\
\hline Distributed decision-authority & 2 & \\
\hline Project governance approach & 2 & \\
\hline $\begin{array}{l}\text { Alignment of vendor and acquirer IT } \\
\text { transaction strategies }\end{array}$ & 1 & \\
\hline Comprehensiveness & 1 & \multirow{7}{*}{$\begin{array}{l}\text { To a lesser extent, research has also examined the } \\
\text { inclusion of IS staff in the planning process (Alaranta and } \\
\text { Henningsson, 2008), the use of formal decision criteria } \\
\text { (LeFave et al., 2008), and how decision authority is } \\
\text { structured during the planning process (Brown } \text { et al., 2003; } \\
\text { Henningsson et al., 2016). Overall, the ISI planning } \\
\text { variables relate to how the merging organizations address } \\
\text { the complexity and lack of information in ISI decision- } \\
\text { making. Two strategic approaches can be discerned among } \\
\text { the independent variables: broad inclusion of individuals, } \\
\text { each of whom brings a component of understanding to } \\
\text { collective decision-making, and emergent decision-making } \\
\text { as the picture becomes clearer. }\end{array}$} \\
\hline Focus & 1 & \\
\hline Flow & 1 & \\
\hline Formalization & 1 & \\
\hline Credible deadlines & 1 & \\
\hline Category total & 32 & \\
\hline & & \\
\hline \multicolumn{3}{|l|}{ External environment } \\
\hline Time pressure & 10 & \multirow{7}{*}{$\begin{array}{l}\text { The category of environmental influence captures the } \\
\text { sources of influence outside the merging organizations. } \\
\text { Among the variables capturing environmental influences, } \\
\text { time pressure (Robertson and Powell, 2001; Mehta and } \\
\text { Hirschheim, 2007), has been studied ten times, } \\
\text { corroborating the emerging understanding that ISI is a } \\
\text { search for the best possible solution given the contextual } \\
\text { constraints, rather than a search for the optimal solution. } \\
\text { Research has also studied industry influence seven times, } \\
\text { focusing on how the dynamics (speed of change and } \\
\text { possibilities for synergies) influence ISI decisions (Jain } \\
\text { and Ramesh, 2015; Toppenberg et al., 2015). }\end{array}$} \\
\hline Industry characteristics & 7 & \\
\hline Legislation & 1 & \\
\hline Shareholder return & 1 & \\
\hline Economic climate & 1 & \\
\hline Category total & 20 & \\
\hline & & \\
\hline \multicolumn{3}{|l|}{ Pre-M\&A relation } \\
\hline Organizational uniformity & 6 & \multirow{10}{*}{$\begin{array}{l}\text { A second group of organizational context variables } \\
\text { includes the pre-M\&A relationships between the two } \\
\text { organizations. This category of variables, examined } 19 \\
\text { times, captures differences and similarities between the } \\
\text { organizations and the consequences for ISI. In this } \\
\text { category, organizational uniformity (Eckert et al., 2012; } \\
\text { Vieru and Rivard, 2015) has been studied six times. The } \\
\text { effect of whether or not the parties in the M\&A are } \\
\text { classified as belonging to the same industries (Tanriverdi } \\
\text { and Uysal, 2015) has been studied three times. Other } \\
\text { variables, including geographical relatedness, } \\
\text { organizational process fit, and the presence of competing }\end{array}$} \\
\hline Industry relatedness & 3 & \\
\hline Geographical relatedness & 2 & \\
\hline Organizational process fit & 2 & \\
\hline Competing business models & 2 & \\
\hline Relative size & 1 & \\
\hline Differences in management needs & 1 & \\
\hline Organizational competency fit & 1 & \\
\hline For-profit status difference & 1 & \\
\hline Category total & 19 & \\
\hline
\end{tabular}


The is the pre-edited version of Henningsson et al. (2018) "A review of information system integration in mergers and acquisitions", published in Journal of Information Technology. http://link.springer.com/article/10.1057/s41265-017-0051-9

\begin{tabular}{|l|r|l|}
\hline & & $\begin{array}{l}\text { business models (Giacomazzi } \text { et al., 1997; Seddon } \text { et al., } \\
\text { 2010), have each been studied twice. }\end{array}$ \\
\hline Total & 619 & \\
\hline
\end{tabular}




\section{Appendix D: Relational details}

TABLE D1. Relations between independent and dependent variables

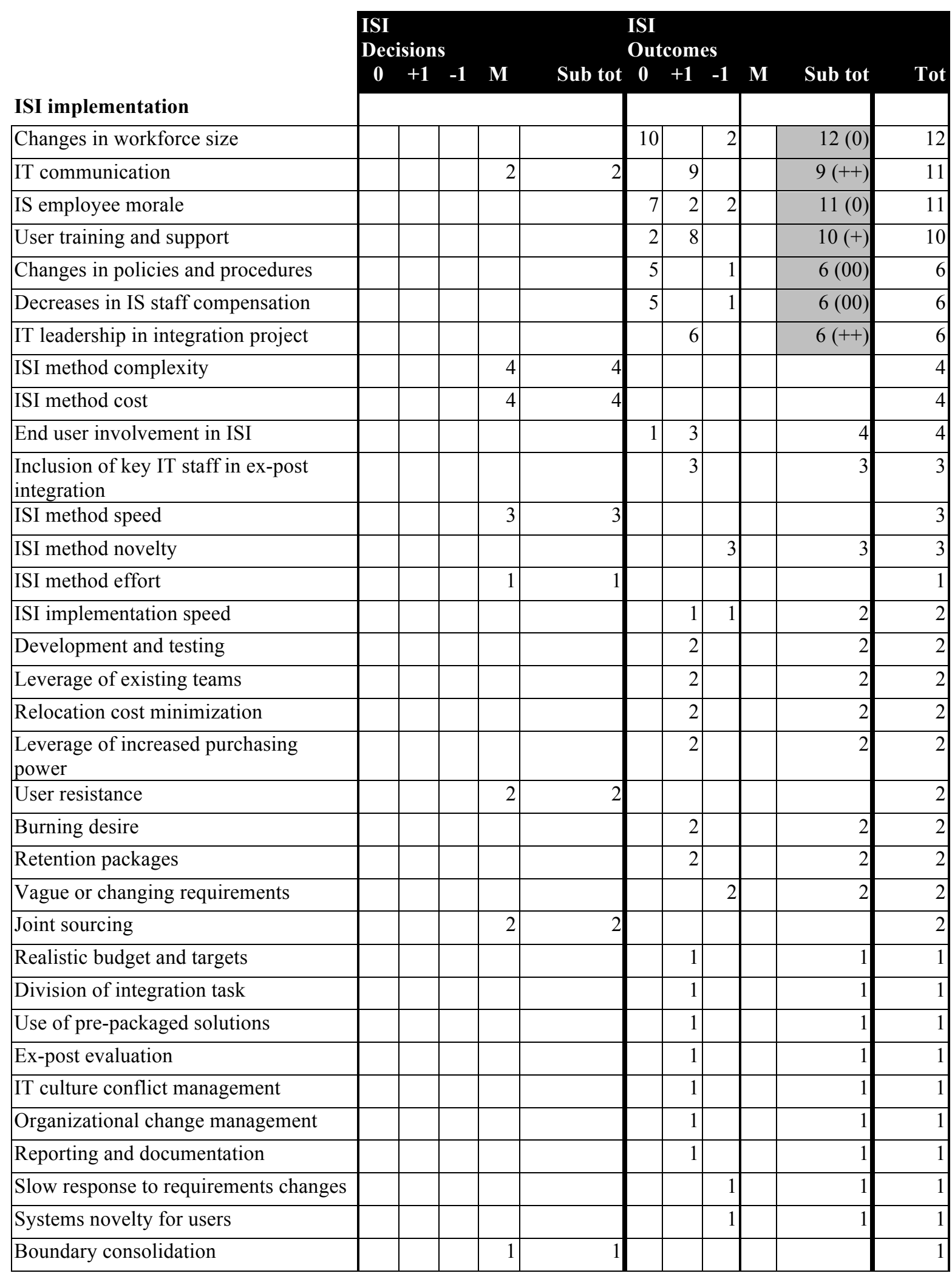


Information security management

ISI process

Vendors knowledge

Category total

Within-firm IS conditions

IS-business collaboration in planning

IT investment at target

Prior ISI experience

Top management support

Level of data sharing pre-M\&A

ISI proactivity (vs reactivity)

Communication of M\&A activities to

IS

IS perception

Attention to IT

IT investment in acquirer

Habits and practice

IT governance mode

User skills

Outsourcing

IS planning

Geographical distribution of IS/IT

Acquirer's IT capability

Related experiences

Pre-existing business-IT relations

Top management steering

Systems importance for business

Business understanding of IS

development

Pre-M\&A alignment

Business and IT alignment

preconditions

IS staff motivation

Cognitive sunk costs

IS strategy

Basic conditions

IS performance

Target's IT capability

Category total

\begin{tabular}{|l|l|l|l|l|}
\hline & & & & \\
\hline & & & & \\
\hline & & & & \\
\hline & & & 19 & 19 \\
\hline
\end{tabular}

\begin{tabular}{|r|r|r|r|r|r|} 
& 1 & & & 1 & 1 \\
\hline & 1 & & & 1 & 1 \\
\hline & 1 & & & 1 & 1 \\
\hline 30 & 54 & 14 & & 98 & 117 \\
\hline
\end{tabular}


Culture clashes

Org integration objectives

M\&A type (hostile etc)

Stakeholder collaboration

Integration cost

M\&A context (general)

Leadership

Defined business strategy

Social context

MA frequency

Same IT-user organization

Experience variation

Business analysis

Search for similar operational logic

Expansion (shrinkage) of target

HR management

Acquiring from another $\mathrm{MBO}$

Acquiring another $\mathrm{MBO}$

Category total

\begin{tabular}{ll|l|l|}
\cline { 3 - 4 } 1 & & & \\
\hline & & & \\
\hline & & & \\
\hline & & & \\
\hline
\end{tabular}

\begin{tabular}{r|r}
2 & \\
5 & $5(\mathrm{MM})$ \\
4 & 4 \\
& \\
\hline & \\
\hline
\end{tabular}

category total

\section{ISI design}

\begin{tabular}{|c|c|c|c|c|c|c|c|c|}
\hline Risk management & 1 & 1 & & 8 & & & $8(++)$ & 9 \\
\hline Collaboration dynamics & 1 & 1 & & 7 & & & $7(++)$ & 8 \\
\hline Business-based priorities & & & 4 & 3 & & & 7 & 7 \\
\hline Political considerations & & & 5 & & 1 & & $6(00)$ & 6 \\
\hline System size/complexity & & & 5 & 1 & & & $6(00)$ & 6 \\
\hline ISI objectives & 5 & $5(\mathrm{MM})$ & & & & & & 5 \\
\hline IS morale & 2 & 2 & & 1 & & & 1 & 3 \\
\hline ISI speed & 1 & 1 & & & & 1 & 1 & 2 \\
\hline $\begin{array}{l}\text { Prioritization of customer-facing } \\
\text { applications }\end{array}$ & & & & 2 & & & 2 & 2 \\
\hline Cost focus & 2 & 2 & & & & & & 2 \\
\hline User involvement in ISI decisions & 1 & 1 & & & 1 & & 1 & 2 \\
\hline Decision process & & & & 1 & & 1 & 2 & 2 \\
\hline Comparative analysis & 2 & 2 & & & & & & 2 \\
\hline Long-term integration vision & & & & 2 & & & 2 & 2 \\
\hline Aligned post-M\&A state & 1 & 1 & & & & & & 1 \\
\hline Alignment of integration objectives & & & & 1 & & & 1 & 1 \\
\hline Short-term considerations & & & & & 1 & & 1 & 1 \\
\hline Common ISI goals & & & & 1 & & & 1 & 1 \\
\hline Complexity a criterion for ISI decision & & & & 1 & & & 1 & 1 \\
\hline IT in charge & & & & & 1 & & 1 & 1 \\
\hline Category total & 16 & 16 & 14 & 28 & 4 & 2 & 48 & 64 \\
\hline
\end{tabular}




\begin{tabular}{|c|c|c|c|c|c|c|c|c|c|c|c|}
\hline Geographical distribution of IT & & & 1 & 1 & 2 & 5 & 1 & 3 & & 9 & 11 \\
\hline IT flexibility & & & & 1 & 1 & & 7 & & & $7(++)$ & 8 \\
\hline IT standardization & & 1 & & & 1 & 1 & 5 & & & $6(++)$ & 7 \\
\hline IT extensiveness & & 1 & & & 1 & 2 & & 2 & & 4 & 5 \\
\hline Existing IS-IT qualities & & & & 4 & 4 & & 1 & & & 1 & 5 \\
\hline IT infrastructure & & & & 3 & 3 & & & & & & 3 \\
\hline Modularity & & & & & & & 2 & & & 2 & 2 \\
\hline Cost-efficient ICT & & & & & & & 2 & & & 2 & 2 \\
\hline Enterprise systems (presence of) & & & & & & & 1 & & & 1 & 1 \\
\hline Language support & & & & 1 & 1 & & & & & & 1 \\
\hline Category total & & 2 & 1 & 10 & 13 & 8 & 19 & 5 & & 32 & 45 \\
\hline \multicolumn{12}{|l|}{ Organizational characteristics } \\
\hline M\&A experience & & 1 & & 1 & 2 & 3 & 4 & & & 7 & 9 \\
\hline Pre-M\&A organizational performance & & & & 1 & 1 & 5 & 1 & & 1 & $7(00)$ & 8 \\
\hline Organizational structure & & & & 3 & 3 & & & 1 & & 1 & 4 \\
\hline Geographical distribution & & & & 2 & 2 & & & 1 & & 1 & 3 \\
\hline Organizational infrastructure & & & & 2 & 2 & & & & & & 2 \\
\hline Need for organizational transformation & & & & 1 & 1 & & & & & & 1 \\
\hline Professional approach & & & & 1 & 1 & & & & & & 1 \\
\hline Operational uniformity & & & & 1 & 1 & & & & & & 1 \\
\hline State of mind & & & & 1 & 1 & & & & & & 1 \\
\hline Company scale & & & & 1 & 1 & & & & & & 1 \\
\hline Planning style & & & & 1 & 1 & & & & & & 1 \\
\hline Company language & & & & 1 & 1 & & & & & & 1 \\
\hline Corporate culture & & & & 1 & 1 & & & & & & 1 \\
\hline Teaching status & 1 & & & & 1 & & & & & & 1 \\
\hline Target size & 1 & & & & 1 & & & & & & 1 \\
\hline Target age & & 1 & & & 1 & & & & & & 1 \\
\hline Financial slack - Target & & & 1 & & 1 & & & & & & 1 \\
\hline High profitability and high-growth firm & & & & & & & 1 & & & 1 & 1 \\
\hline High profitability and low-growth firm & & & & & & 1 & & & & 1 & 1 \\
\hline Low profitability and high-growth firm & & & & & & 1 & & & & 1 & 1 \\
\hline Management style & & & & 1 & 1 & & & & & & 1 \\
\hline Level of location integration & & & & 1 & 1 & & & & & & 1 \\
\hline Category total & 2 & 2 & 1 & 19 & 24 & 10 & 6 & 2 & 1 & 19 & 43 \\
\hline \multicolumn{12}{|l|}{ IS relational } \\
\hline Application and IT compatibility & & & & 1 & 1 & 3 & 10 & & & $13(+)$ & 14 \\
\hline IS configuration fit & & & & 2 & 2 & & 5 & & & $5(++)$ & 7 \\
\hline IS organizational compatibility & & & & 1 & 1 & & 4 & & & 4 & 5 \\
\hline Relative IT capability & & 1 & & & 1 & 2 & 1 & 1 & & 4 & 5 \\
\hline IS strategy compatibility & & & & 1 & 1 & & 2 & & & 2 & 3 \\
\hline Systems capability fit & & & & & & 2 & & & & 2 & 2 \\
\hline Systems technology fit & & & & & & 1 & 1 & & & 2 & 2 \\
\hline
\end{tabular}


Simplicity of integration

Vendor carve-out strategy

Category total

\section{ISI decision}

ISI method

Data integration

Integration alignment

Degree of ISI

Digital resource redeployment

ISI area personnel

ISI area application

IS culture integration

Category total

\section{ISI capabilities}

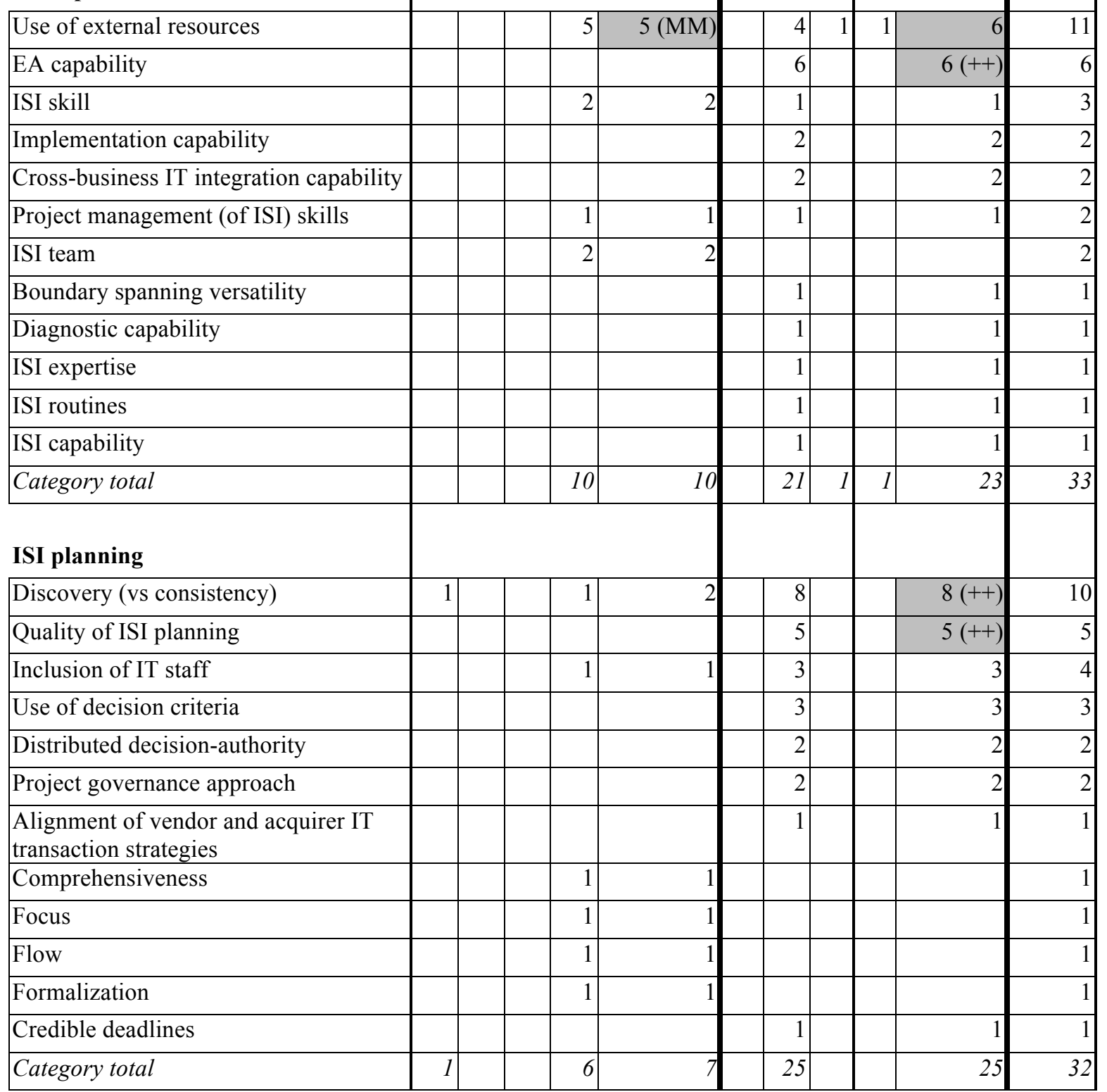




\begin{tabular}{|c|c|c|c|c|c|c|c|c|c|c|}
\hline \multicolumn{11}{|l|}{ External environment } \\
\hline Time pressure & & & 5 & $5(\mathrm{MM})$ & & 1 & 4 & & $5(-)$ & 10 \\
\hline Industry characteristics & & & 4 & 4 & 2 & 1 & & & 3 & 7 \\
\hline Legislation & & & 1 & 1 & & & & & & 1 \\
\hline Shareholder return & & & 1 & 1 & & & & & & 1 \\
\hline Economic climate & & & 1 & 1 & & & & & & 1 \\
\hline Category total & & & 12 & 12 & 2 & 2 & 4 & & 8 & 20 \\
\hline \multicolumn{11}{|l|}{ Pre-M\&A relation } \\
\hline Organizational uniformity & & 1 & 1 & 2 & & 3 & & 1 & 4 & 6 \\
\hline Industry relatedness & & & & & 1 & 2 & & & 3 & 3 \\
\hline Geographical relatedness & 1 & & 1 & 2 & & & & & & 2 \\
\hline Organizational process fit & & & & & 2 & & & & 2 & 2 \\
\hline Relative size & & 1 & & 1 & & & & & & 1 \\
\hline Competing business models & & & & & & & 2 & & 2 & 2 \\
\hline Differences in management needs & & & 1 & 1 & & & & & & 1 \\
\hline Organizational competency fit & & & & & 1 & & & & 1 & 1 \\
\hline For-profit status difference & 1 & & & 1 & & & & & & 1 \\
\hline Category total & 2 & 2 & 3 & 7 & 4 & 5 & 2 & 1 & 12 & 19 \\
\hline Grand total & & & & 172 & & & & & 447 & 619 \\
\hline
\end{tabular}

Notes: This appendix details the relationships between independent variables and ISI decision and ISI outcome variables. Cells show the frequency with which a relationship was found to be a ' +1 ' indicating a positive and significant relationship; ' -1 ' indicating a negative and significant relationship; ' 0 ' indicating a not significant relationship; ' $\mathrm{M}$ ' indicating the independent variable mattered when operationalized as a categorical variable (see Table 2 for detailed explanations). The relationships that were examined at least five times are shaded. The relationships that were examined at least 5 times and met the criteria for consistent results as described in the text are marked with $(++),(+),(--),(-),(00),(0)$, (MM), (M). No such markings within a shaded cell indicate lack of consistent findings per our criteria. 